\title{
Pedigree Analysis of the MELCOR 1.8.2 Code to be Used for ITER's Report Preliminary on Safety
}

\author{
R. L. Moore \\ June 2007
}

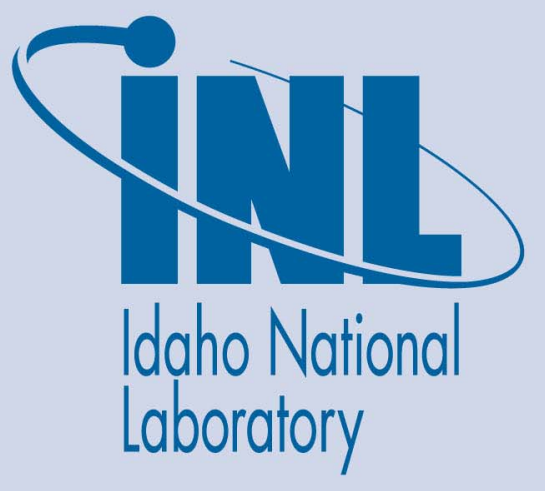

The INL is a U.S. Department of Energy National Laboratory operated by Battelle Energy Alliance 
INL/EXT-07-12856

\title{
Pedigree Analysis of the MELCOR 1.8.2 Code to be Used for ITER's Report Preliminary on Safety
}

\author{
R. L. Moore
}

June 2007

\begin{abstract}
Idaho National Laboratory
Idaho Falls, Idaho 83415
\end{abstract}

Prepared for the

U.S. Department of Energy

Office of Nuclear Energy

Under DOE Idaho Operations Office

Contract DE-AC07-05ID14517 


\title{
Pedigree Analysis of the MELCOR 1.8.2 Code to be Used for ITER's Report Preliminary on Safety
}

\author{
INL/EXT-07-12856
}

June 2007

Approved by
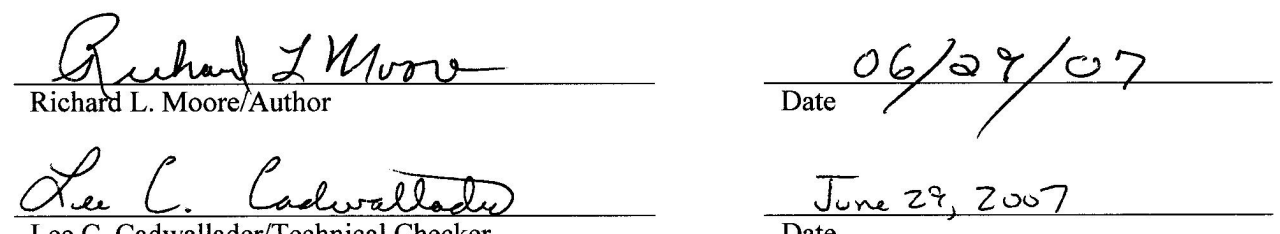

Lee C. Cadwallader/Technical Checker

$\frac{\text { June 29, } 2007}{\text { Date }}$
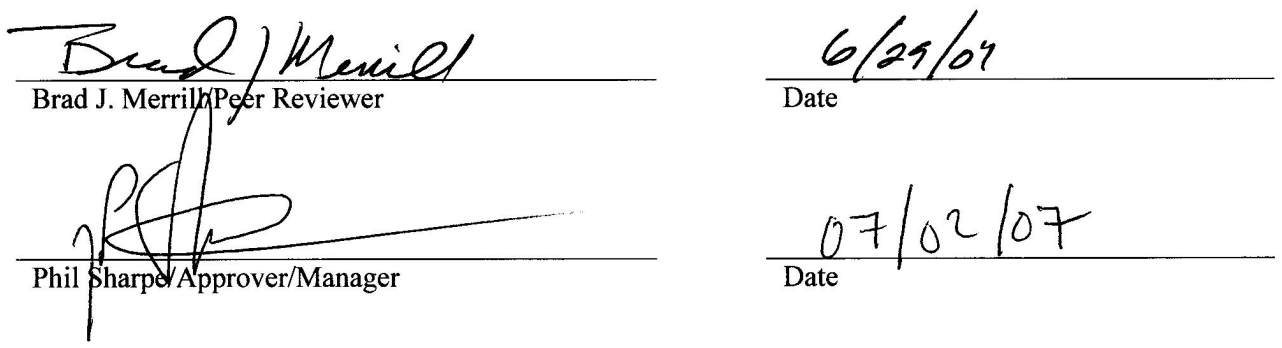


\section{Table of Contents}

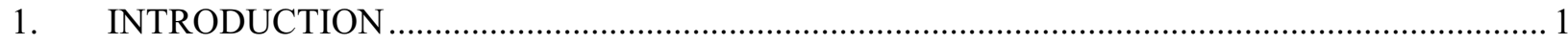

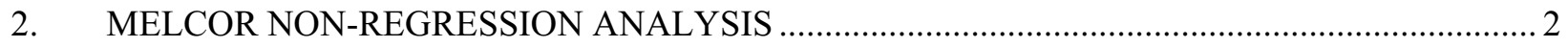

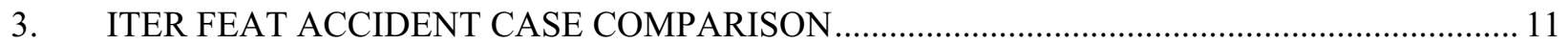

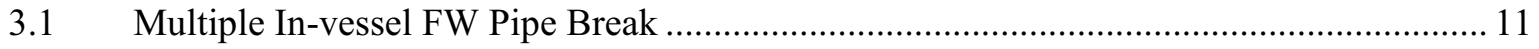

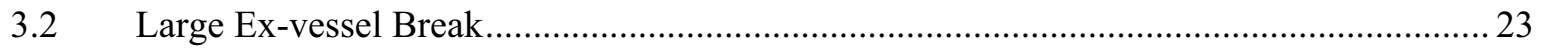

3.3 VV \& Cryostat Boundary Failure Accident …............................................................. 29

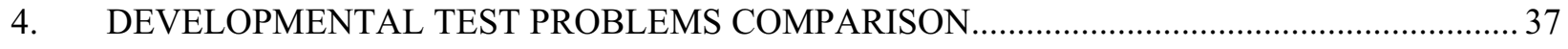

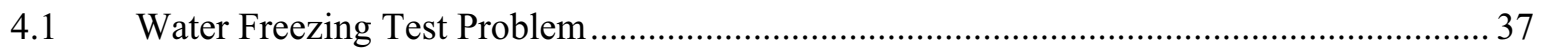

4.1.1 Water Freezing Test Problem Model Description......................................... 37

4.1.2 Water Freezing Test Problem Results .............................................................. 38

4.2 Air Condensation Test Problem .................................................................................... 41

4.2.1 Air Condensation Test Problem Model Description ....................................... 41

4.2.2 Air Condensation Test Problem Results ....................................................... 41

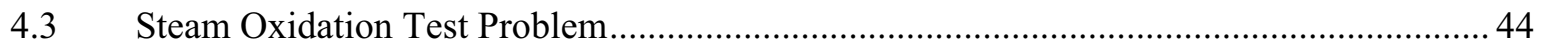

4.3.1 Steam Oxidation Test Problem Model Description .......................................... 44

4.3.2 Steam Oxidation Test Problem Results for Beryllium ..................................... 45

4.3.3 Steam Oxidation Test Problem Results for Carbon ........................................... 47

4.4 Enclosure Thermal Radiation Heat Transport Model......................................................... 48

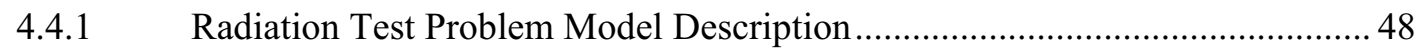

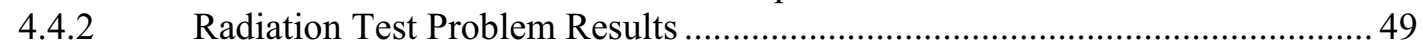

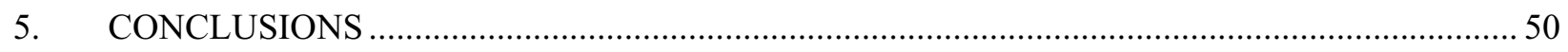

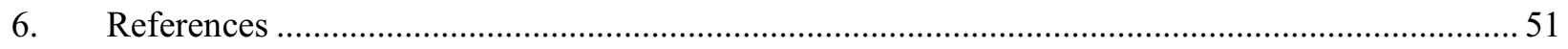




\section{Table of Figures}

Figure 1. Drywell concrete floor temperature comparison for the test problem sent with the MELCOR 1.8.2 distribution.

Figure 2. Reactor shroud temperature comparison for test problem sent with the MELCOR 1.8.2 distribution

Figure 3. Shroud ring temperature comparison for the test problem sent with the MELCOR 1.8.2 distribution.

Figure 4. Shroud ring temperature regression comparison for the test problem sent with the MELCOR 1.8.2 distribution

Figure 5. Reactor core pressure comparison for the test problem sent with the MELCOR 1.8.2 distribution.

Figure 6. Wetwell pressure comparison for the test problem sent with MELCOR 1.8.2 distribution......... 6

Figure 7. Core water temperature comparison for the test problem sent with the MELCOR 1.8.2 distribution.

Figure 8. Wetwell water temperature comparison for the test problem sent with the MELCOR 1.8.2 distribution.

Figure 9. Reactor core mass flow comparison for the test problem sent with the MELCOR 1.8.2 distribution.

Figure 10. Reactor core steel mass comparison for the test problem sent with the MELCOR 1.8.2 distribution.

Figure 11. Reactor core hydrogen mass generation comparison for the test problem sent with the MELCOR 1.8.2 distribution.

Figure 12. Reactor bottom head debris mass comparison for the test problem sent with the MELCOR

1.8.2 distribution.

Figure 13. Aerosol mass release comparison for the test problem sent with the MELCOR 1.8.2 distribution.

Figure 14. Water mass flow rate from outboard break.

Figure 15. Integrated water mass flow from outboard break.

Figure 16. Water mass flow rate from inboard break.

Figure 17. Integrated water mass flow from inboard break.

Figure 18. Water mass flow rate through drain line 129

Figure 19. Integrated mass flow through drain line 129. 


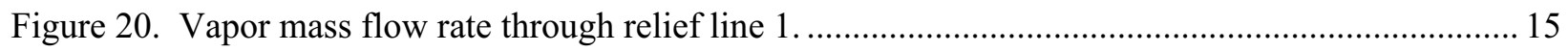

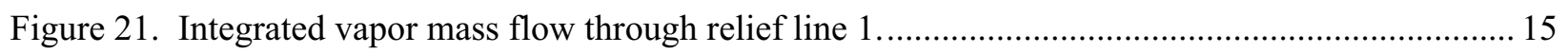

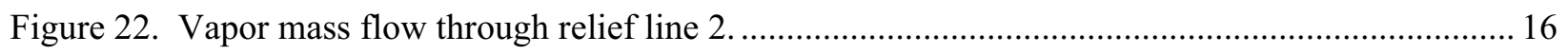

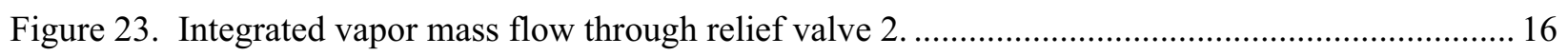

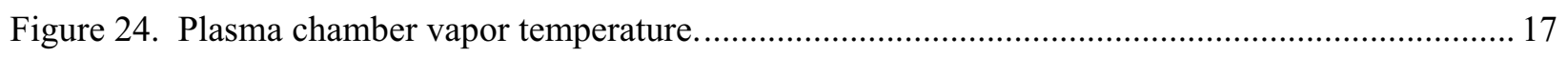

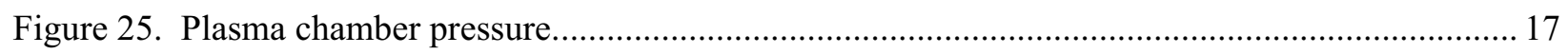

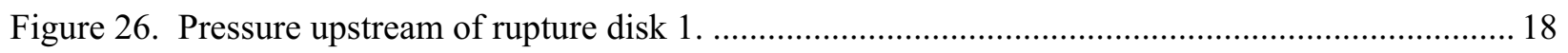

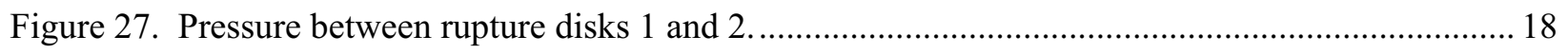

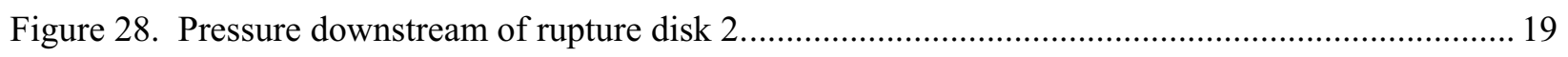

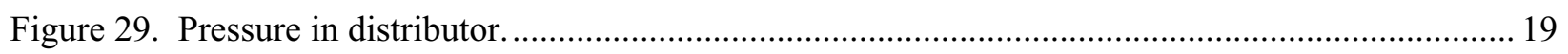

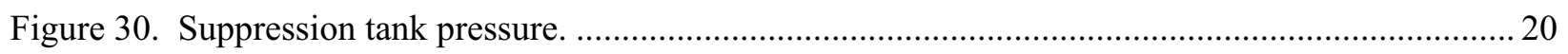

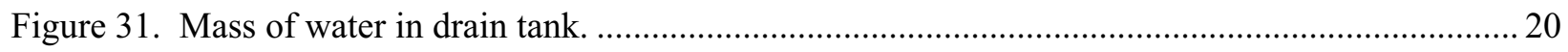

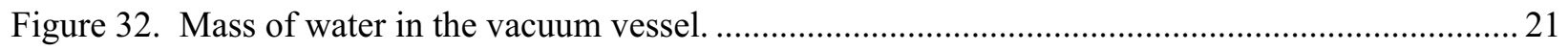

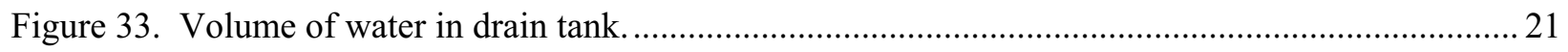

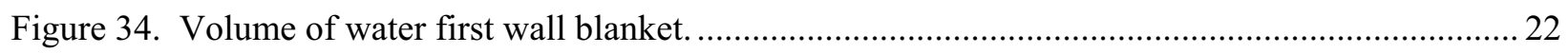

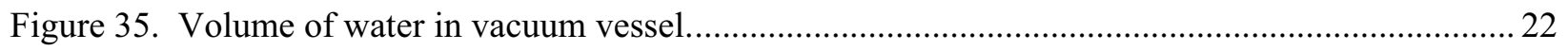

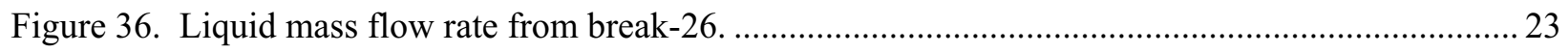

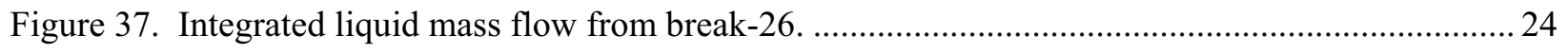

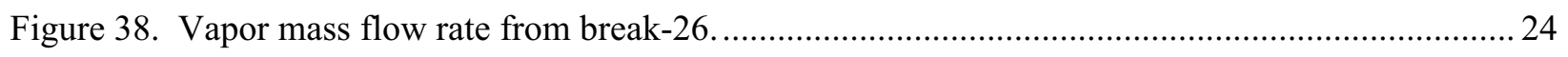

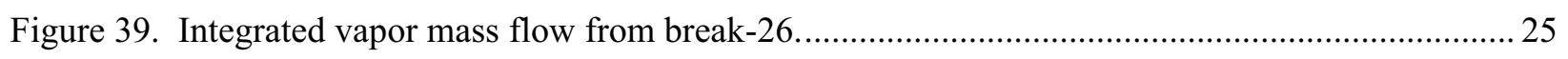

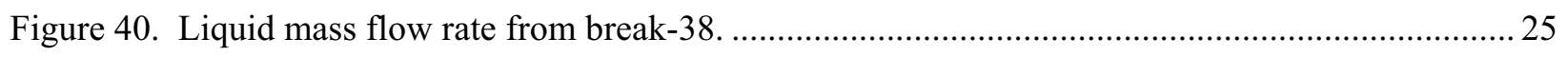

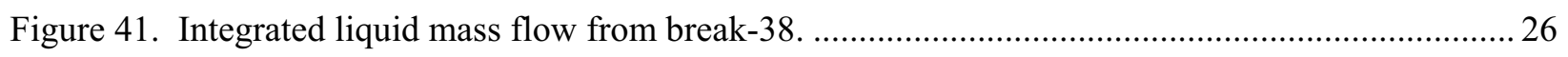

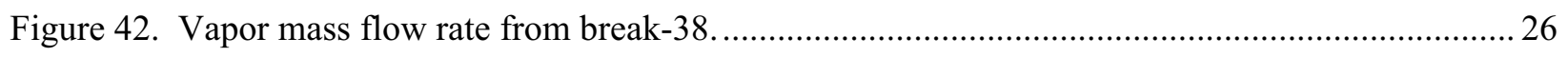

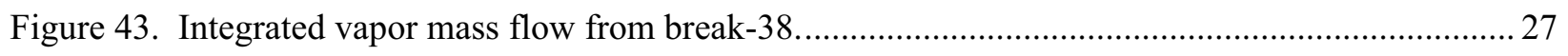

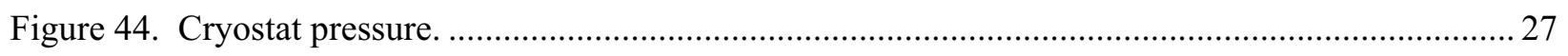

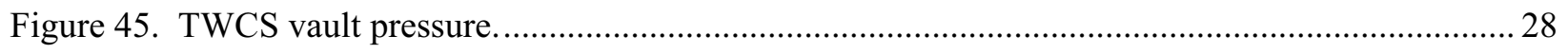


Figure 46. Vapor temperature in TWCS vault.

Figure 47. Helium mass flow rate from cryostat space room to cryostat (flow path 001)....................... 30

Figure 48. Helium mass flow rate from cryostat space room to cryostat (flow path 021 )...................... 30

Figure 49. Integrated net helium mass flow from cryostat room to cryostat. ........................................ 31

Figure 50. Nitrogen mass flow rate from cryostat space room to cryostat (flow path 001).................... 31

Figure 51. Nitrogen mass flow rate from cryostat space room to cryostat (flow path 021)..................... 32

Figure 52. Integrated net nitrogen mass flow from cryostat space room to cryostat. ............................ 32

Figure 53. Vapor mass flow rate from VV to cryostat (flow path 014) ................................................ 33

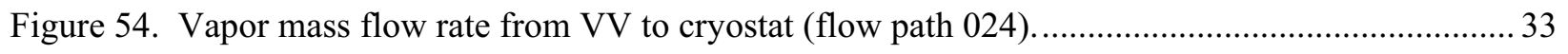

Figure 55. Integrated vapor mass flow from VV to cryostat (flow path 014)........................................ 34

Figure 56. Integrated vapor mass flow from VV to cryostat (flow path 024)....................................... 34

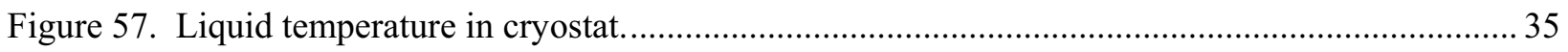

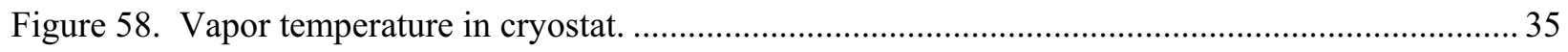

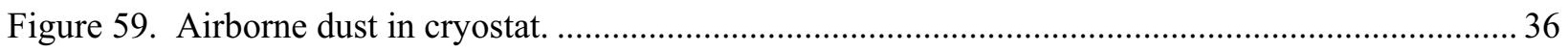

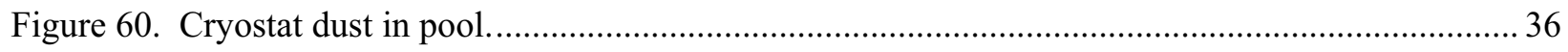

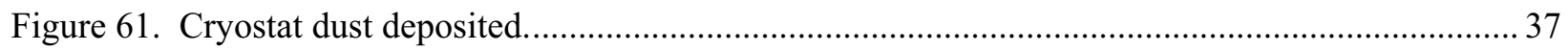

Figure 62. Single cell test problem for testing MELCOR ice freezing modifications............................. 38

Figure 63. Magnet heat structure temperature single cell water freezing test problem.......................... 39

Figure 64. Pressure for the single cell water freezing test problem.................................................. 40

Figure 65 . Vapor temperature for the single cell freezing test problem. ............................................ 40

Figure 66. Ice thickness on magnet heat structure for the single cell water freezing test problem............ 41

Figure 67. Cryostat volume pressure for the air condensation test problem........................................ 42

Figure 68. Condensed air mass for the air condensation test problem............................................... 43

Figure 69. Cryostat volume air temperature for the air condensation test problem............................... 43

Figure 70. Magnet heat structure temperature for the air condensation test problem............................ 44

Figure 71. Schematic of MELCOR model developed for the oxidation model test problem................... 45 
Figure 72. FW temperature for the oxidation model test problem with beryllium as a PFC material....... 46

Figure 73. Hydrogen generation for the oxidation model test problem with beryllium as a PFC material.46

Figure 74. FW temperature for the oxidation model test problem with carbon as a PFC material........... 47

Figure 75. Hydrogen generation for the oxidation model test problem with carbon as a PFC material.... 48

Figure 76. Schematic of test problem for enclosure net radiation model. ............................................. 49

Figure 77. Wall surface and atmosphere temperature for an enclosure that contains an atmosphere that

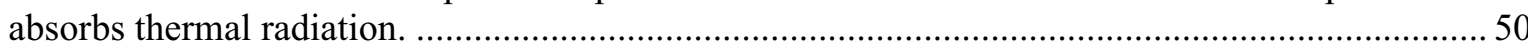




\section{Executive Summary}

This report documents the pedigree analysis of the MELCOR 1.8.2 code to be used for ITER's Report Preliminary on Safety. To pedigree the code the process involved four steps. The first step was taking the modified MELCOR 1.8.2 code used by the ITER Joint Central Team (JCT) for analyses in previous ITER Safety Assessments and comparing the FORTRAN code of this version line-by-line to the original 1.8.2 version of MELCOR. The second step was a nonregression analysis which involves comparing the results from the pedigreed version against those predicted by the original, unmodified version of MELCOR 1.8.2. The third step involved comparing the pedigreed version results to results from the MELCOR version used by the ITER JCT for the Generic Site Safety Report (GSSR) against a set of accident problems analyzed for the safety report. The fourth and final step involved a comparison between the pedigreed version of the code and the developmental test problems cited in the change documents referenced in this report. The results from the pedigree process are described in this report. 


\title{
Pedigree Analysis of the MELCOR 1.8.2 Code to be Used for ITER's Report Preliminary on Safety
}

\author{
R. L. Moore and B. J. Merrill
}

\section{INTRODUCTION}

In the early days of the International Thermonuclear Experimental Reactor (ITER) program (prior to 1995) the MELCOR 1.8.2 code was chosen as one of several codes to be used to perform ITER safety analyses. These codes were needed to assess the thermal hydraulic response of the cooling systems in ITER and the transport of radionuclides during a number of specified design basis accidents (dba) and beyond design basis accidents (bdba). This meant that the codes to be used, one of which was MELCOR 1.8.2, had to have the capability of predicting coolant pressure, temperature, mass flow rate and radionuclide transport in the various coolant flow loops which are an integral part of ITER. The codes must also predict structural temperatures (i.e. first wall, blanket, divertor, and vacuum vessel) resulting from energy produced by radioactive decay heat and/or chemical reactions (oxidation). The codes also had to be able to predict the transport of aerosols produced by the oxidation of these structures.

The MELCOR ${ }^{1,2}$ code is currently under development at the Sandia National Laboratory (SNL) for the Nuclear Regulatory Commission (NRC) to model the progression of severe accidents in light water nuclear reactors. A number of versions of the code have been released since the first version (1989) with the latest official release being 1.8.6. The MELCOR code has the capability of modeling a number of physical phenomena associated with nuclear reactor accident scenarios. These phenomena include thermal-hydraulics of the reactor coolant system; heat transfer in the core and confinement building; aerosol physics; and fission product release and transport. Using the above listed capabilities, along with some modifications to the code proposed by the Fusion Safety Program (FSP) ${ }^{3}$ at the Idaho National Laboratory (INL), the ITER Joint Central Team (JCT) recognized that the MELCOR code could be used to model accidents associated with ITER, and contracted FSP at INL to modify the MELCOR 1.8.2 code for use as a safety analysis code for ITER.

From 1994 to 1997 a number of fusion related modification were made to the MELCOR 1.8.2 code as reported in References 4,5,6 and 7. These modifications included adding the capability to address water freezing, air condensation, beryllium, carbon and tungsten oxidation in steam and air environments, flow boiling in the coolant loops, and radiation in enclosures. These References are change documents for this version of the MELCOR 1.8.2 code which contain the equations associated with the modifications, test problem descriptions and test problem results used to assess the execution of the modified code, and listings of the FORTRAN coding changes made to, or added to, the MELCOR 1.8.2 code.

After the US left the ITER program in the 1998 the INL became evolved in looking at safety problems associated with other fusion concepts which used coolants other than water, such as Lead Lithium, Flibe, and Helium. At approximately the same time SNL released a new version of MELCOR designated as MELCOR 1.8.5. The INL obtained a copy of this version of the code and ported all the fusion modifications from 1.8.2 to 1.8.5. The 1.8 .5 version was also modified such that it was capable of using the multi-fluid equation of state package from the RELAP5 ${ }^{8}$ code. Thus; modifications to MELCOR 1.8.2 were stopped and any new modifications and corrections to MELCOR were incorporated into the INL fusion version of MELCOR 1.8.5.

Because the US reentered the ITER Project in 2004, the Safety Group of the ITER International Team (IT) decided that the MELCOR code should be used to perform the safety analysis for the ITER's Report Preliminary on Safety (RPrS). At the urging of the INL FSP, the ITER IT decided that most appropriate version of MELCOR to use for the RPrS is the modified version of MELCOR 1.8.2 because of Quality Assurance (QA) considerations required by the ITER licensing process and the tight schedule associated 
with completing the RPrS. This decision was also based on the fact that it would be easier to pedigree the modifications and corrections made to the MELCOR 1.8.2 code than to strip the multi-fluids modifications from the INL version of MELCOR 1.8.5 and then pedigree this new version of MELCOR 1.8.5.

To pedigree the code, the process involved four steps. First, taking the modified MELCOR 1.8.2 code used by the ITER JCT for analyses in previous ITER Safety Assessments ${ }^{9,10,11}$ and compared the FORTRAN code of this version line-by-line to the original 1.8.2 version of MELCOR. All identified coding changes were flagged in the source code and the changes linked to the appropriate Change Document through a citation. An example is the following:

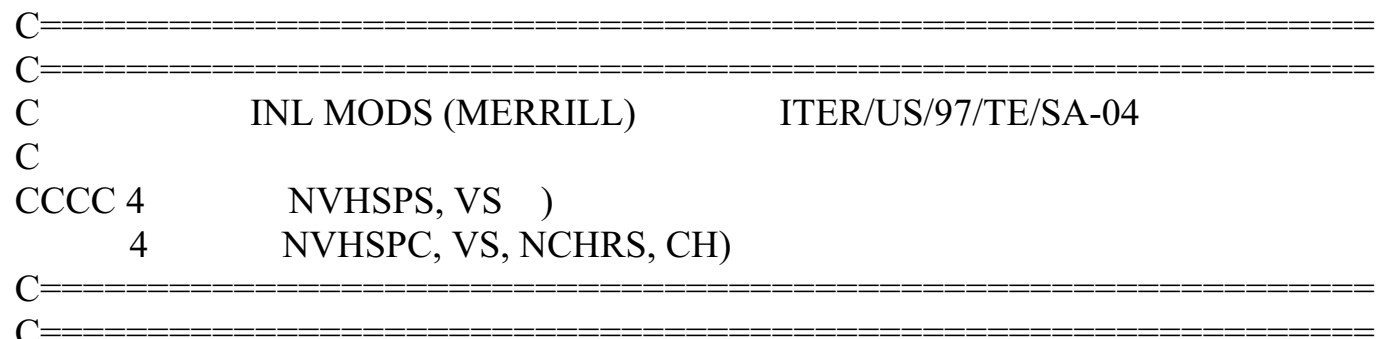

where every code change made by the FSP has been placed between distinctive comment banners that identify the change as an INL modification by the phase "INL MODS" followed by a callout of the person responsible for the change and citation that documents the purpose of this change. The second step was a non-regression analysis which involves comparing the results from the pedigreed version against those predicted by the original, unmodified version of MELCOR 1.8.2. The purpose of this nonregression analysis is to demonstrate that the modifications made to the MELCOR 1.8.2 code do not drastically alter the intended functions of the MELCOR base code, and if they do to explain why the departure occurs and if the change is needed. The analysis was performed by executing a demonstration problem that came with the MELCOR 1.8.2 source distribution. The third step involved comparing the pedigreed version results to results from the MELCOR version used by the ITER JCT for the Generic Site Safety Report $(\mathrm{GSSR})^{11}$ against a set of accident problems analyzed for the safety report. The fourth and final step involved a comparison between the pedigreed version of the code and the developmental test problems cited in the change documents. The results from the pedigree process appear in the following sections of this report.

\section{MELCOR NON-REGRESSION ANALYSIS}

As mentioned earlier, the version of MELCOR being pedigreed for accident analyses that are to be included in ITER's Report Preliminary on Safety (RPrS) is a modified version of MELCOR 1.8.2. The MELCOR 1.8.2 source code used to develop this modified version was originally installed on an IBM AIX UNIX computer system on March $1^{\text {st }}$ of 1994 . As part of this pedigree process a non-regression analysis was performed with a test problem selected to check that the modifications made to MELCOR 1.8.2 for fusion do not drastically alter the predictions of the original MELCOR 1.8.2 code. The test problem selected is the demonstration problem which is part of the MELCOR 1.8.2 code distribution files. This demonstration problem is designed to exercise all of the MELCOR physics packages in a single transient calculation. While this problem does not activate every single option available in MELCOR, it does activate each of the 16 physics packages available in the MELCOR code which are used to simulate fluid flow, heat transfer, core disassembly, debris cavity formation, hydrogen burn, aerosol transport, and decay heat production, just to name a few. The sample problem is a simple model of a fission reactor plant. The accident being analyzed is a severe bypass accident. The model contains 5 fluid cells, 8 flow paths, and 11 heat structures, one core and one cavity or bottom head region which collectively represent a fission reactor and its containment building. As such, this model is not intended to represent any real fission reactor system nor is it a recommended approach by the MELCOR developers to modeling a real fission system. 
Figures 1 through 3 contain predicted surface temperatures of heat structures that represent the drywell concrete floor, reactor shroud, and reactor shroud ring. These figures contain the predictions of both the original and modified versions of the MELCOR 1.8.2 code. As can be seen, the temperature trends of these heat structures are similar between the two versions of the MELCOR code but shifted slightly in time. Most of this shift is due to two modifications made for the fusion version. These modifications are the new heat structure surface boiling subroutines for internal flow, ${ }^{5}$ and the modifications made to subroutine HSDMTC, which calculates the rate of condensation on a given heat structure. ${ }^{4}$ In the original version of the code the boundary layer next to the heat structure was assumed to always be air. In the modified version this assumption was removed and the actual time-dependent gas composition next to the heat structure, as calculated by the code, was used to define the boundary layer composition.

When these two changes are reversed in the modified code, the result is as noted in Figure 4, which contains an additional curve labeled "Pedigreed 1.8.2 Regression", denoting the regression back towards the original version. Both of these changes were made to the original code to make it more accurate for ITER analyses.

Figures 5 and 6 contain core and wetwell pressures for this test problem. The predictions are similar between these two versions of MELCOR, with the same time delay noted previously for the heat structure temperatures. Figures 7 and 8 contain predicted liquid and vapor temperatures in these same components, with excellent agreement obtained between these two versions of the MELCOR code. The same can be said about the predicted core mass flow which appears in Figure 9.

Figures 10 and 11 present the predicted core steel mass and hydrogen generation, respectively, for this comparison. While the trends are similar, there was $8 \%$ more steel mass lost from the core in the original version's prediction when compared to that of the modified version. However, there is excellent agreement in predicted hydrogen generation. Figure 12 shows the predicted oxide and metal layer masses that form at the bottom of the cavity during this test problem. There is the same noted trend as the core steel mass with the same deviation at the end of the problem that is $\sim 8 \%$. Since these variables are sensitive to heat structure temperatures, then any changes made to heat structure heat transfer, e.g. flow boiling modifications mentioned previously, would also affect the predicted results for these variables.

Figure 13 presents the predicted total aerosol mass release to the environment for this test problem. There is a noticeable difference between the modified and original version's prediction for this parameter, which is $235 \mathrm{~kg}$ versus $370 \mathrm{~kg}$, respectively. For the most part this difference is due to the aerosol deposition modifications that have been made for the fusion version of the code ${ }^{6}$. The original version of MELCOR 1.8.2 assumes that the atmosphere in which the aerosol resides is always air. In the modified version of MELCOR 1.8.2, the atmosphere is treated as the gas composition predicted by the code at any point in time, for example a mixture of steam and air. To verify that this creates the difference noted between theses two predictions, the aerosol deposition parameters of the modified fusion version was set back to those of air and the test problem re-ran. The result is the curve of Figure 13 labeled "Pedigreed 1.8.2 STD AERO", designating that the standard, or original, MELCOR 1.8.2 aerosol packages is being used. 


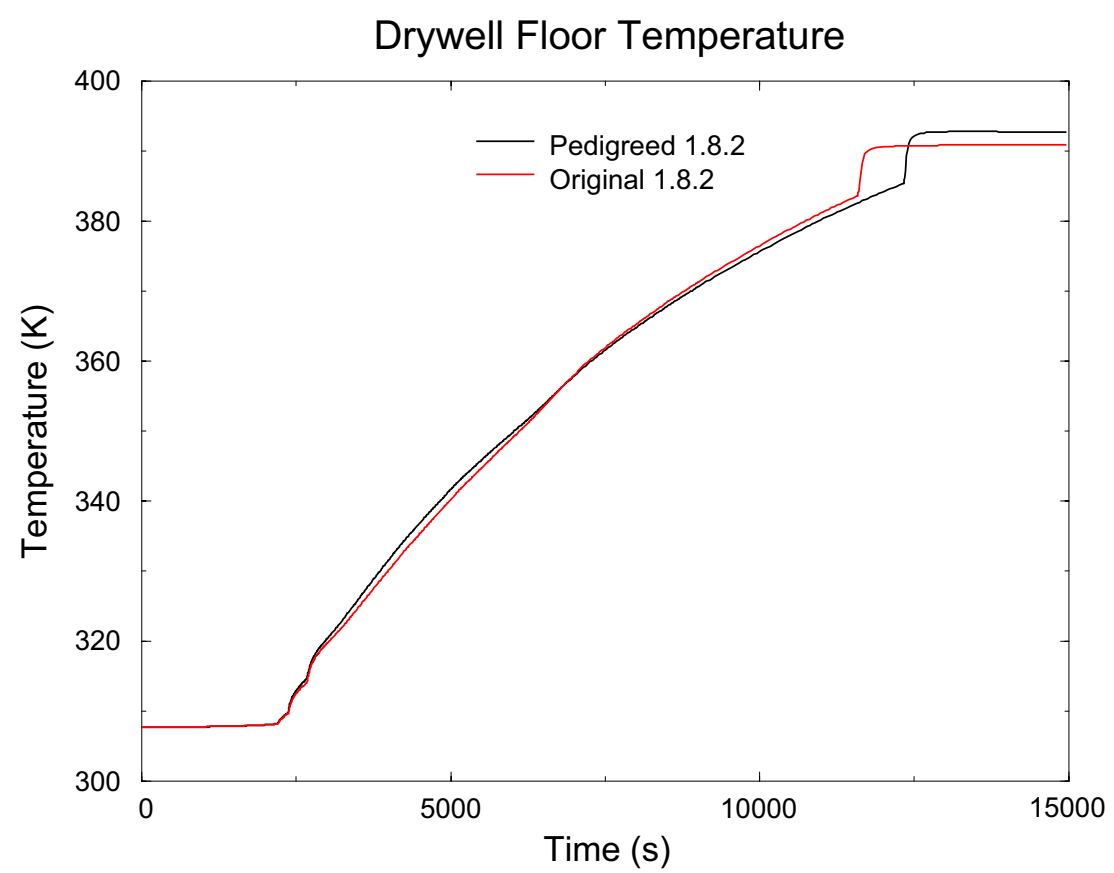

Figure 1. Drywell concrete floor temperature comparison for the test problem sent with the MELCOR 1.8.2 distribution.

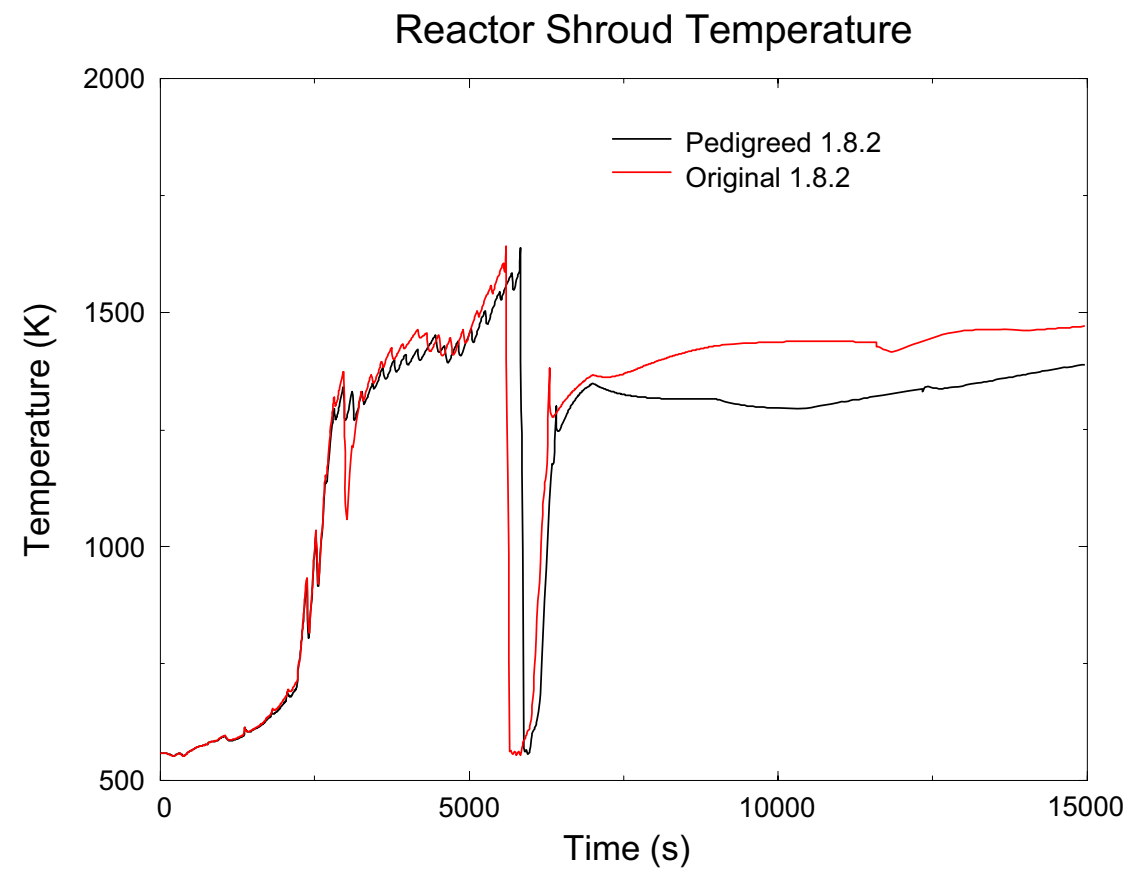

Figure 2. Reactor shroud temperature comparison for test problem sent with the MELCOR 1.8.2 distribution. 


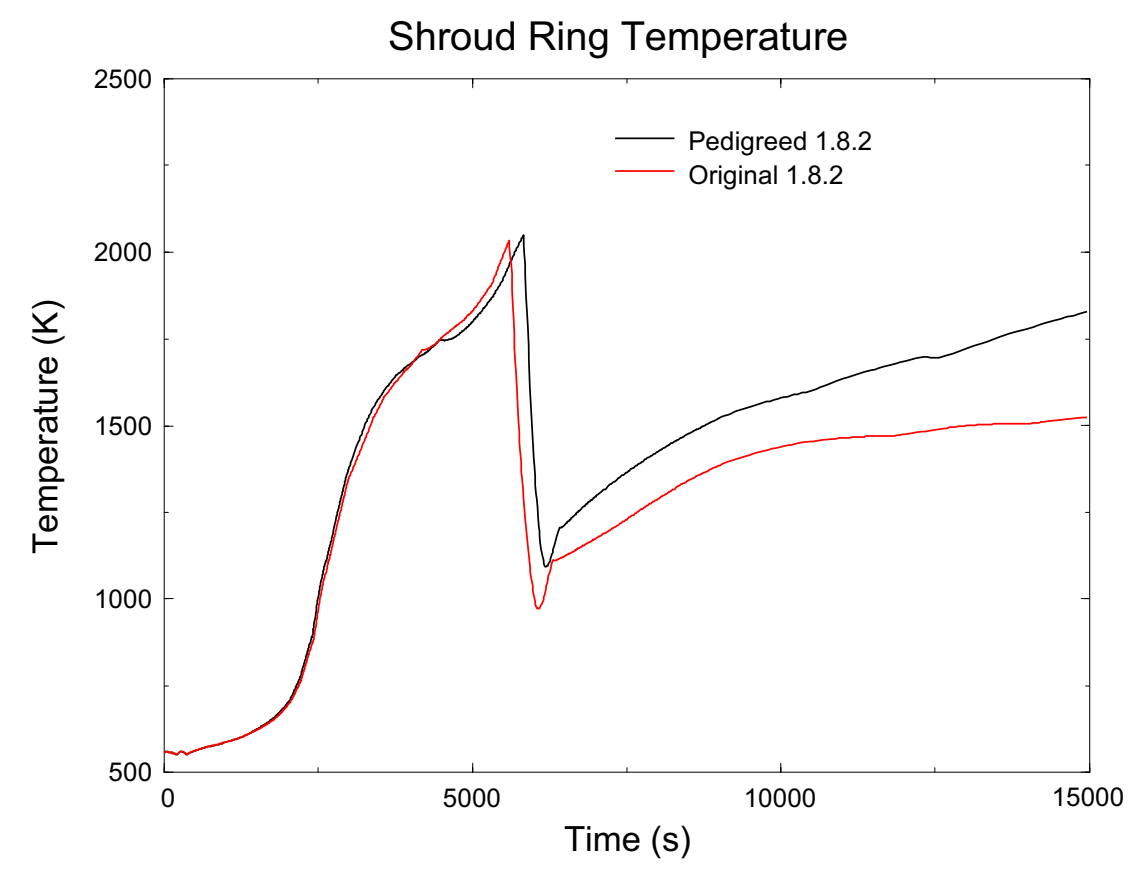

Figure 3. Shroud ring temperature comparison for the test problem sent with the MELCOR 1.8.2 distribution.

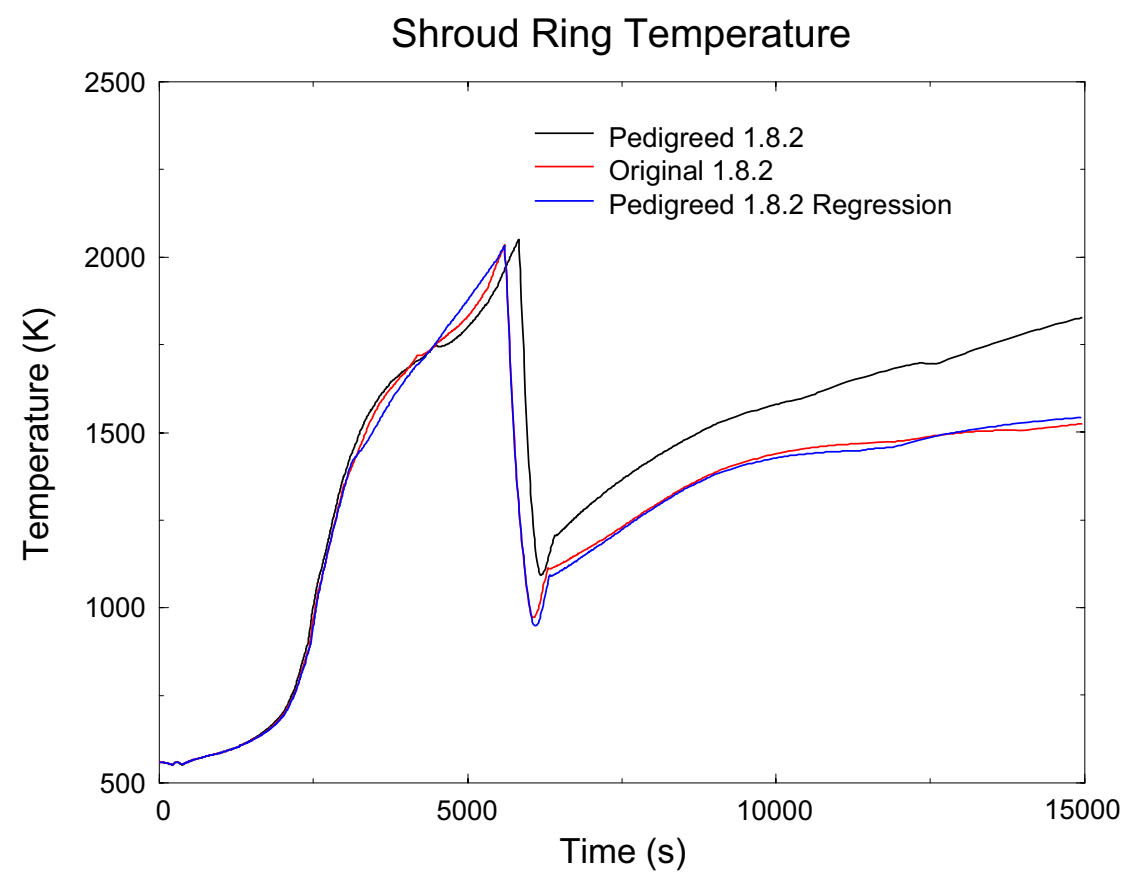

Figure 4. Shroud ring temperature regression comparison for the test problem sent with the MELCOR 1.8.2 distribution. 


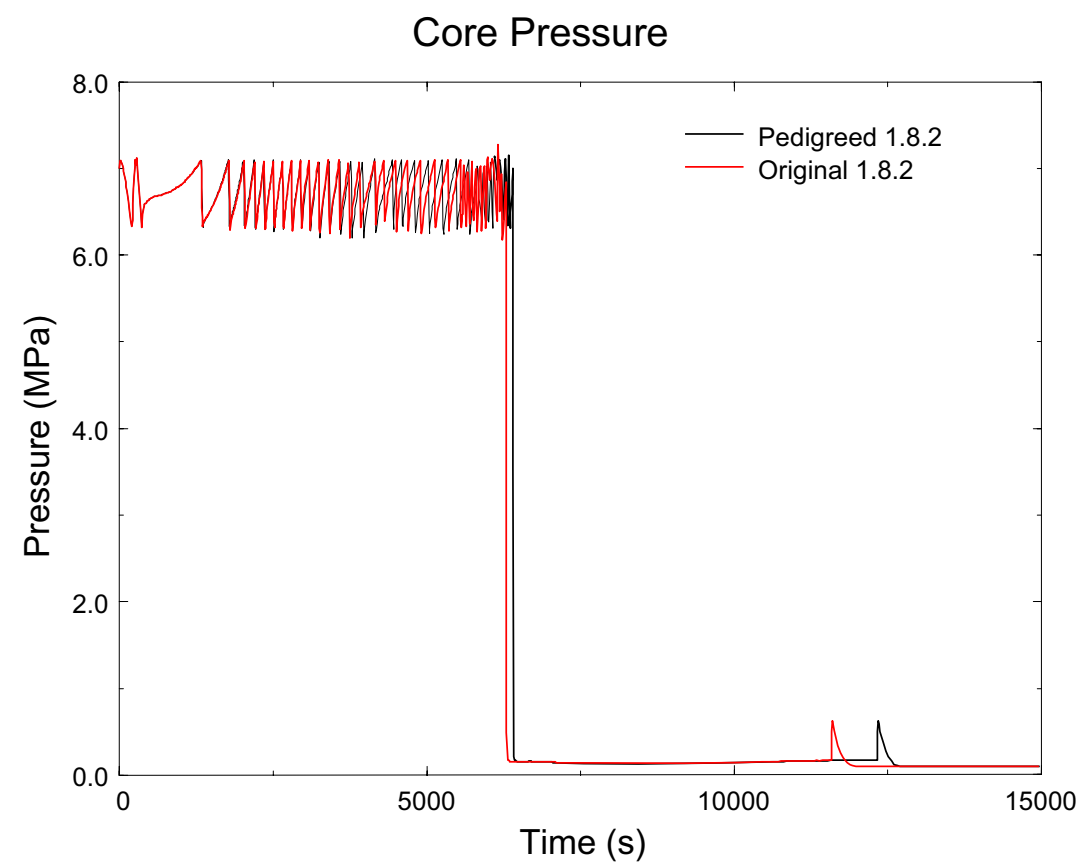

Figure 5. Reactor core pressure comparison for the test problem sent with the MELCOR 1.8.2 distribution.

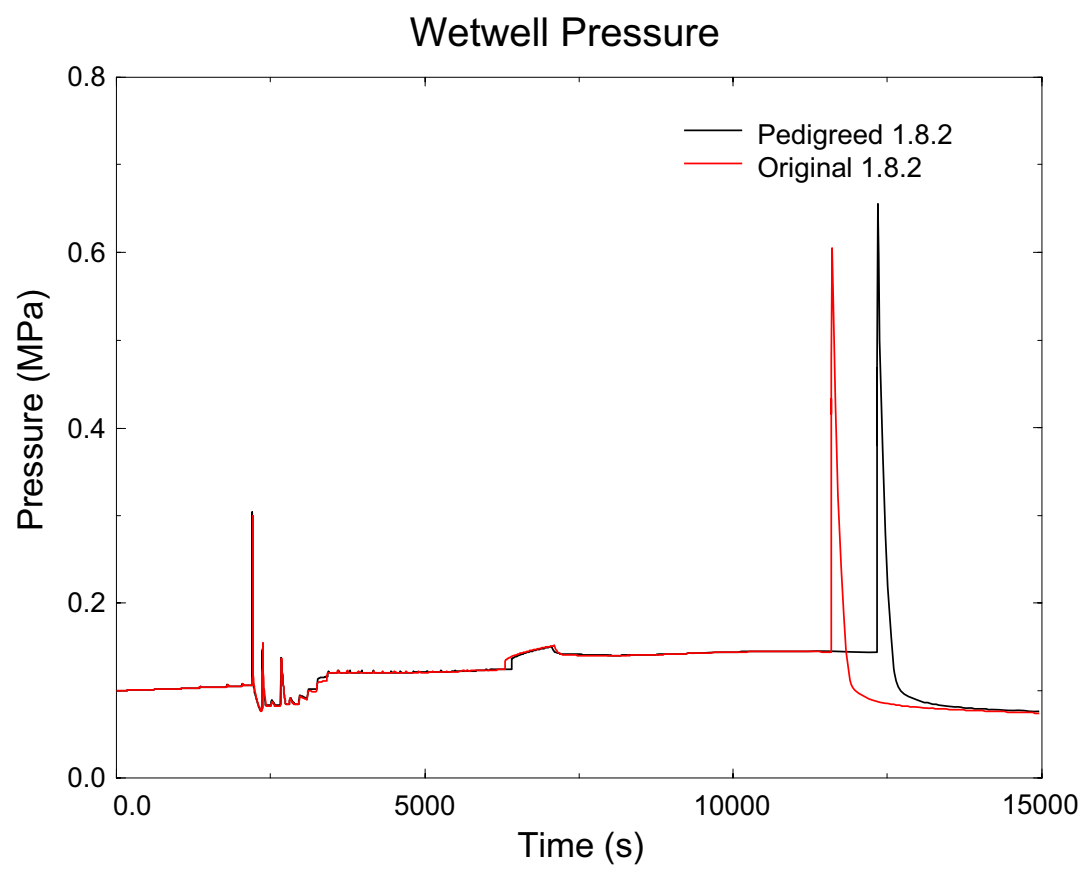

Figure 6. Wetwell pressure comparison for the test problem sent with MELCOR 1.8.2 distribution. 


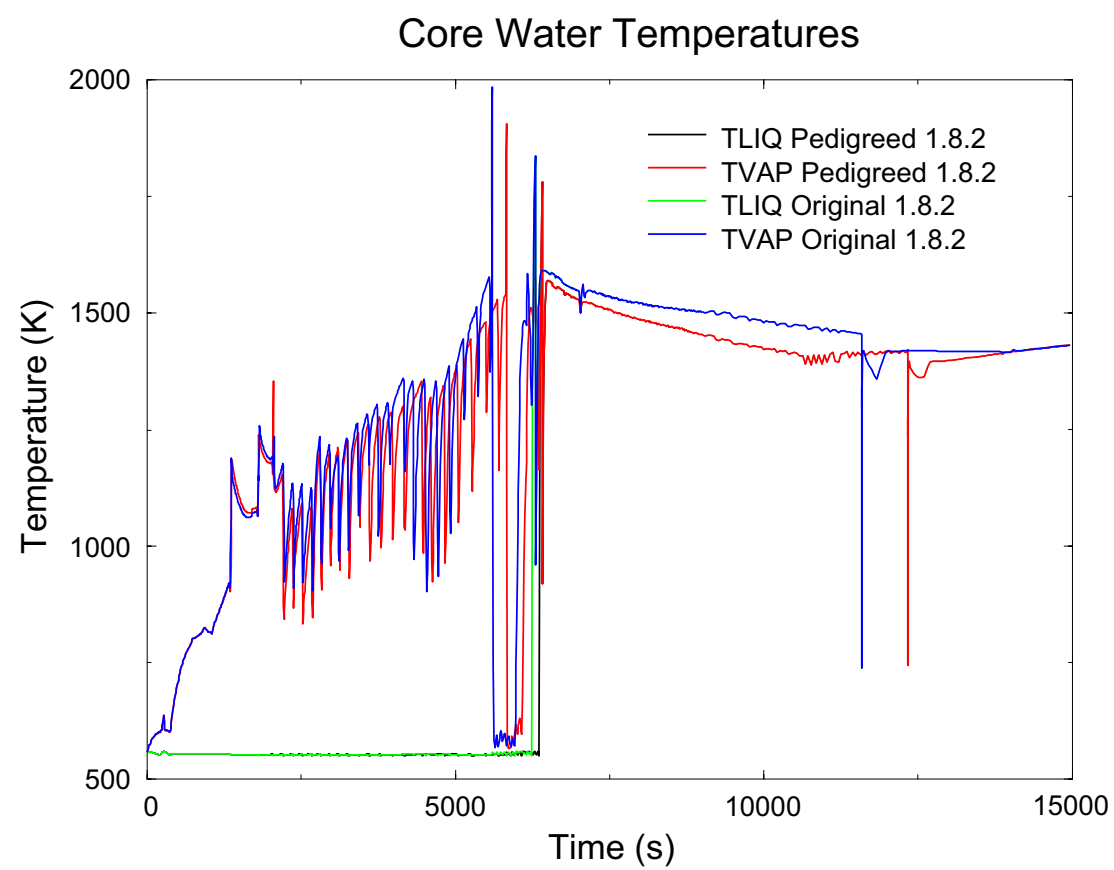

Figure 7. Core water temperature comparison for the test problem sent with the MELCOR 1.8.2 distribution.

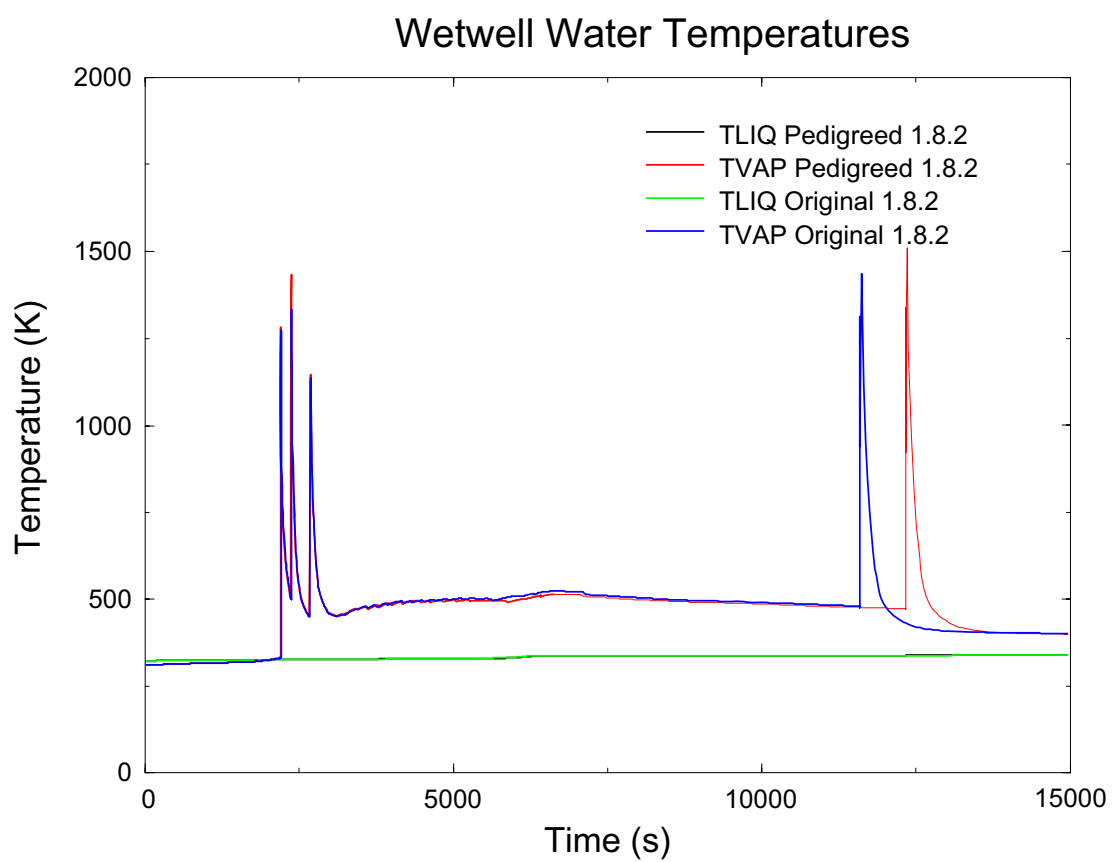

Figure 8. Wetwell water temperature comparison for the test problem sent with the MELCOR 1.8.2 distribution. 


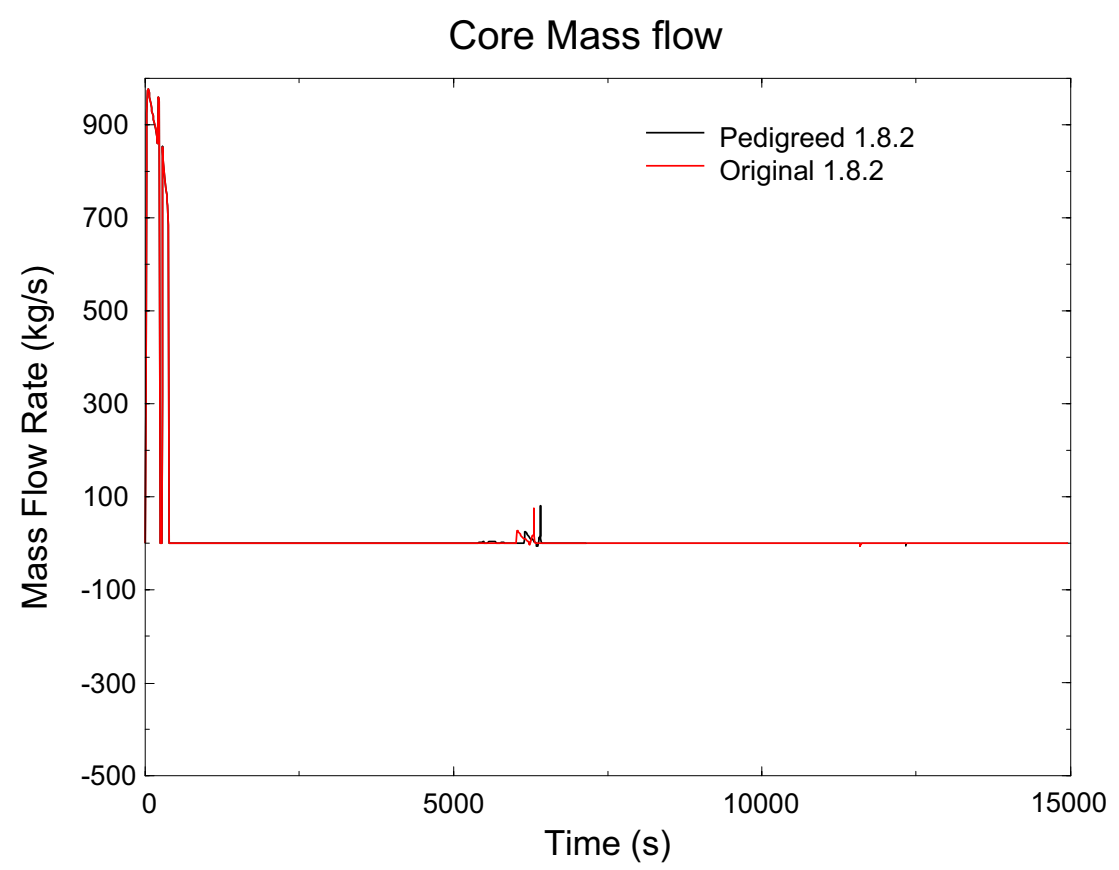

Figure 9. Reactor core mass flow comparison for the test problem sent with the MELCOR 1.8.2 distribution.

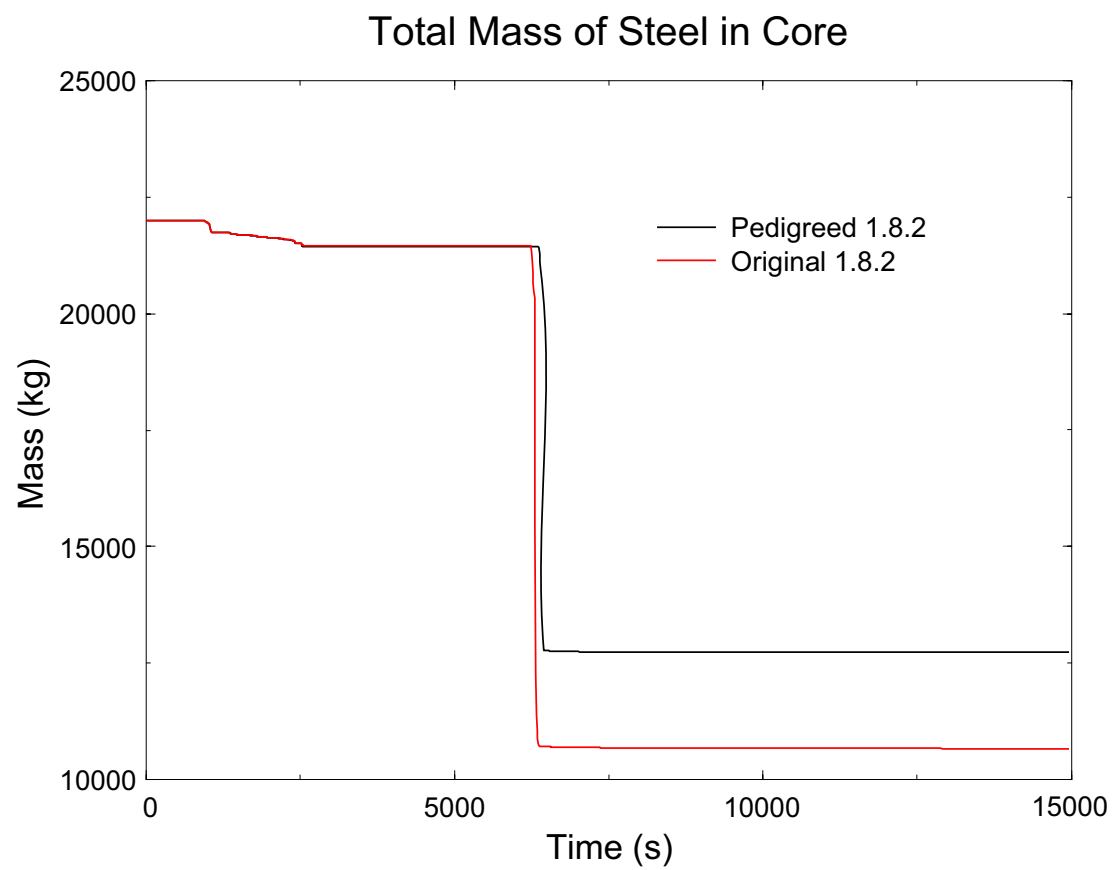

Figure 10. Reactor core steel mass comparison for the test problem sent with the MELCOR 1.8.2 distribution. 


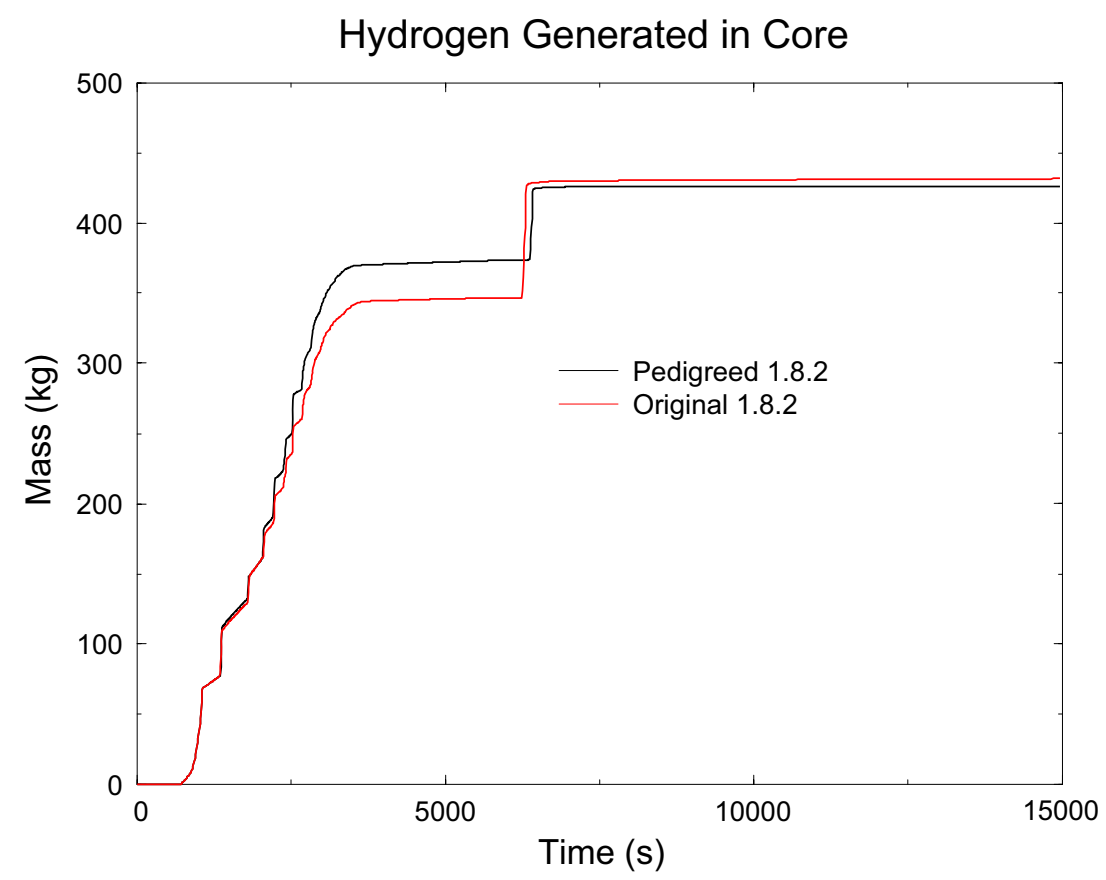

Figure 11. Reactor core hydrogen mass generation comparison for the test problem sent with the MELCOR 1.8.2 distribution.

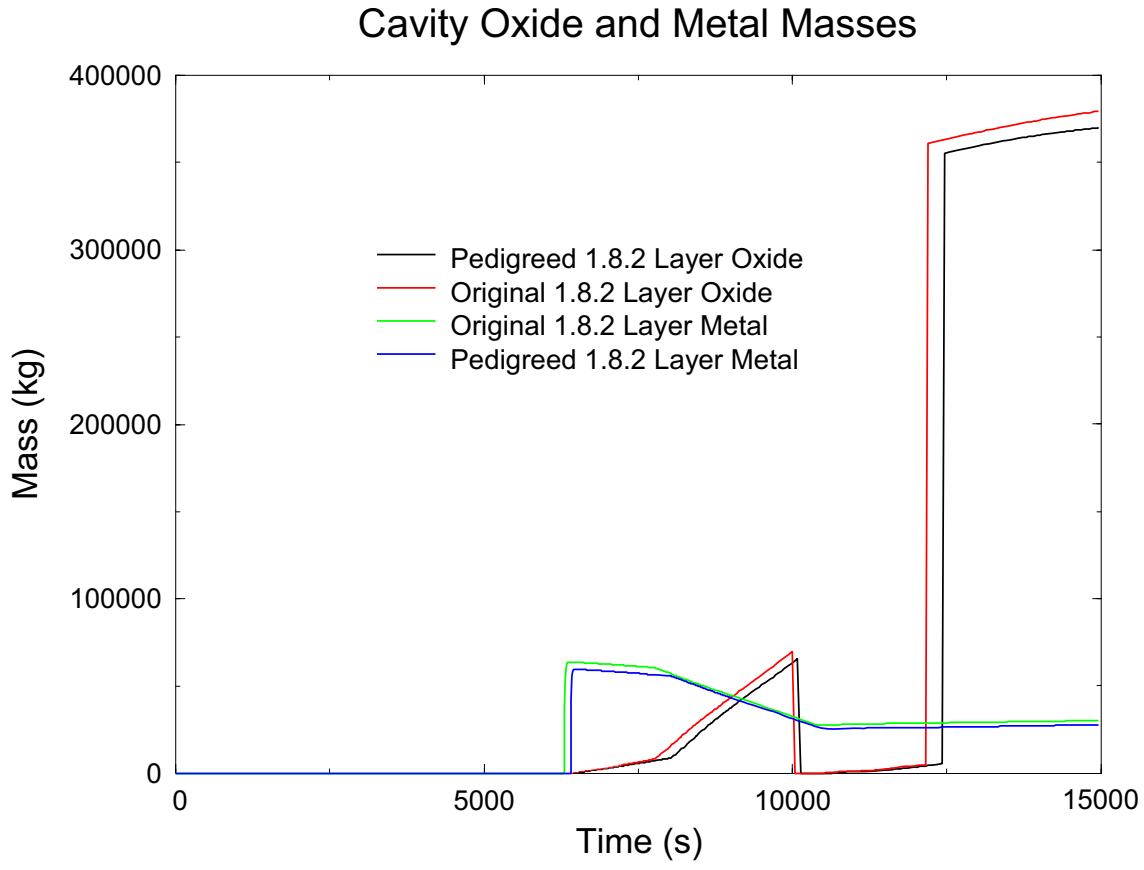

Figure 12. Reactor bottom head debris mass comparison for the test problem sent with the MELCOR 1.8.2 distribution. 


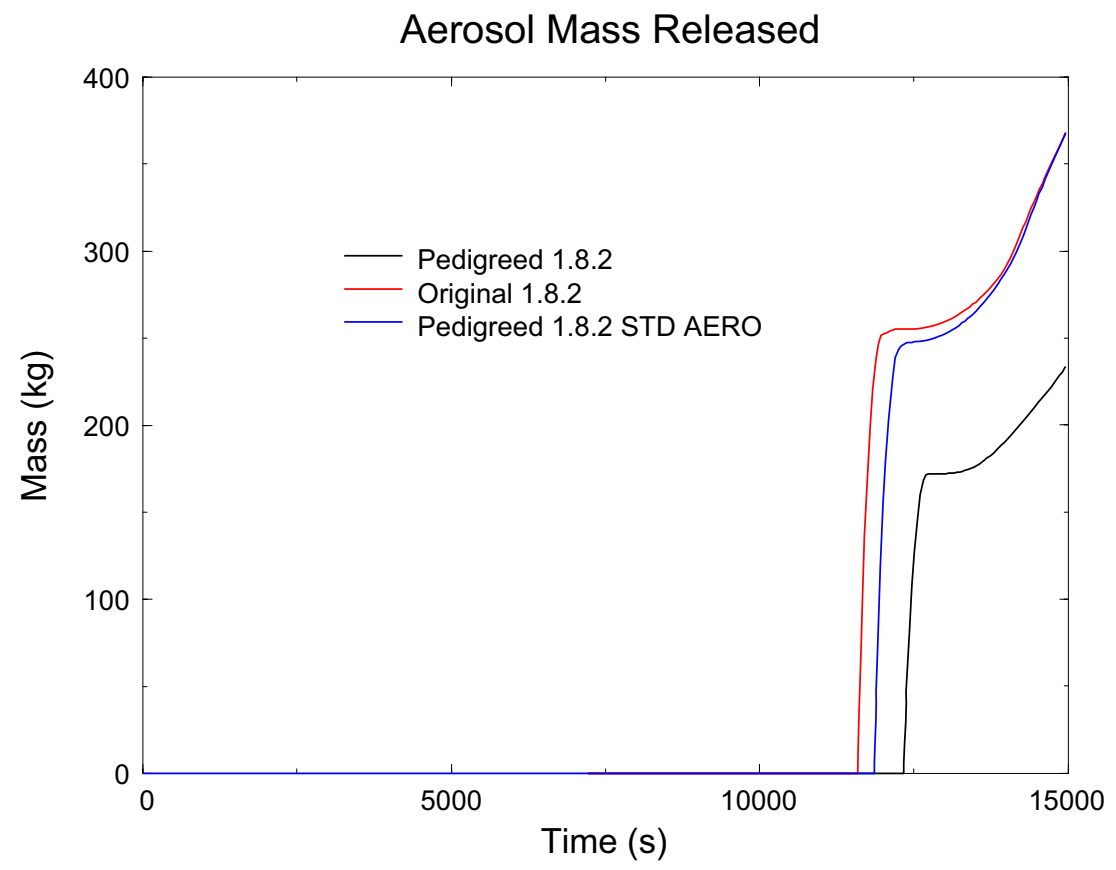

Figure 13. Aerosol mass release comparison for the test problem sent with the MELCOR 1.8.2 distribution. 


\section{ITER FEAT ACCIDENT CASE COMPARISON}

In 2005 four relevant ITER FEAT accident cases selected by the ITER International Team (IT) for a basis of comparison of the fusion version of the MELCOR 1.8.2 code provided by the INL to the IT prior to 1998 against similar prediction obtained using the multi-fluids version of MELCOR 1.8.5. The results of that comparison were reported in Reference 14. Since we have the result from those four accident cases we compared these results obtained using the ITER FEAT version of the MELCOR 1.8.2 code with result from the same accident input files using the pedigreed version of MELCOR 1.8.2. Three of the four accident cases that were selected by the IT are examined in this report, which are: (1) a large ex-vessel pipe break, (2) multiple in-vessel FW pipe break, and (3) vacuum vessel (VV) \& cryostat boundary failures. The input decks and output plot files for these accidents were also supplied to the INL by the IT as well as a list of the variables to be compared for each accident. A detailed description of the accidents analyzed can be found in Reference 11. The fourth case, a divertor ex-vessel coolant pipe break, was not included in this report although the agreement was very good. What was noticed during this comparison was a round-off error problem in the wall temperatures for the Heat Transport System (HTS) vault. This is an inherent problem with MELCOR because this code is written in single precision FORTRAN. The INL FSP has developed a fix for this problem but this change is not part of the version being pedigreed. Our intent is to introduce the change if the problem persists for this accident case for RPrS analyses.

\subsection{Multiple In-vessel FW Pipe Break}

This postulated event is the double-ended rupture of multiple 10-mm diameter first wall (FW) coolant pipes during a plasma burn. All FW/shield modules around the inboard and outboard toroidal circumference of the machine are postulated to be damaged by this event. The number of modules involved is estimated to be 54 . This bounds the worst possible damage to perfectly aligned $\mathrm{FW} /$ shield modules during a hypothetical plasma transient. Coolant will be discharged at a high flow rate directly into the VV from a total FW break area of $0.2 \mathrm{~m}^{2}$. The rapid coolant ingress will terminate the plasma by a disruption.

Figures 14 and 15 contain the mass flow rate and the integrated mass flow associated with the outboard break, respectively. Similarly, the mass flow rate and integrated mass flow from the inboard break are shown in Figures 16 and 17. As seen there is no little in the break mass flow rates between the ITER FEAT version of MELCOR 1.8.2 and the pedigreed version.

Results for the water mass flow rate and the integrated mass flow through the drain line are shown in Figures 18 and 19. The vapor mass flow rate through relief lines 1 and 2 and their corresponding integrated mass flows are shown in Figures 20, 21, 22 and 23, respectively. As seen there is little difference in the results produced by the ITER FEAT version compared to the pedigreed version.

A comparison of the plasma chamber vapor temperature and pressure is shown in Figures 24 and 25, respectively. Again there is little difference in the results.

In Figures 26, 27, 28, 29, and 30 the pressure as a function of time is shown for different locations between the plasma chamber and the suppression tank. There is less than a $1 \%$ difference in the results produced by the two versions of the code.

The mass of water in the drain tank and the vacuum vessel are shown in Figures 31 and 32. Figures 33, 34 , and 35 contain the corresponding volume of water in the drain tank, FW blanket and the vacuum vessel. There is little difference between the results from the ITER FEAT version of MELCOR 1.8.2 and the pedigreed version of MELCOR 1.8.2. 
Overall the agreement between the ITER FEAT version of MELCOR 1.8.2 and the pedigreed version of MELCOR 1.8.2 for this accident is excellent.

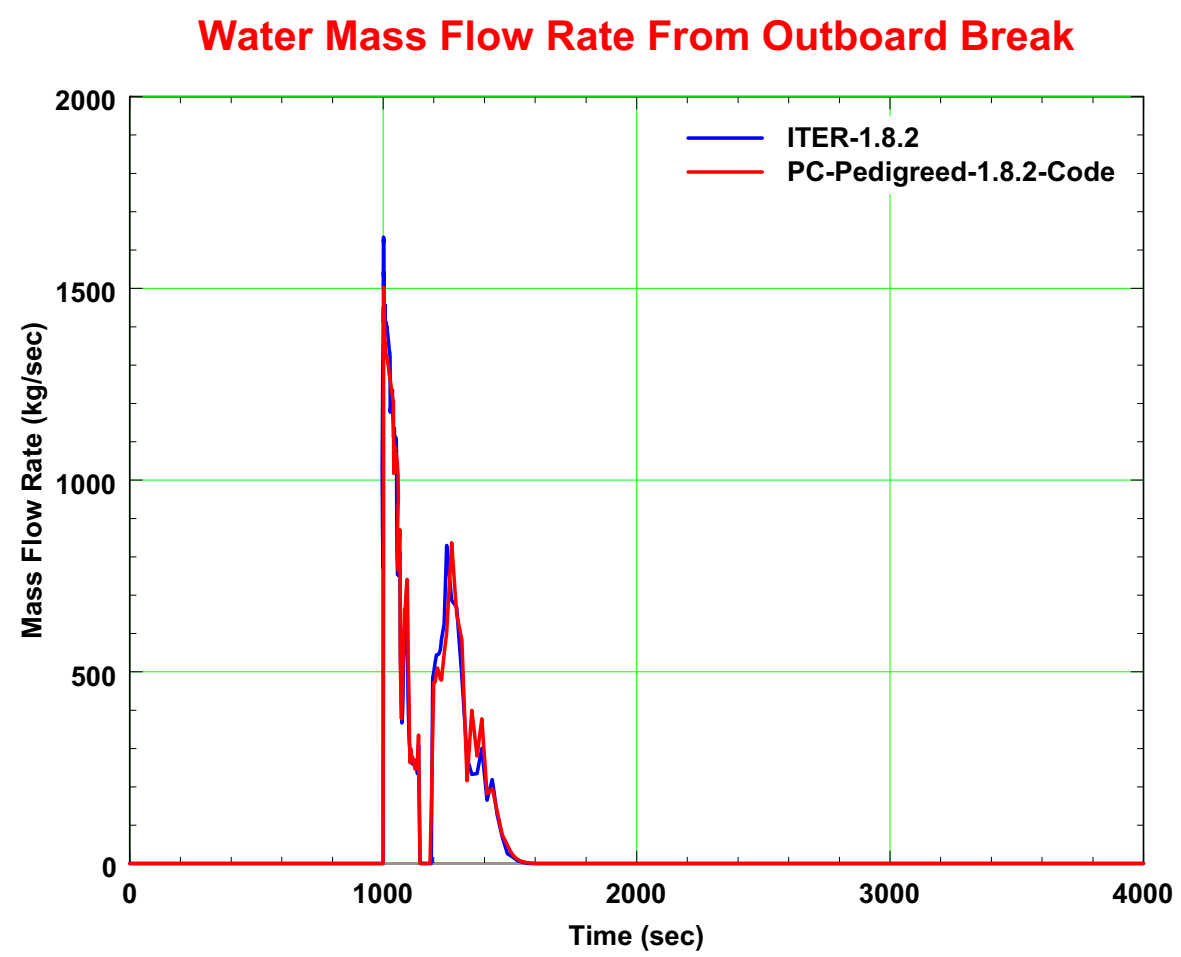

Figure 14. Water mass flow rate from outboard break.

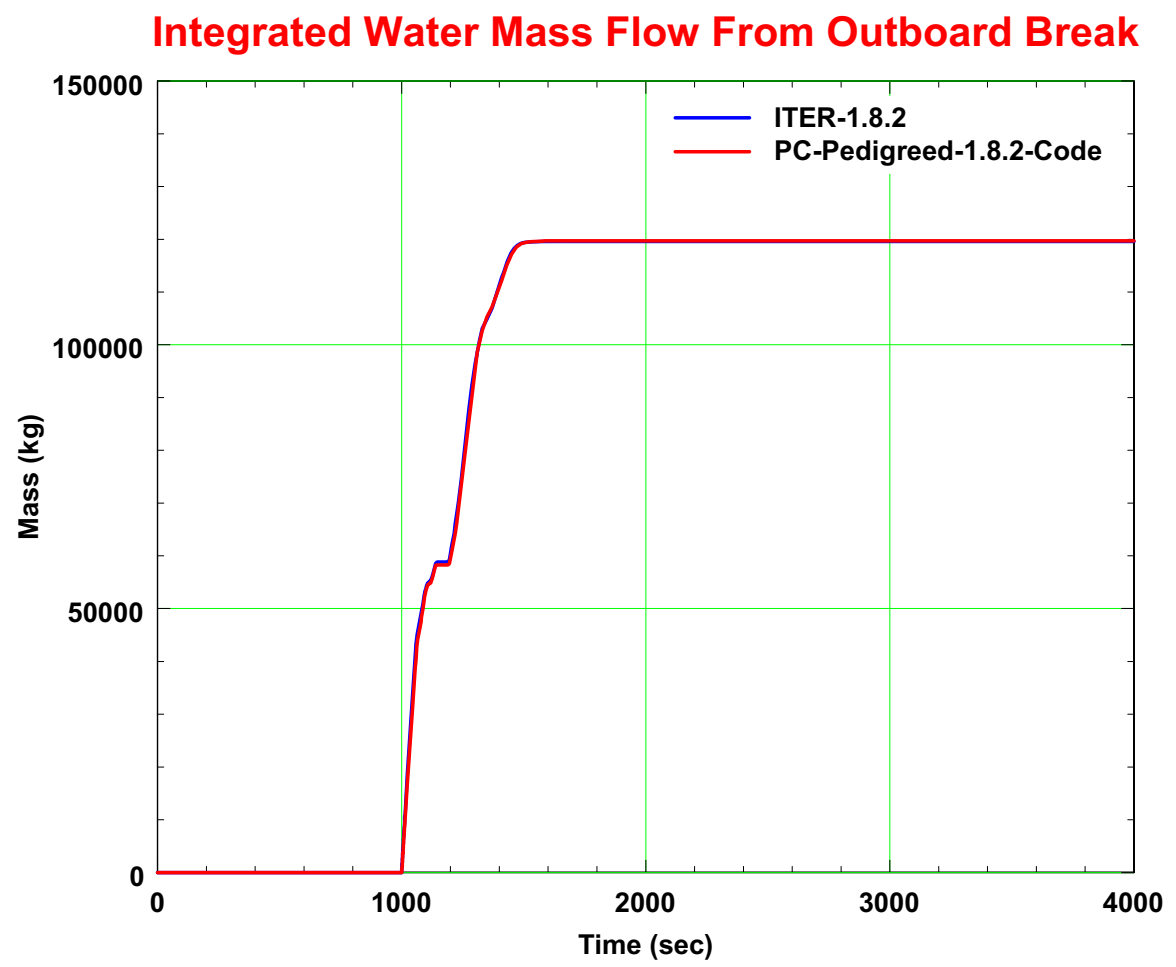

Figure 15. Integrated water mass flow from outboard break. 


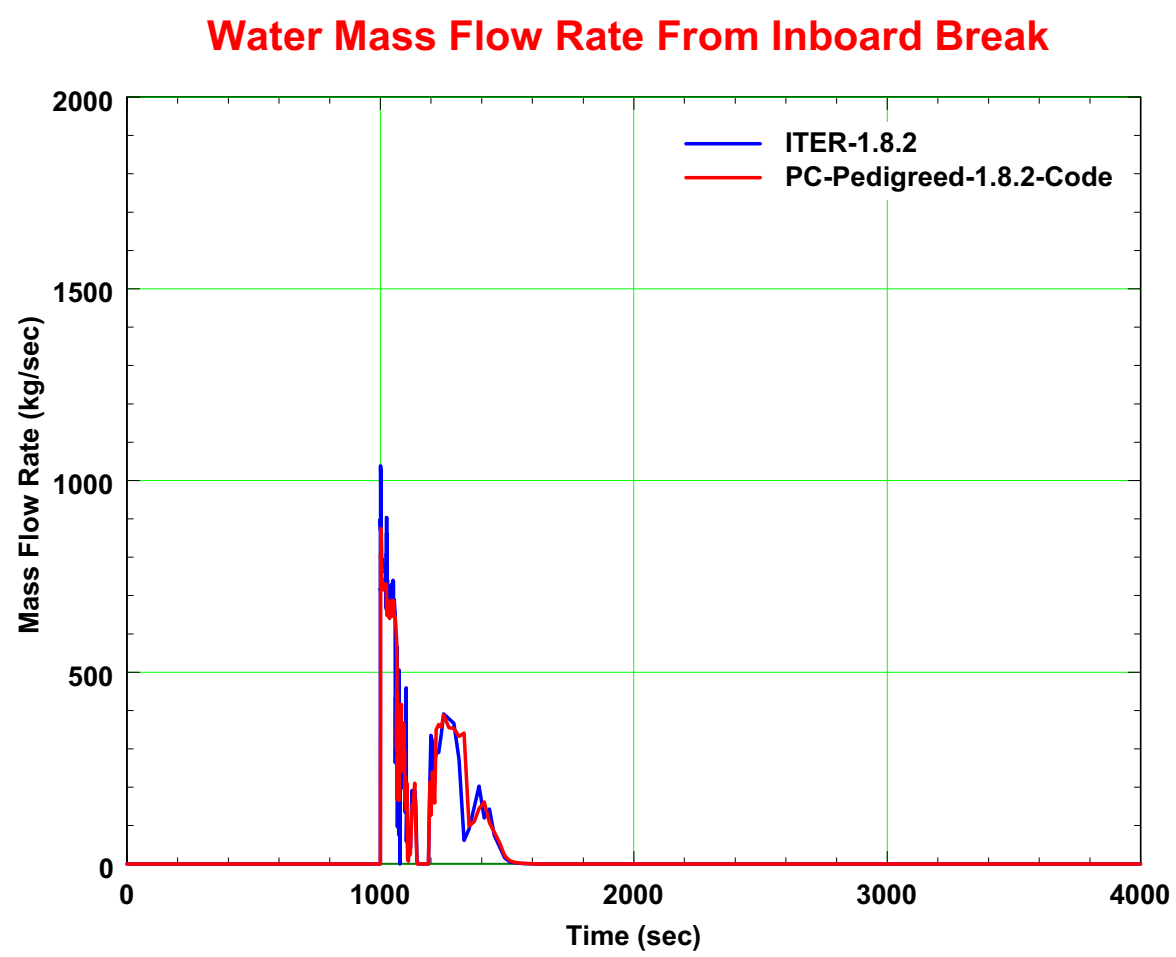

Figure 16. Water mass flow rate from inboard break.

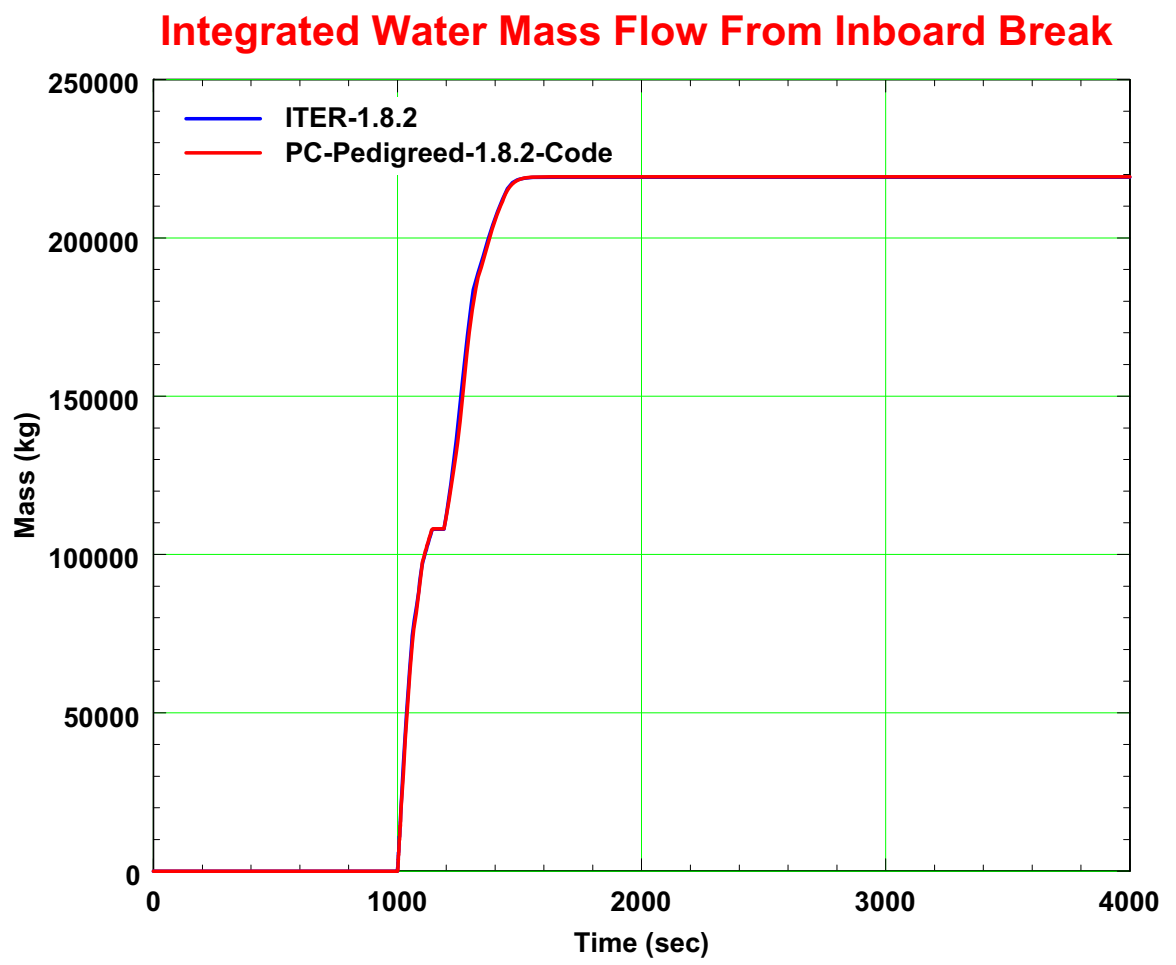

Figure 17. Integrated water mass flow from inboard break. 


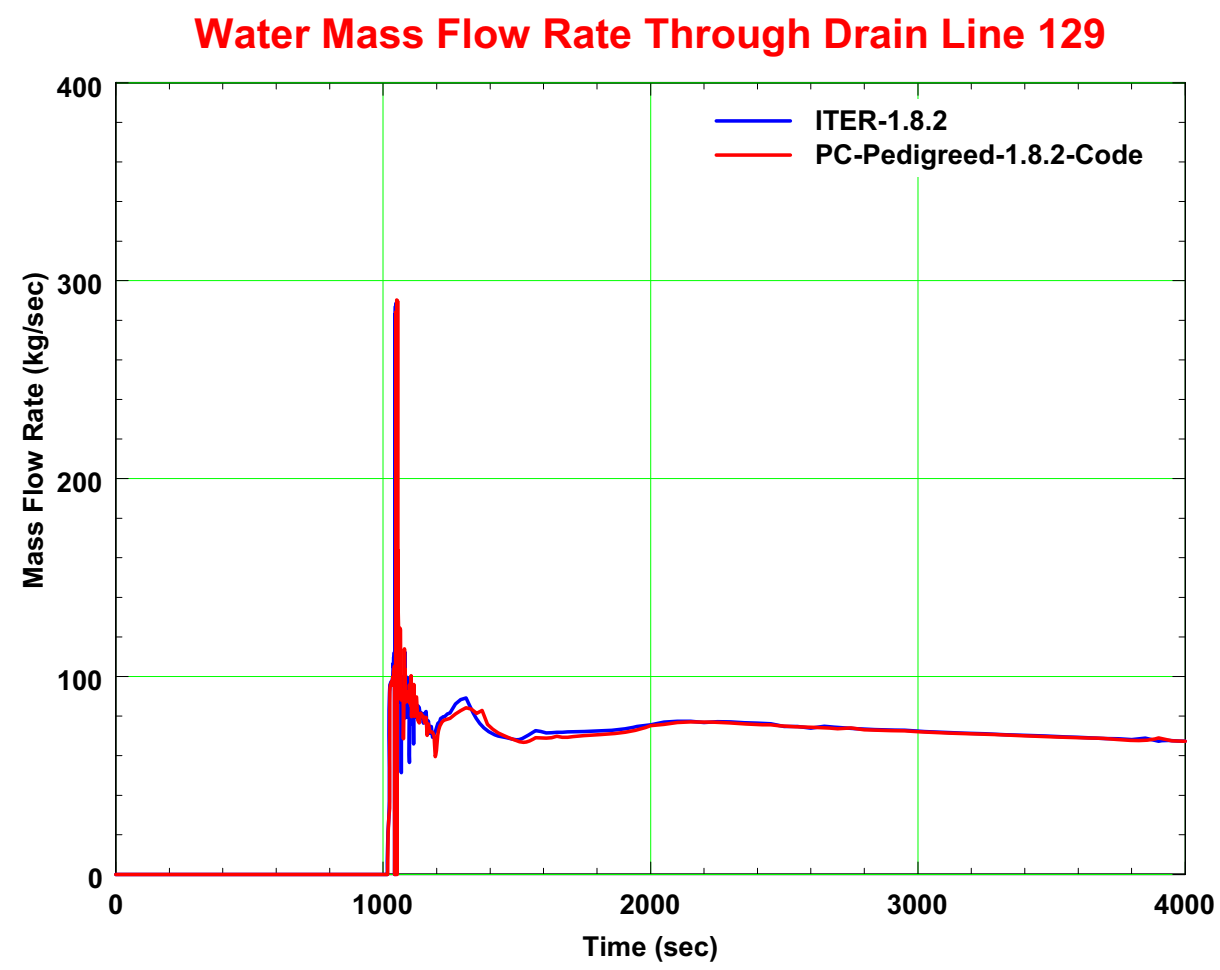

Figure 18. Water mass flow rate through drain line 129.

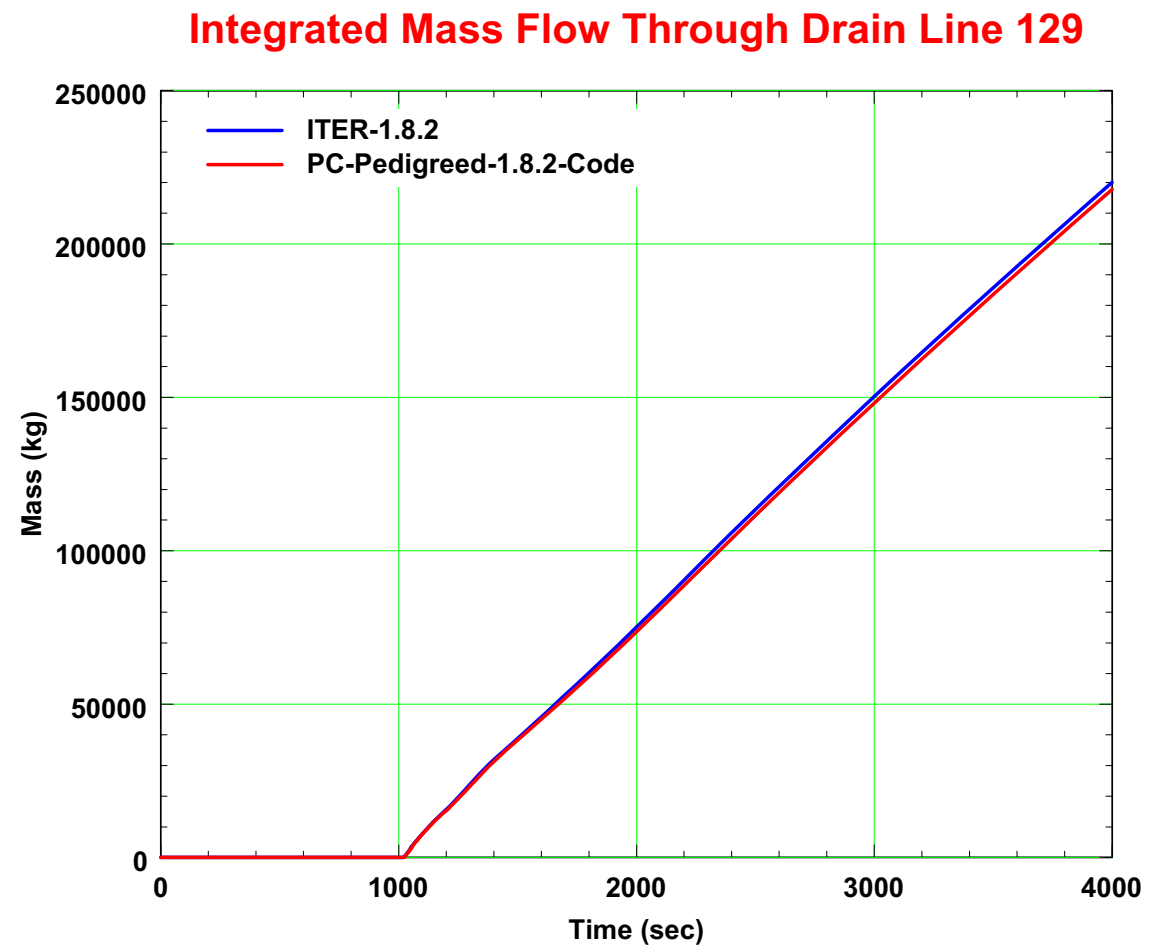

Figure 19. Integrated mass flow through drain line 129. 


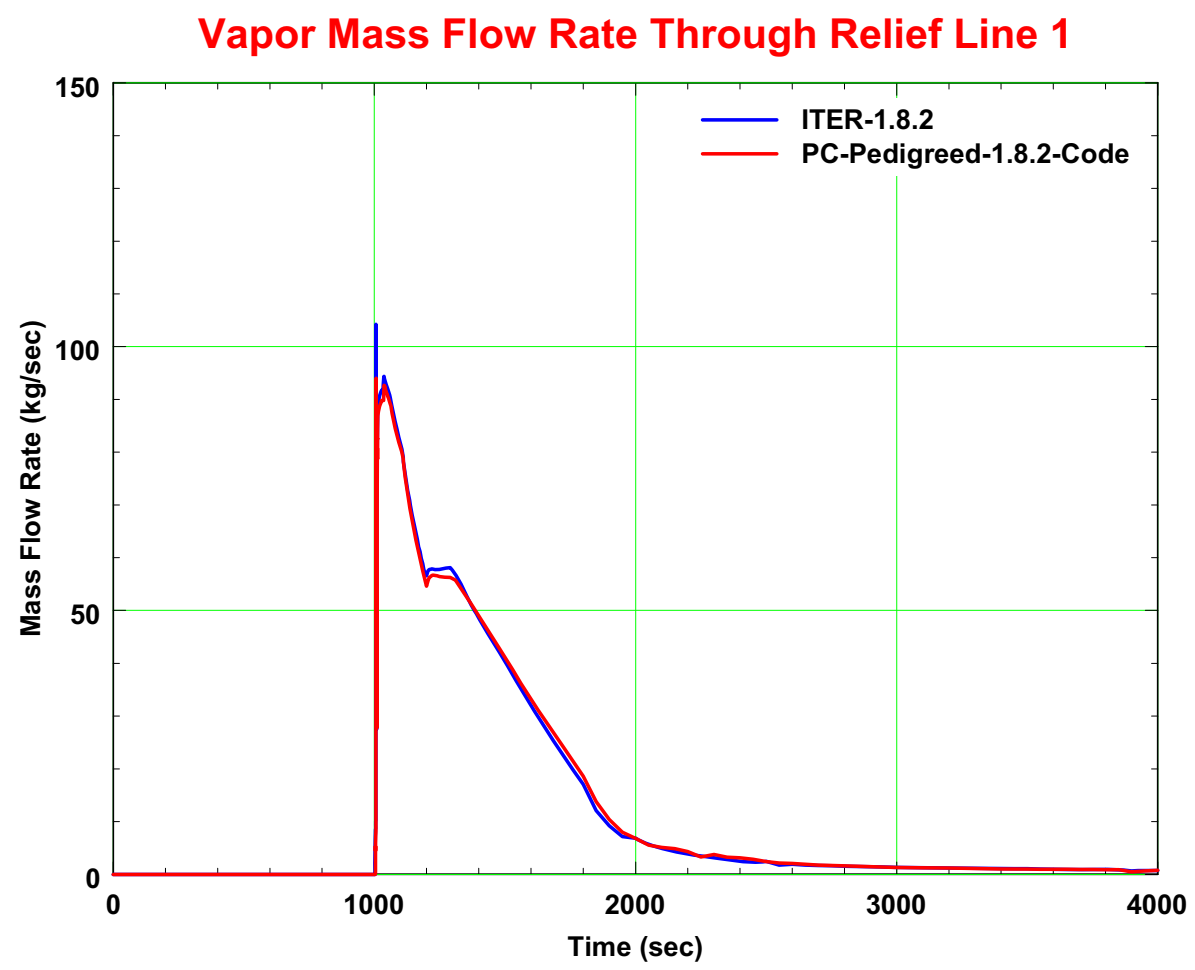

Figure 20. Vapor mass flow rate through relief line 1.

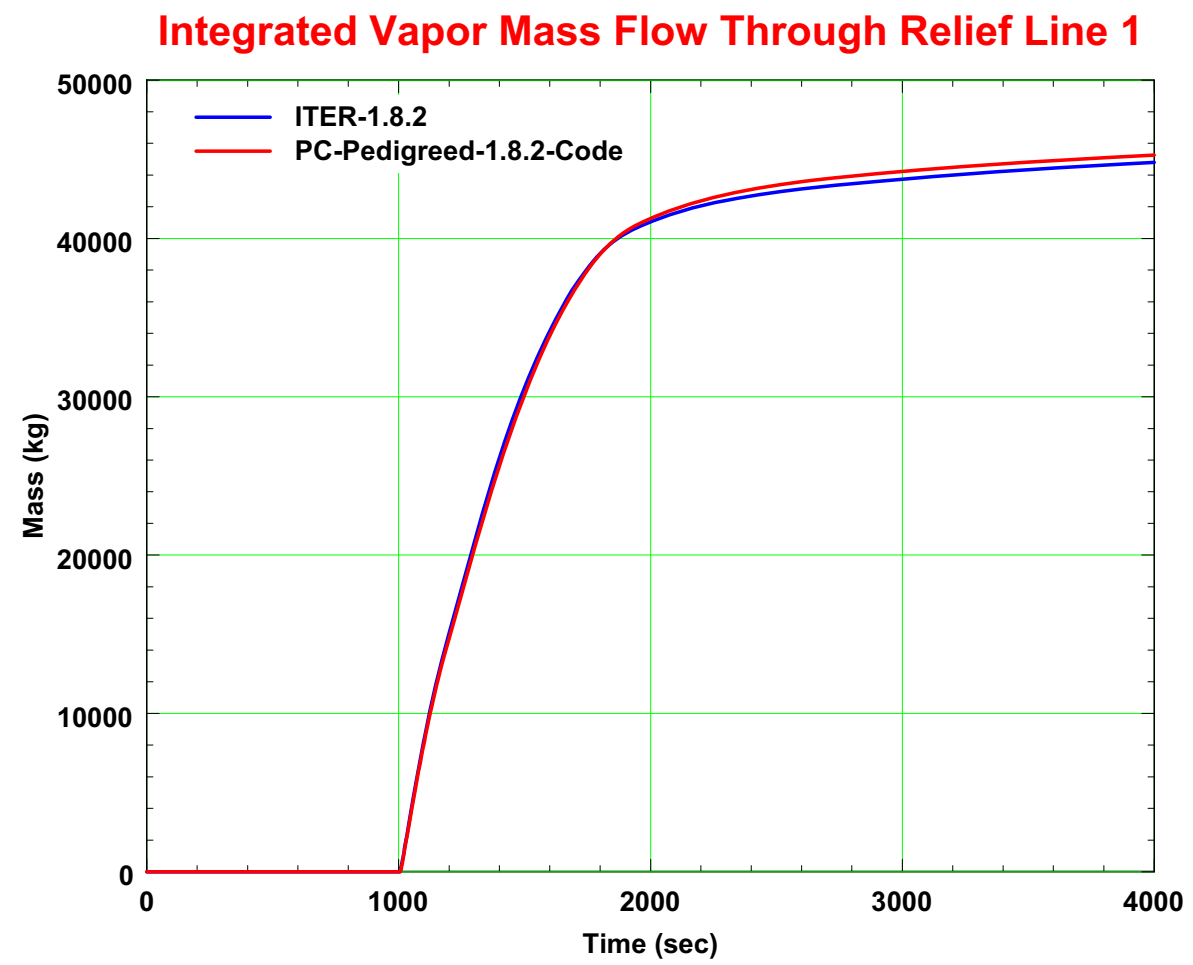

Figure 21. Integrated vapor mass flow through relief line 1. 


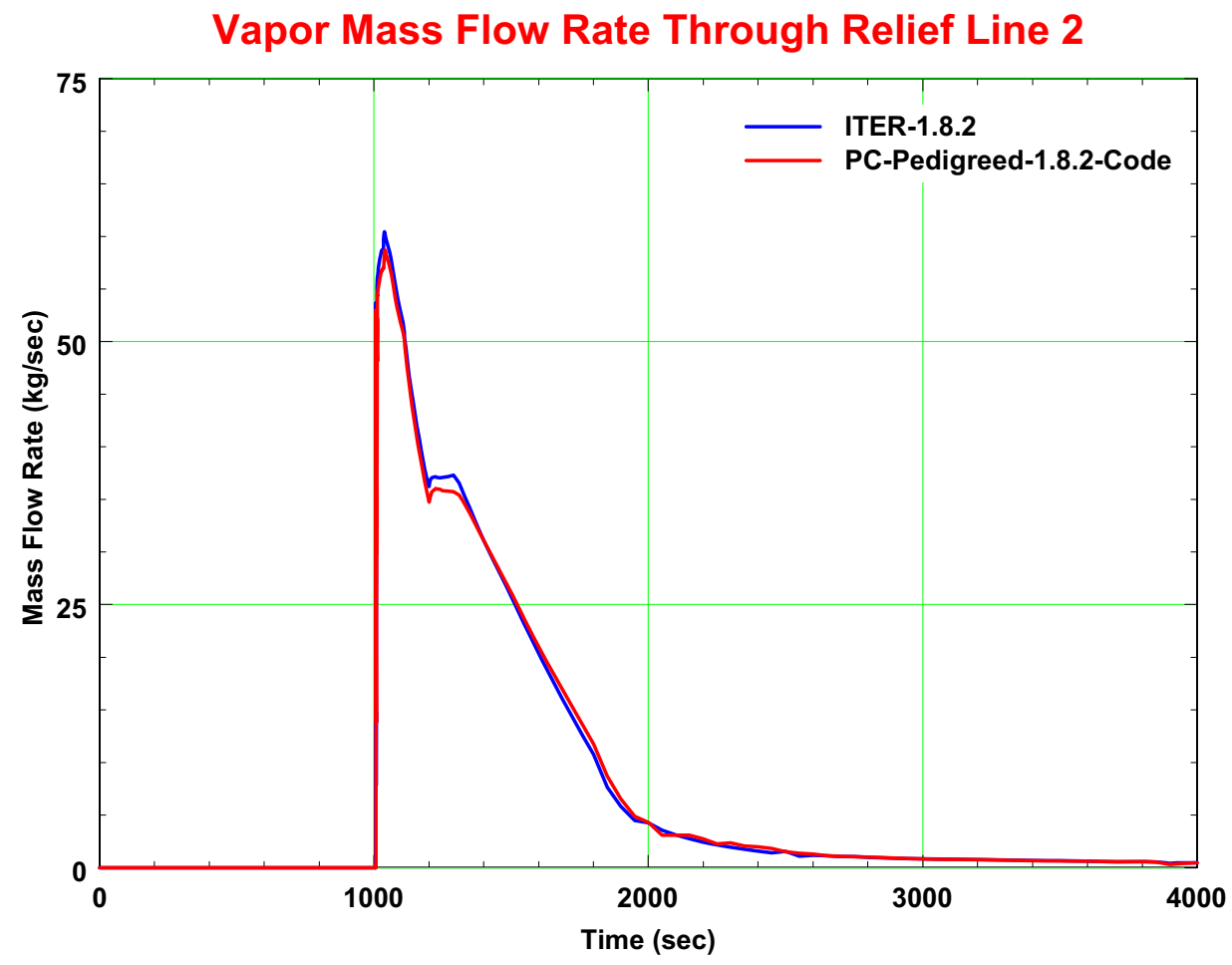

Figure 22. Vapor mass flow through relief line 2.

Integrated Vapor Mass Flow Through Relief Line 2

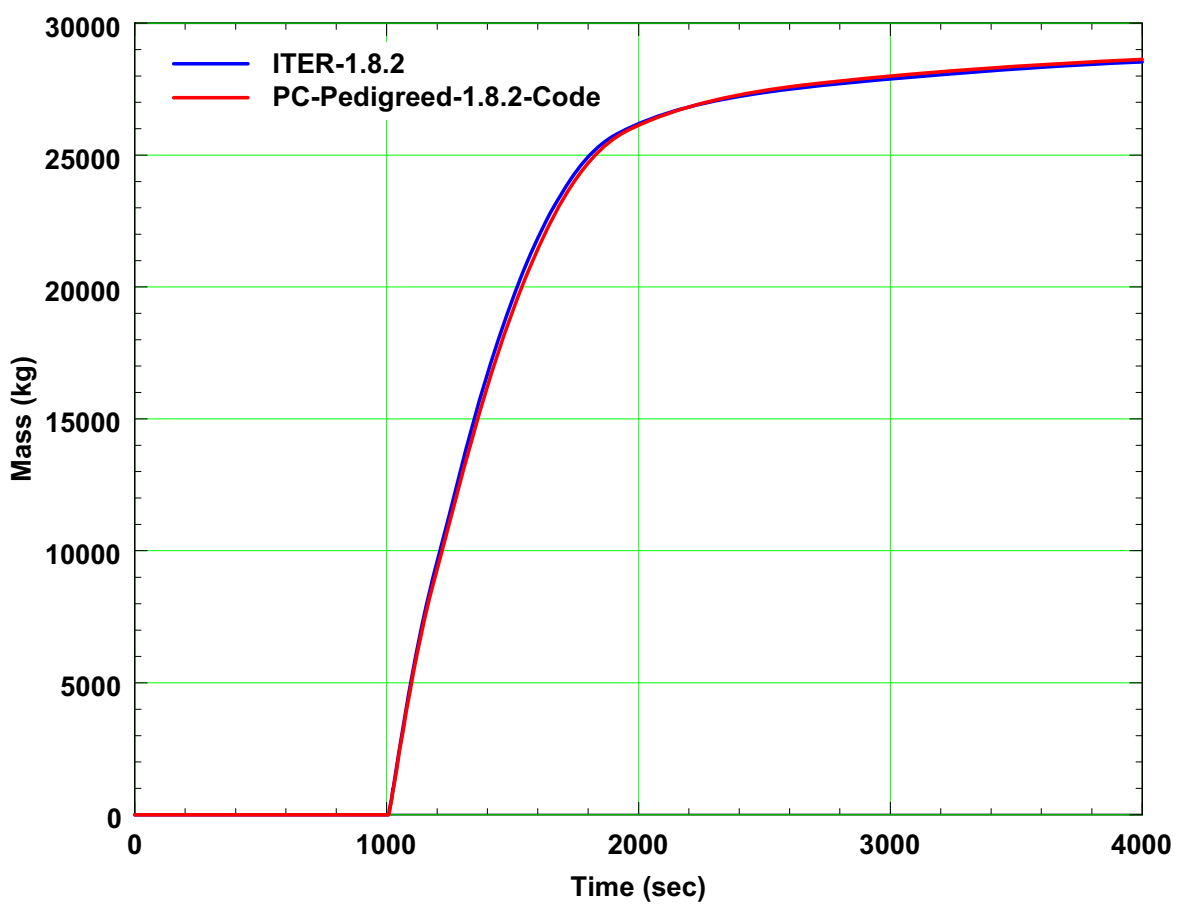

Figure 23. Integrated vapor mass flow through relief valve 2 . 


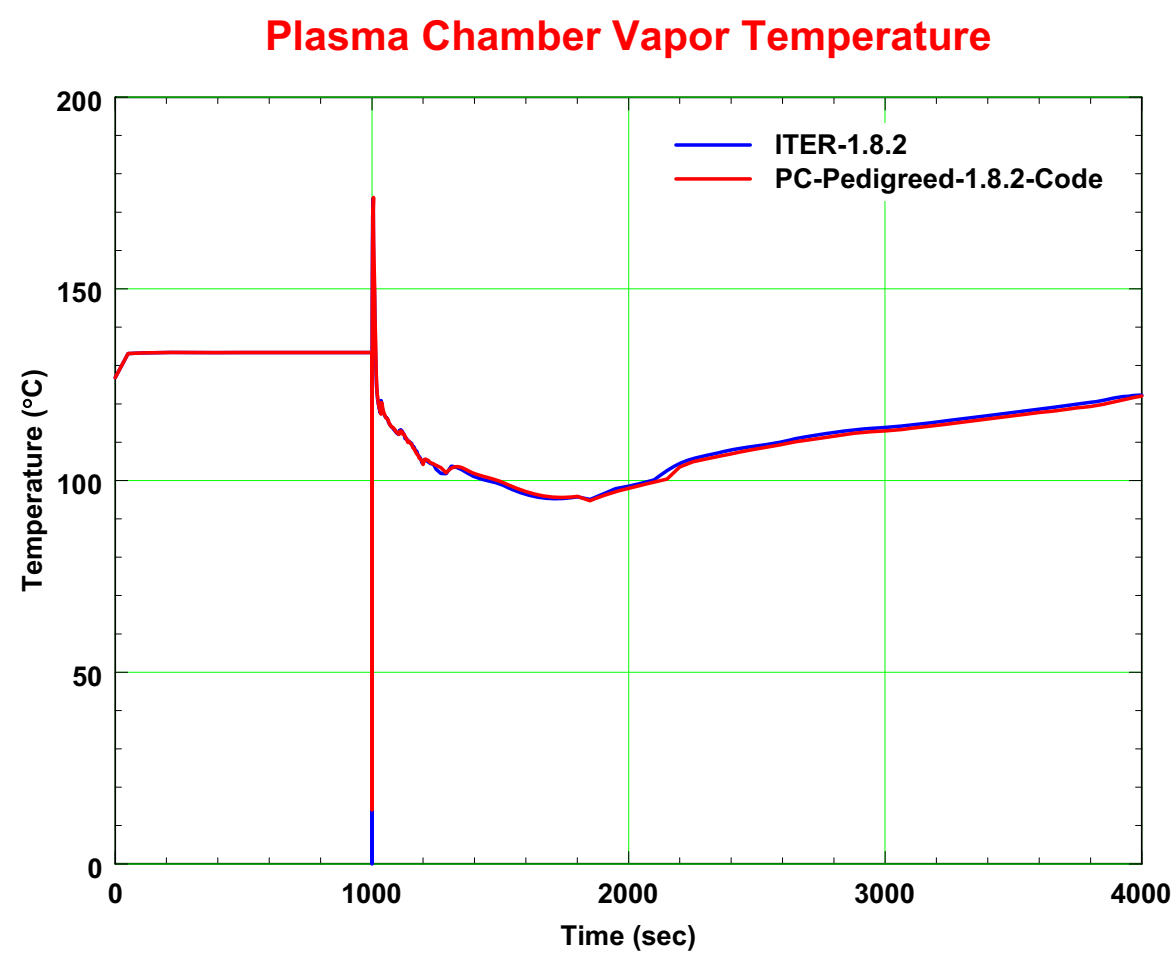

Figure 24. Plasma chamber vapor temperature.

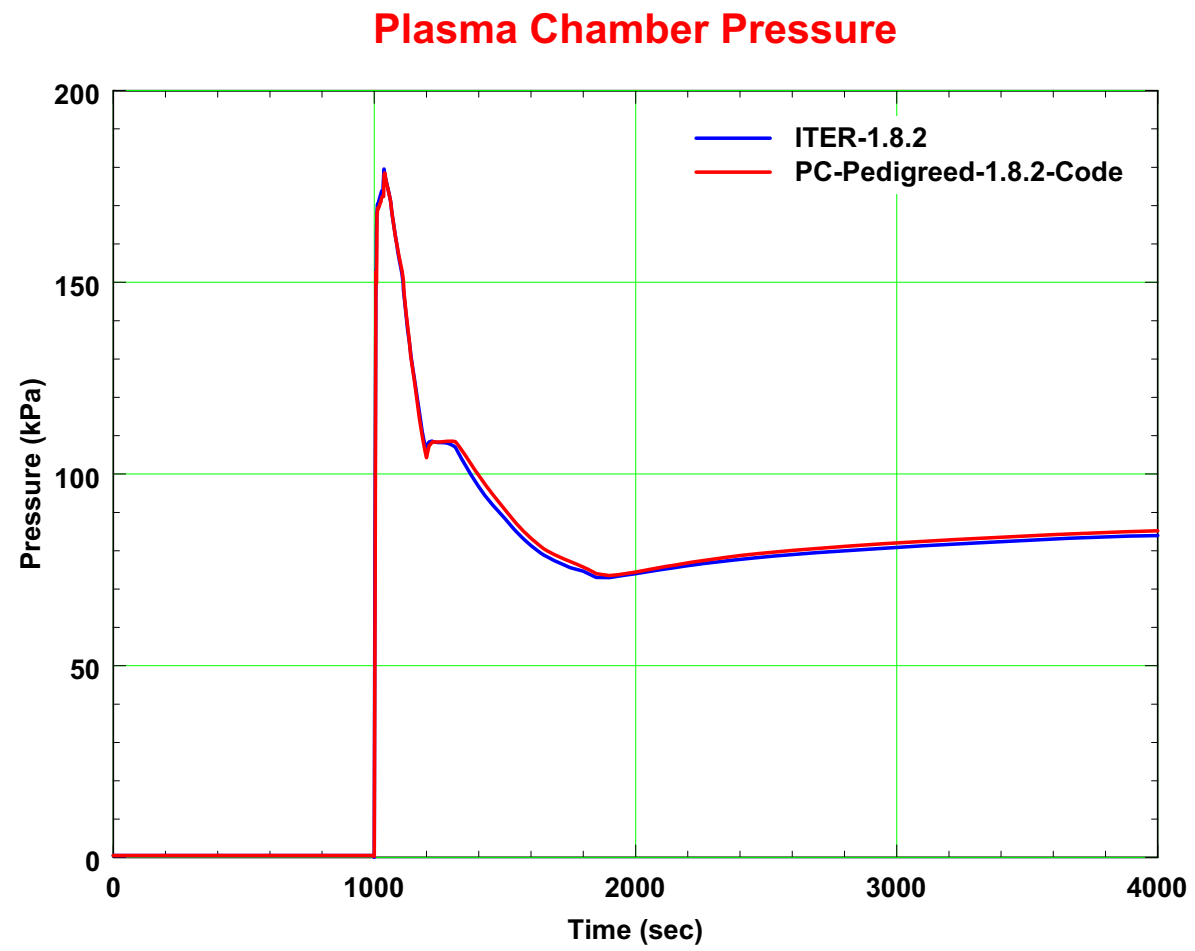

Figure 25. Plasma chamber pressure. 


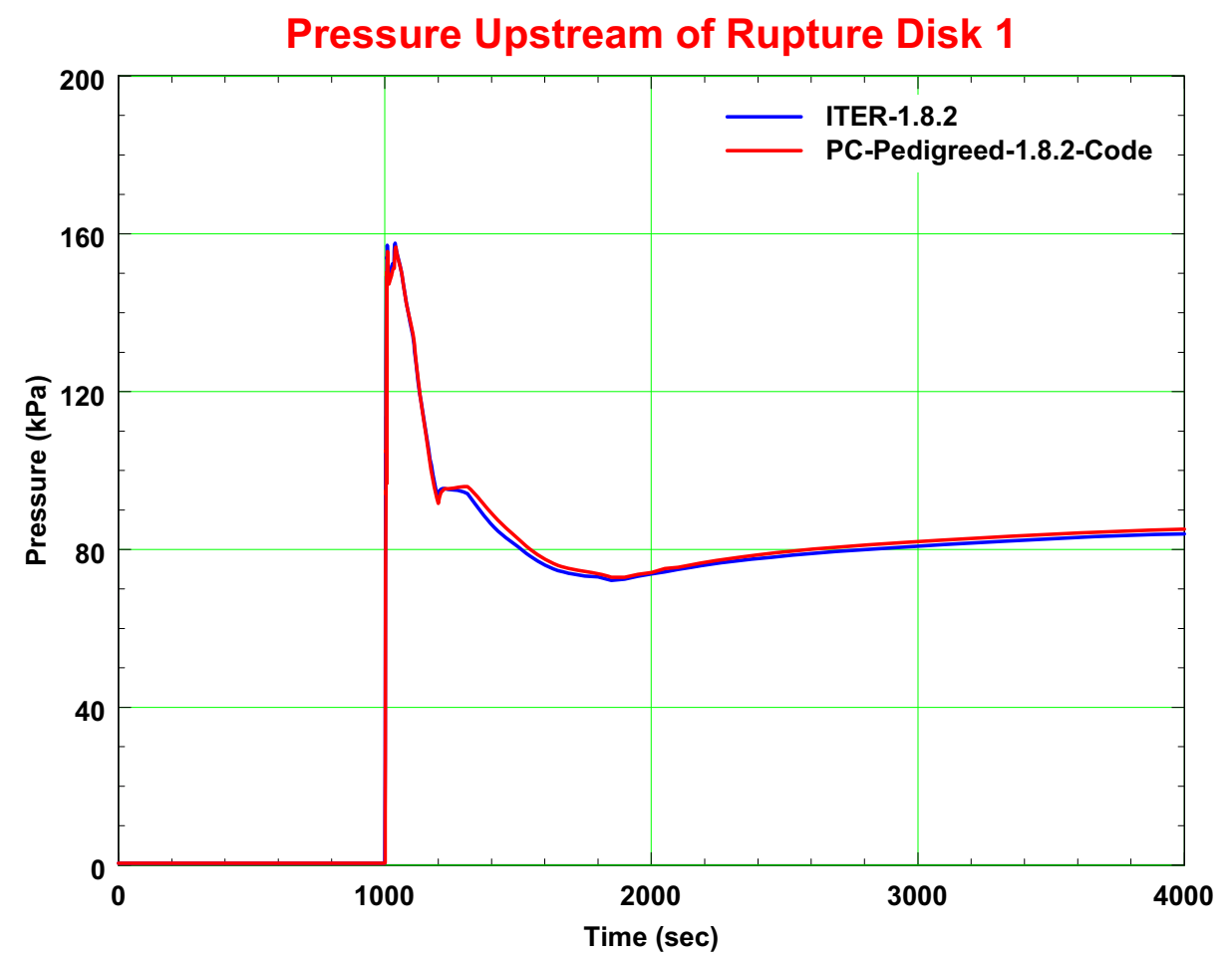

Figure 26. Pressure upstream of rupture disk 1.

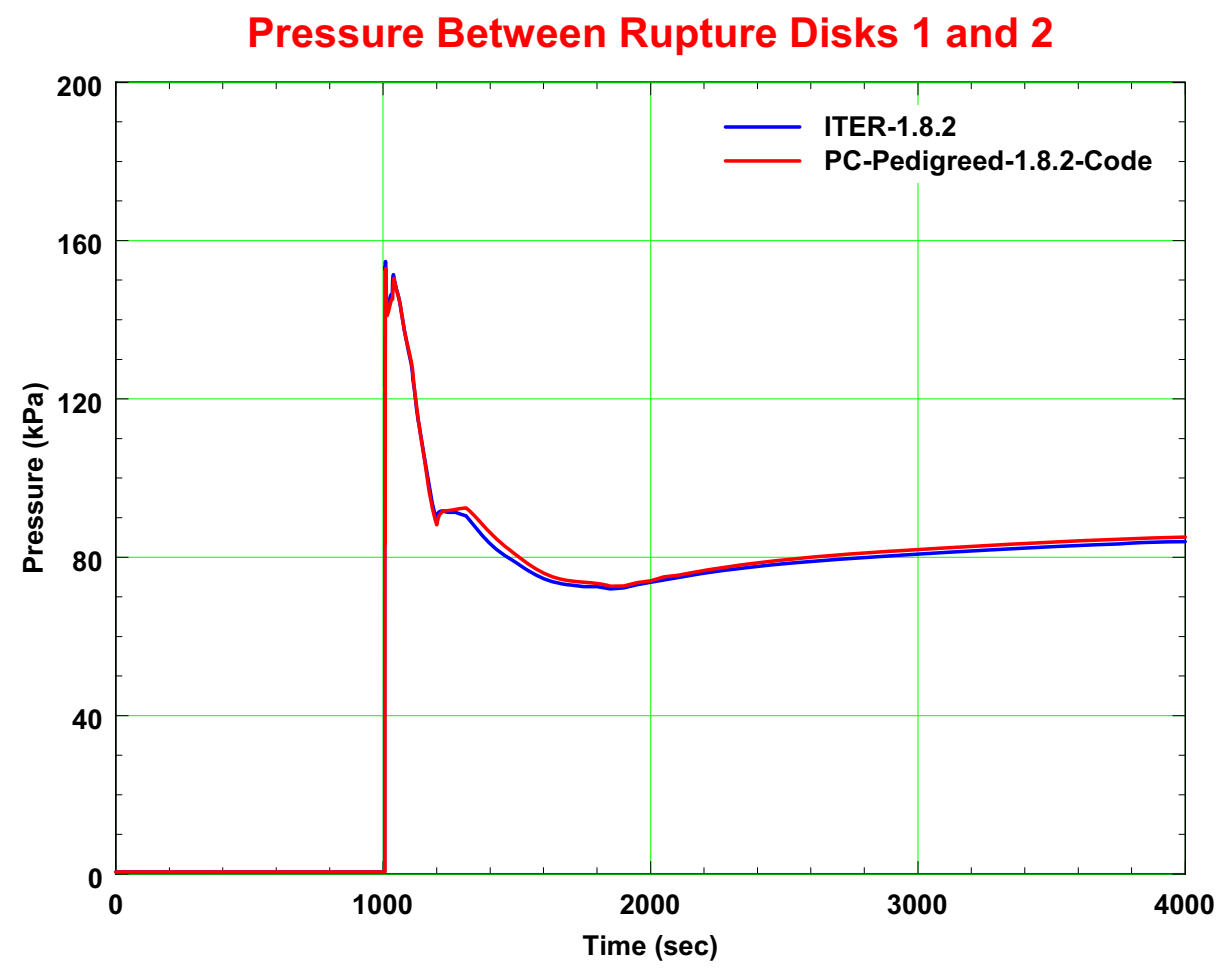

Figure 27. Pressure between rupture disks 1 and 2 . 


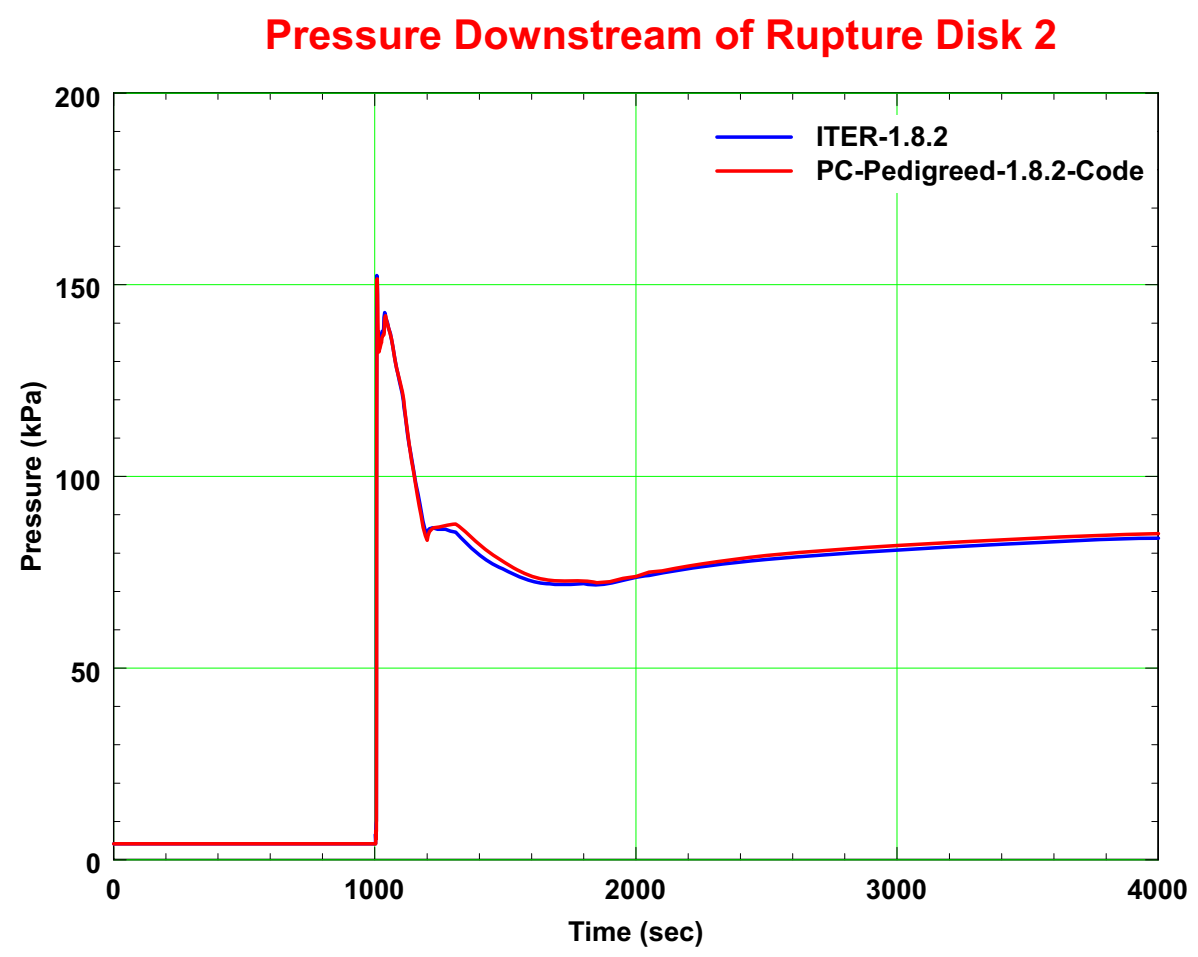

Figure 28. Pressure downstream of rupture disk 2.

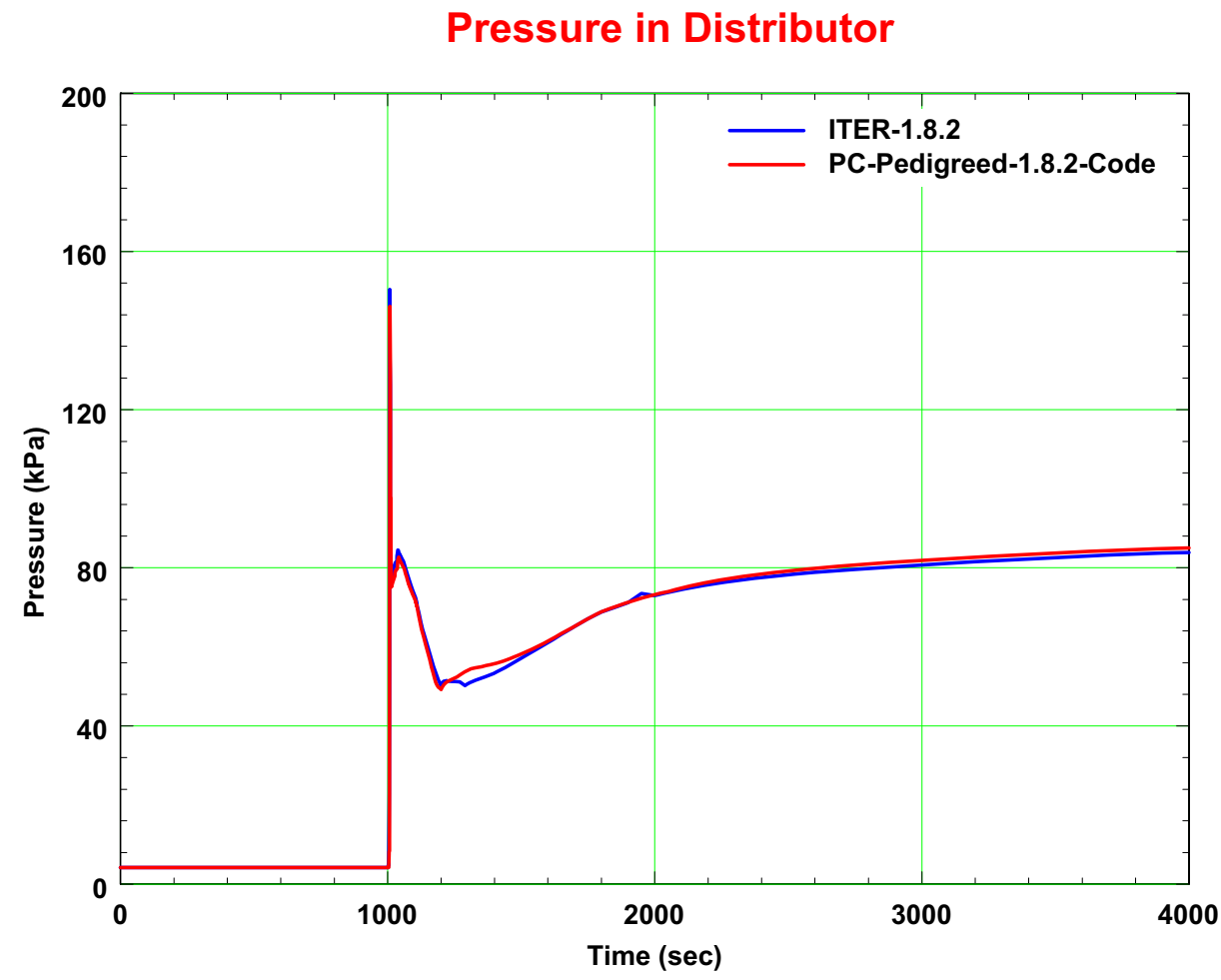

Figure 29. Pressure in distributor. 


\section{Suppression Tank Pressure}

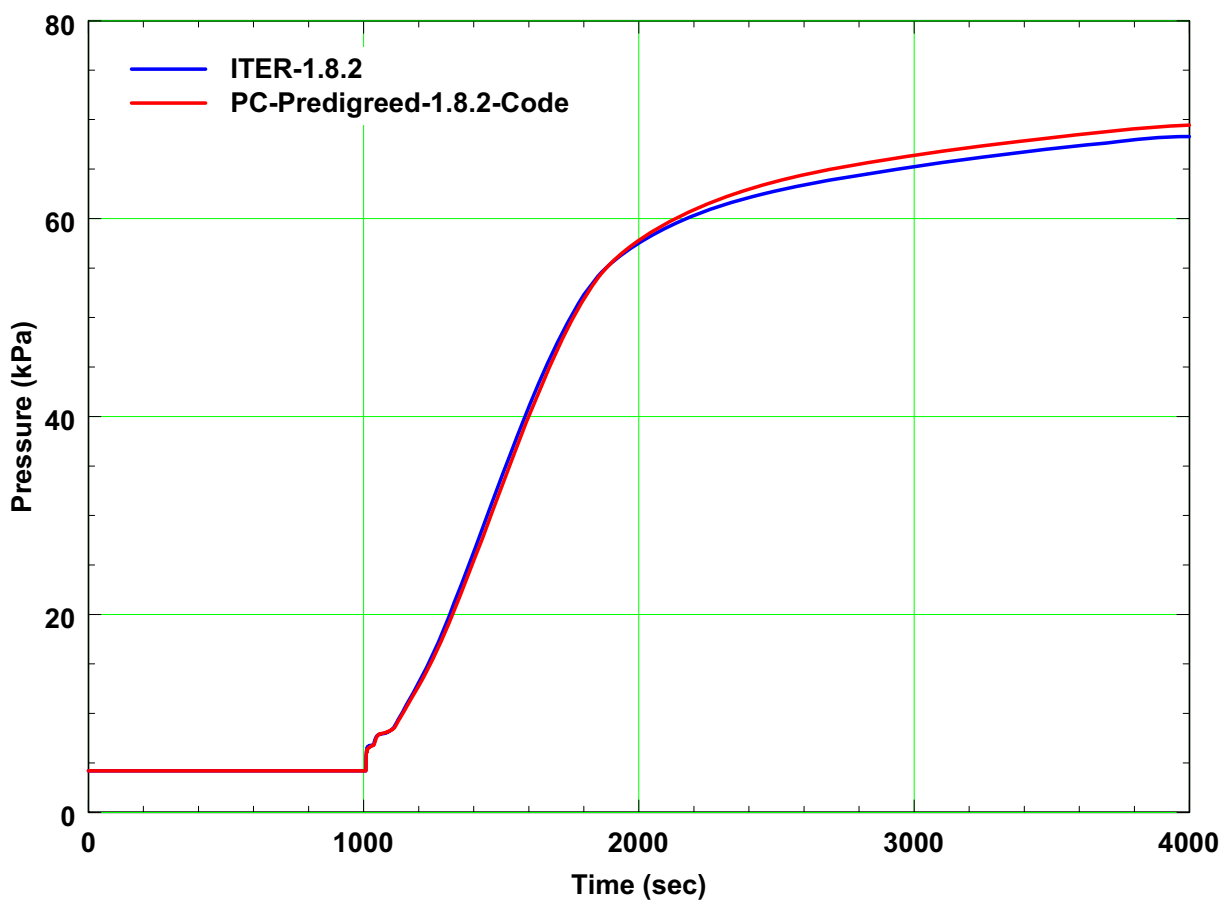

Figure 30. Suppression tank pressure.

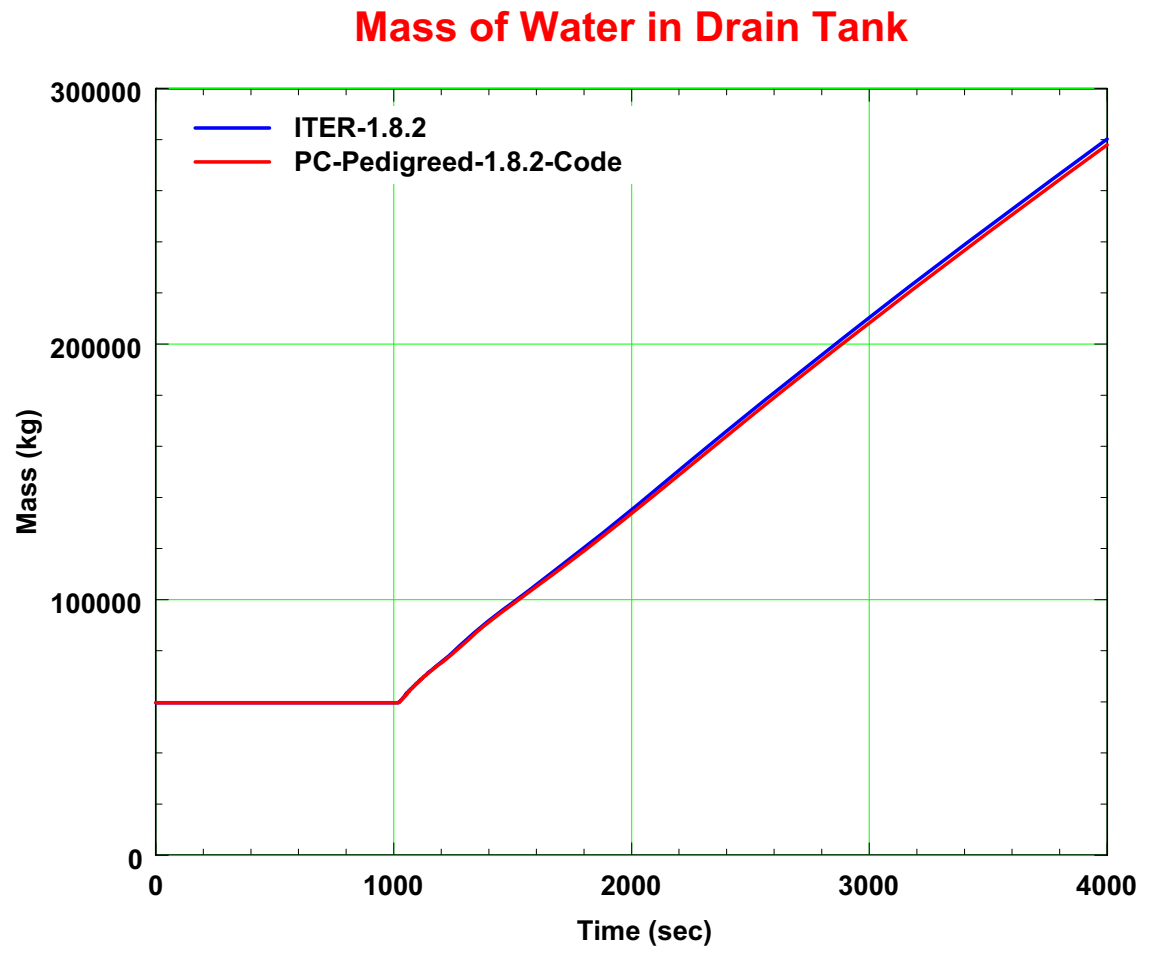

Figure 31. Mass of water in drain tank. 


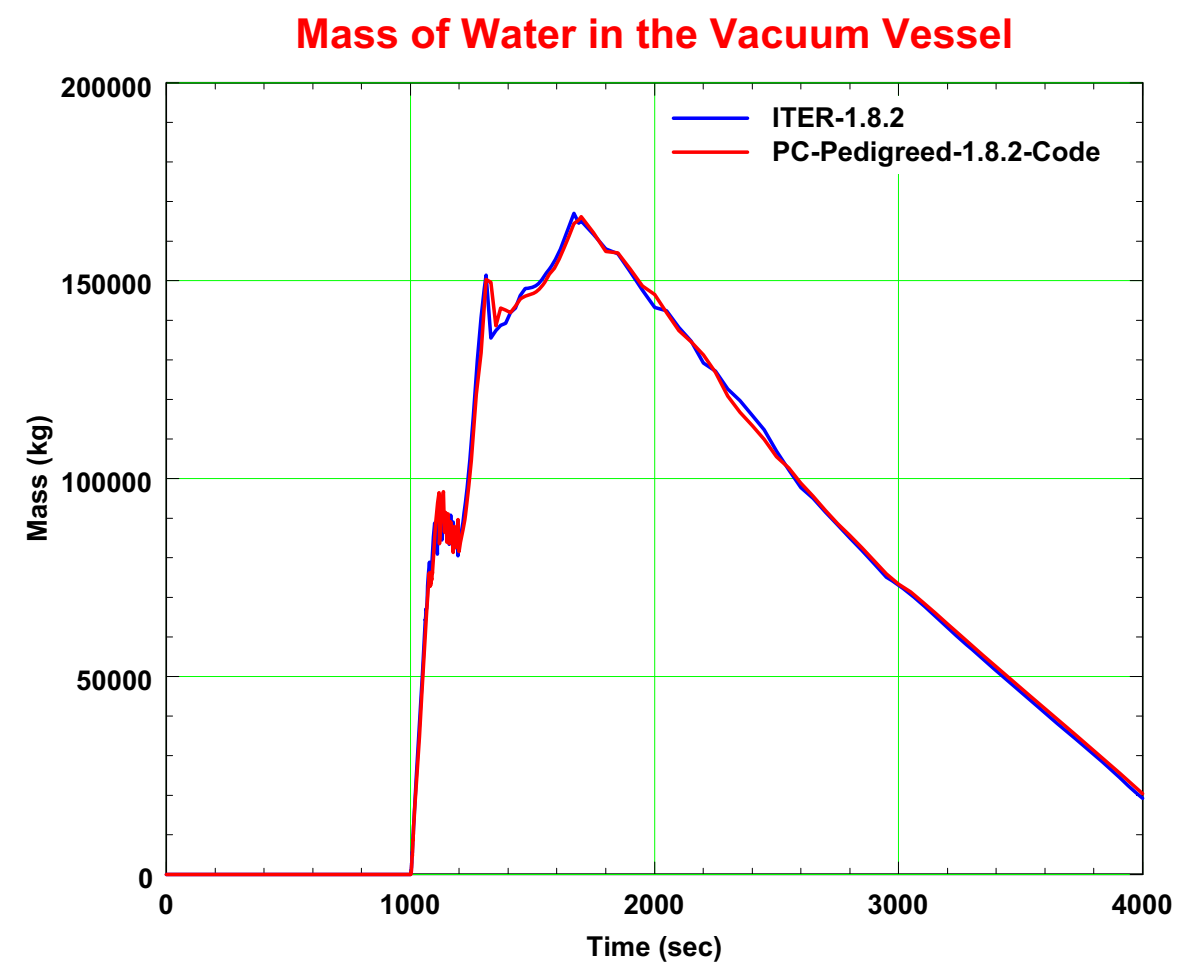

Figure 32. Mass of water in the vacuum vessel.

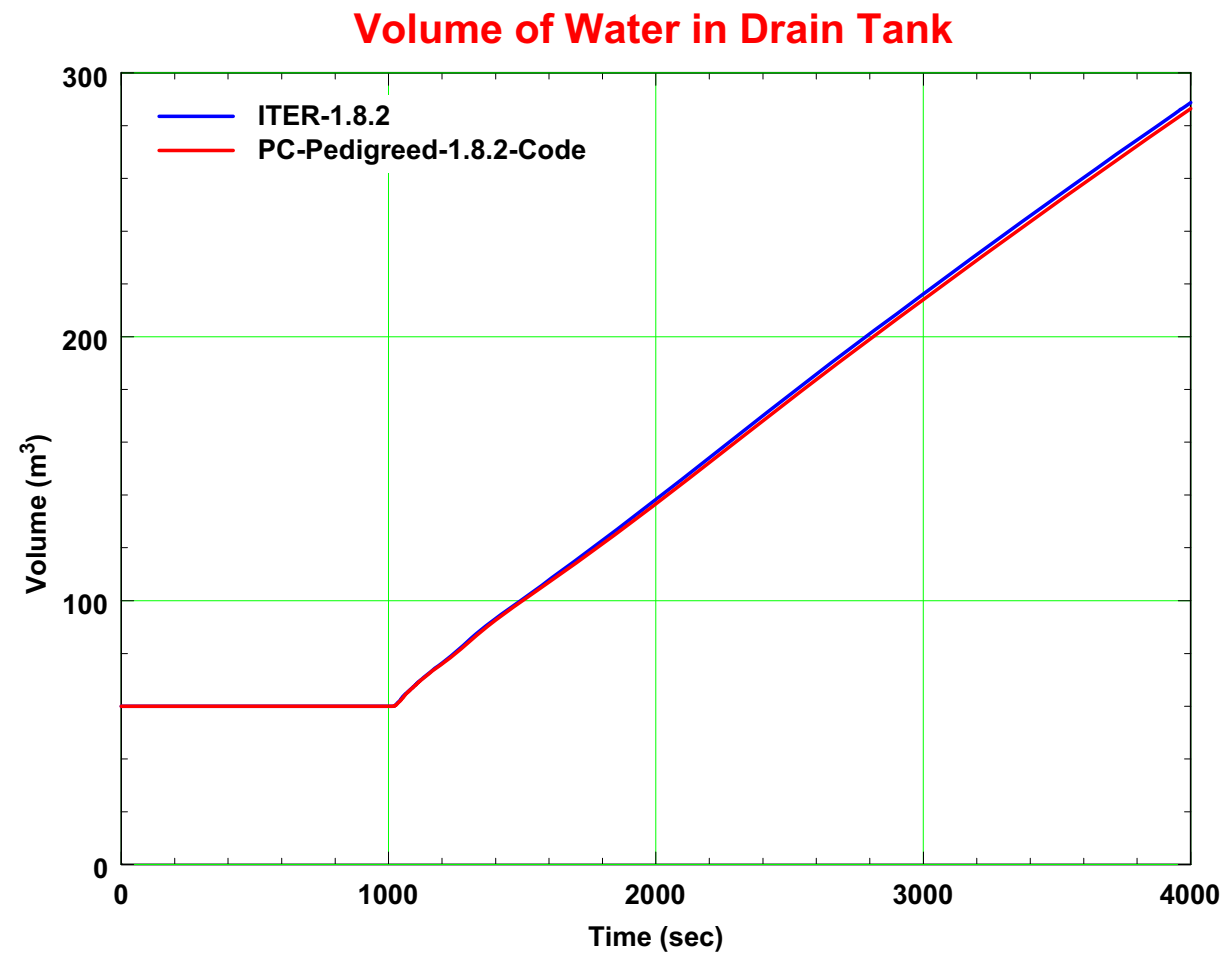

Figure 33. Volume of water in drain tank. 


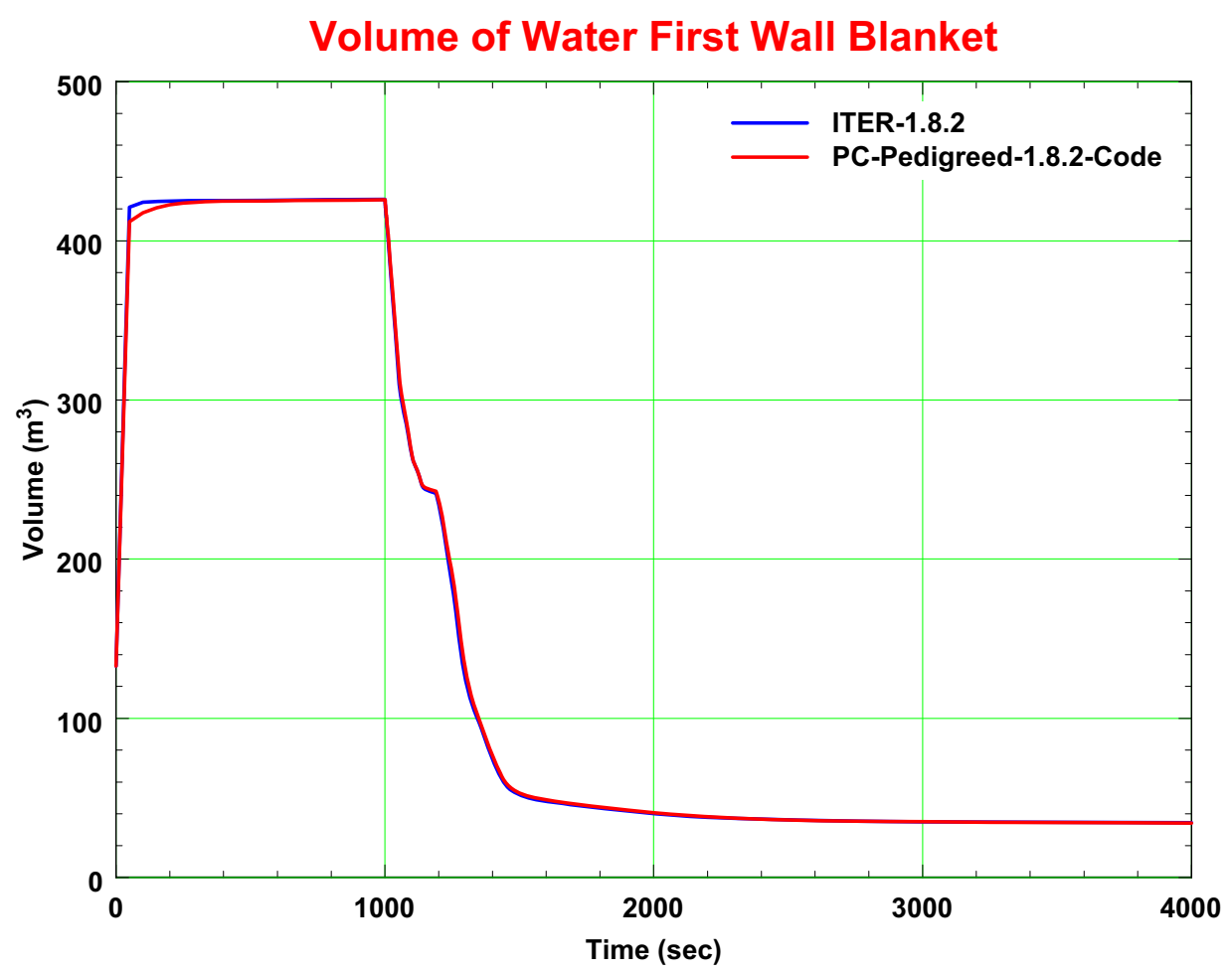

Figure 34. Volume of water first wall blanket.

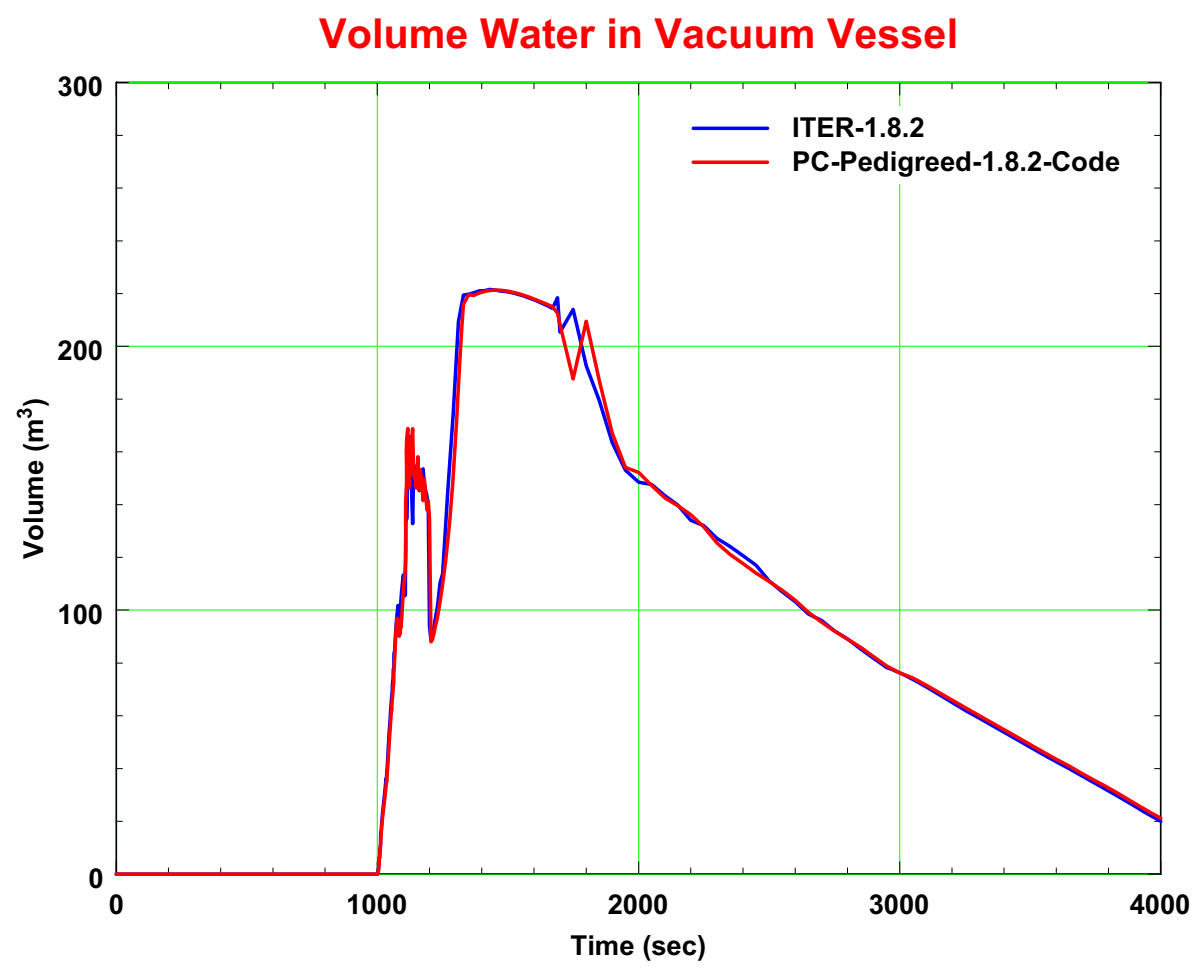

Figure 35. Volume of water in vacuum vessel. 


\subsection{Large Ex-vessel Break}

This postulated event is a double-ended pipe rupture of the largest cooling pipe of the VV cooling system outside of the building. In such an event, coolant will be discharged at a high rate onto the roof of the tritium building. The plasma is assumed to continue burning for 1000 seconds, which is a conservative assumption because the nominal ITER pulse length is 475 seconds. It is assumed that no additional plasma pulses will be started after the accident until the VV coolant loop is repaired.

Figures 36 through 46 contain the results generated by this accident. Viewing the figures we see that there is little or no difference between the results generated by the ITER FEAT version of MELCOR 1.8.2 and the pedigreed version of MELCOR 1.8.2.

Overall the agreement between the ITER FEAT version of MELCOR 1.8.2 and the pedigreed version of MELCOR 1.8.2 for this accident is excellent.

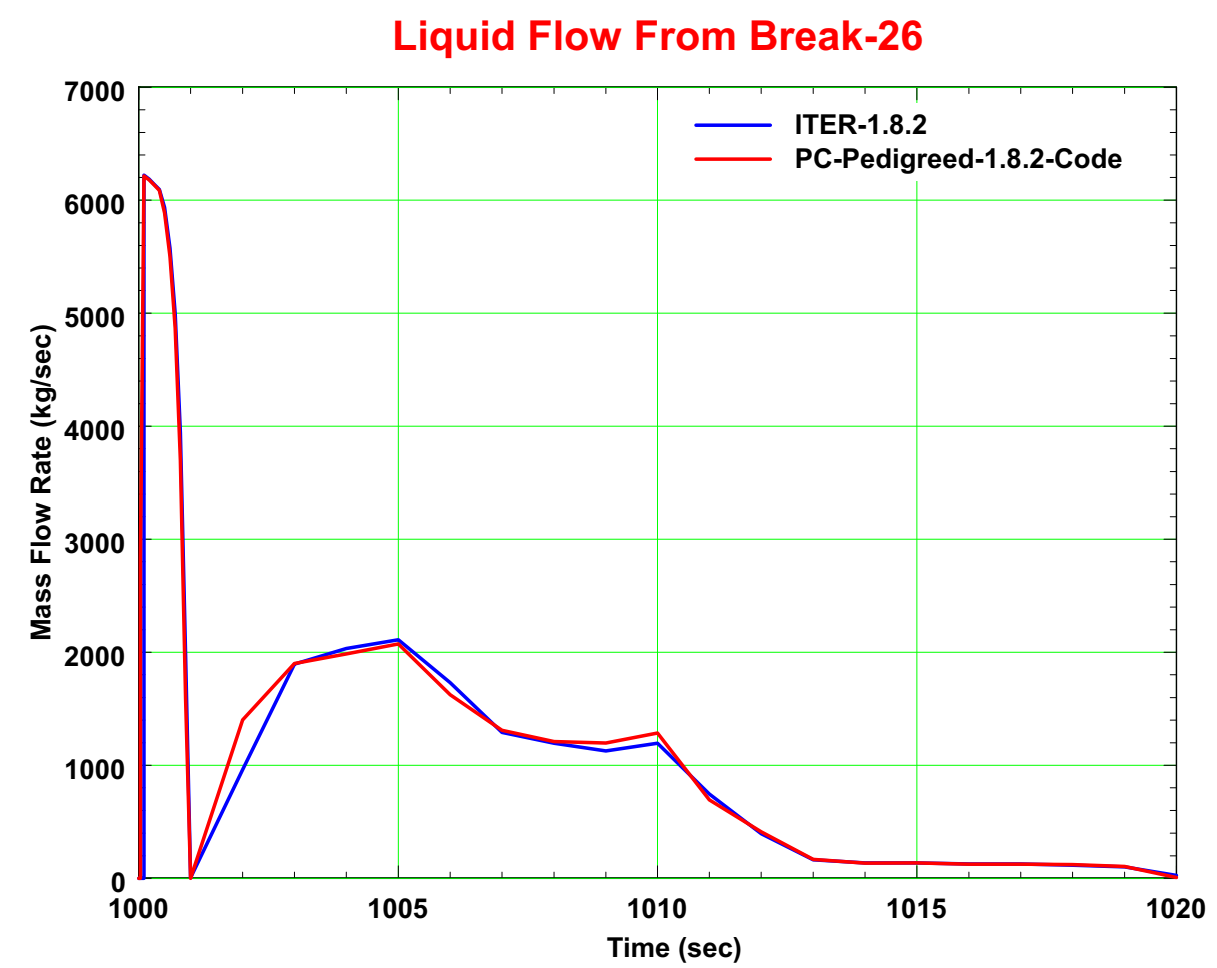

Figure 36. Liquid mass flow rate from break-26. 


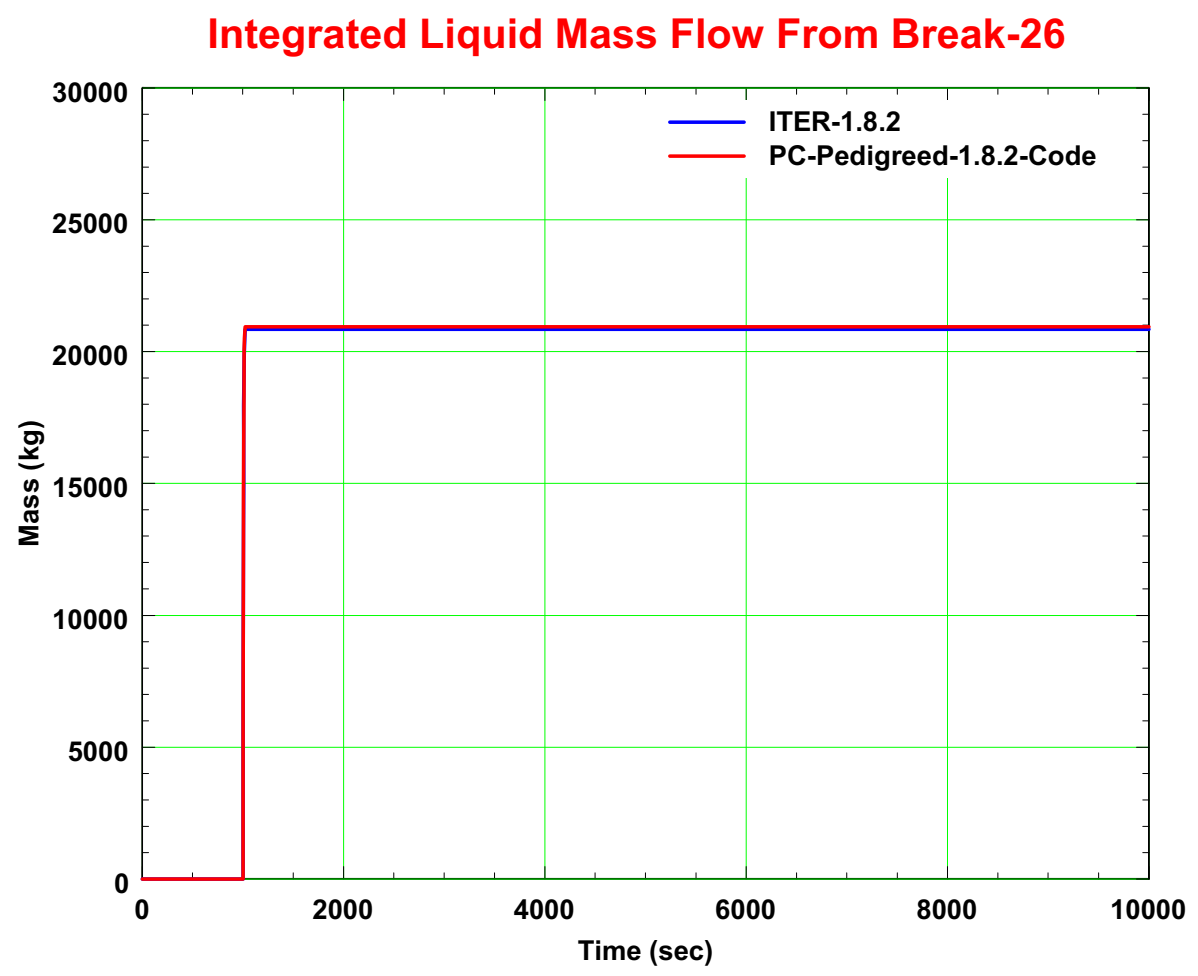

Figure 37. Integrated liquid mass flow from break-26.

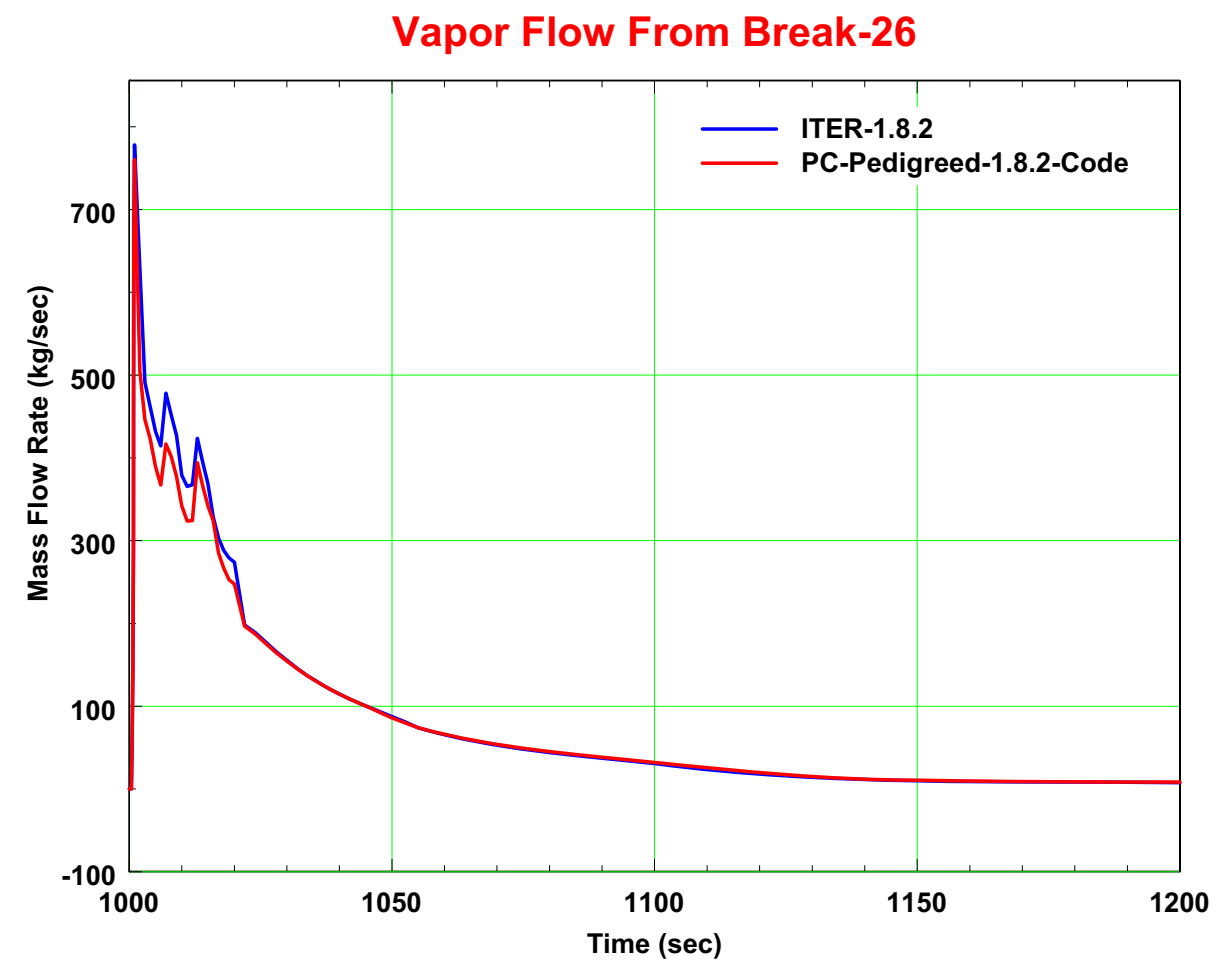

Figure 38. Vapor mass flow rate from break-26. 


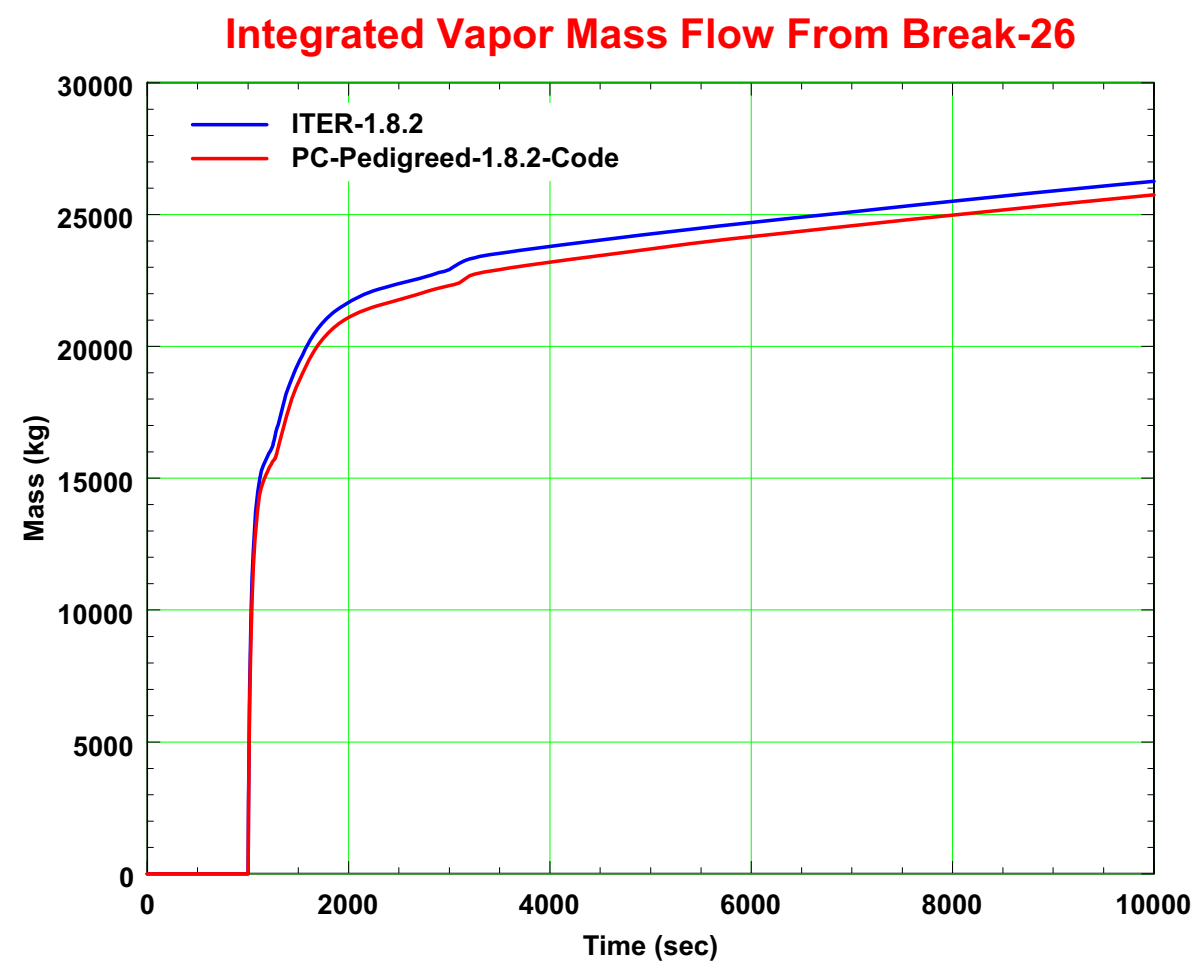

Figure 39. Integrated vapor mass flow from break-26.

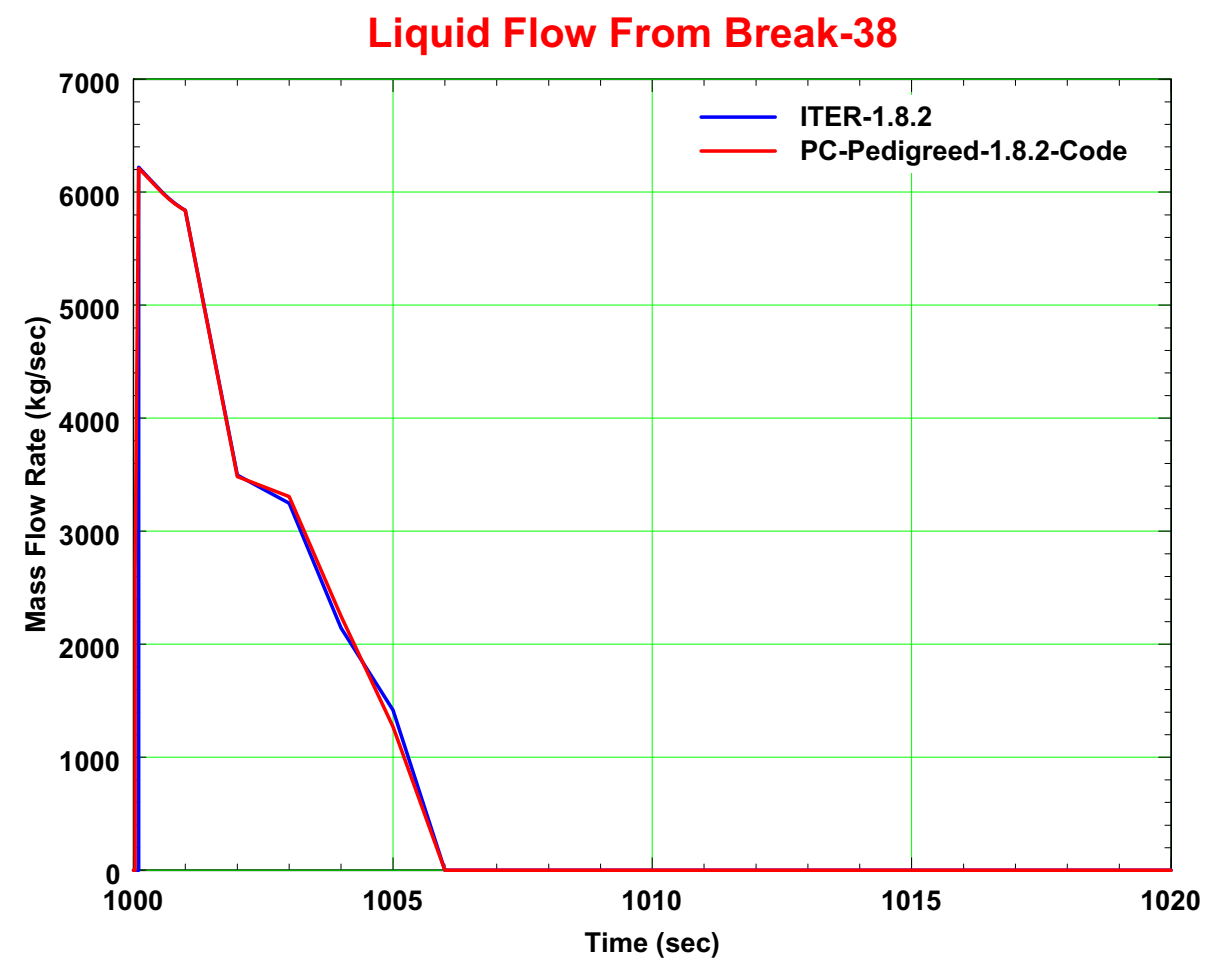

Figure 40. Liquid mass flow rate from break-38. 


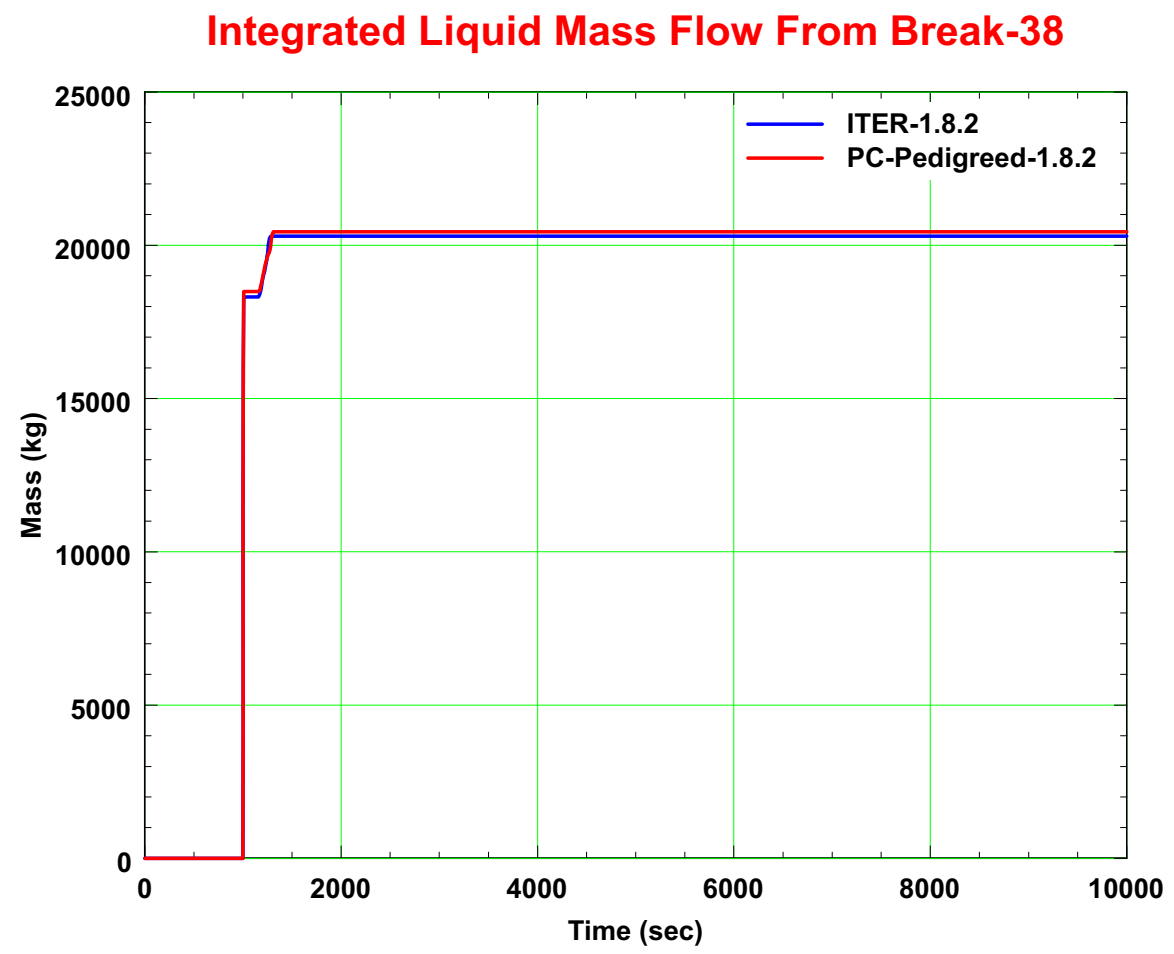

Figure 41. Integrated liquid mass flow from break-38.

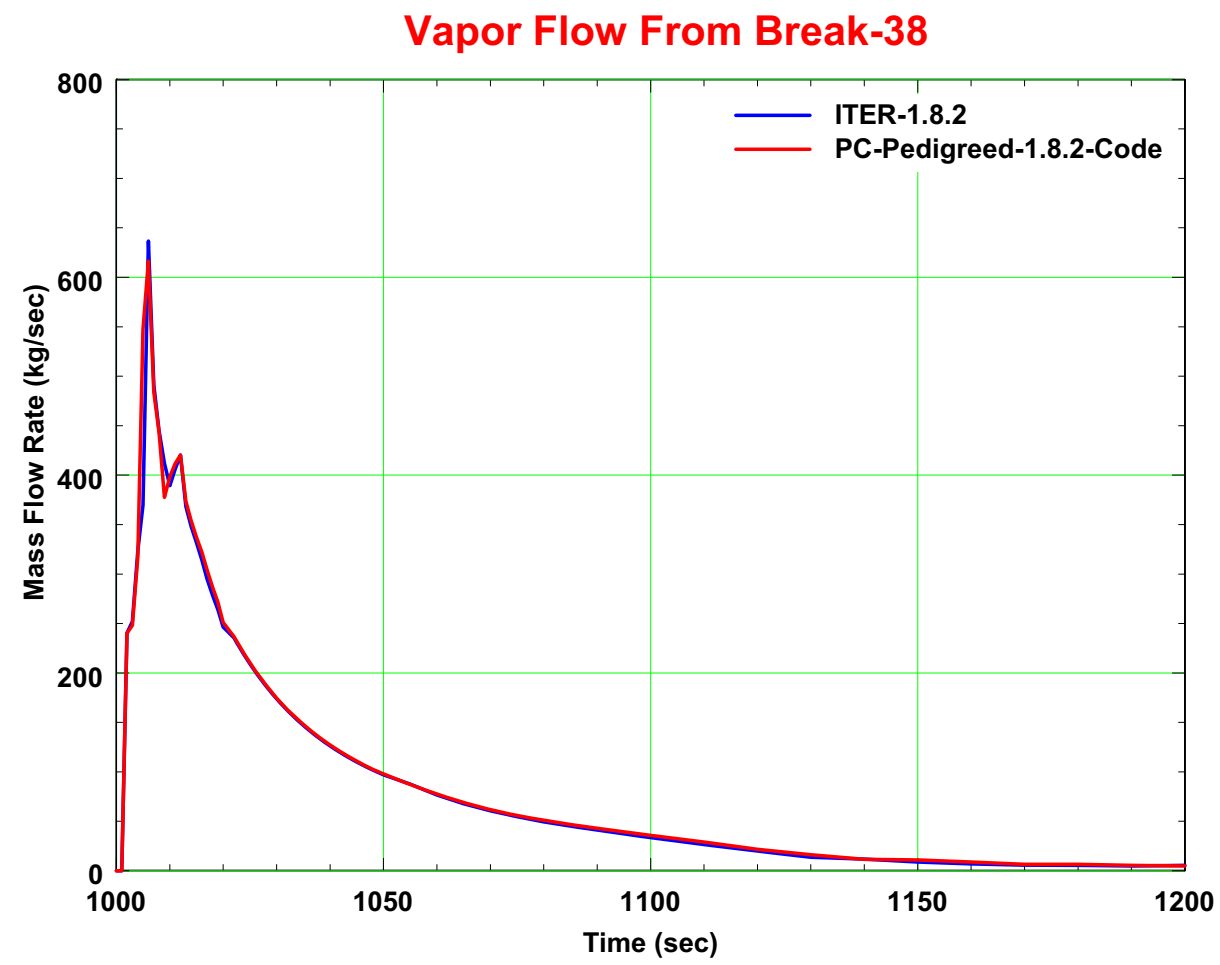

Figure 42. Vapor mass flow rate from break-38. 


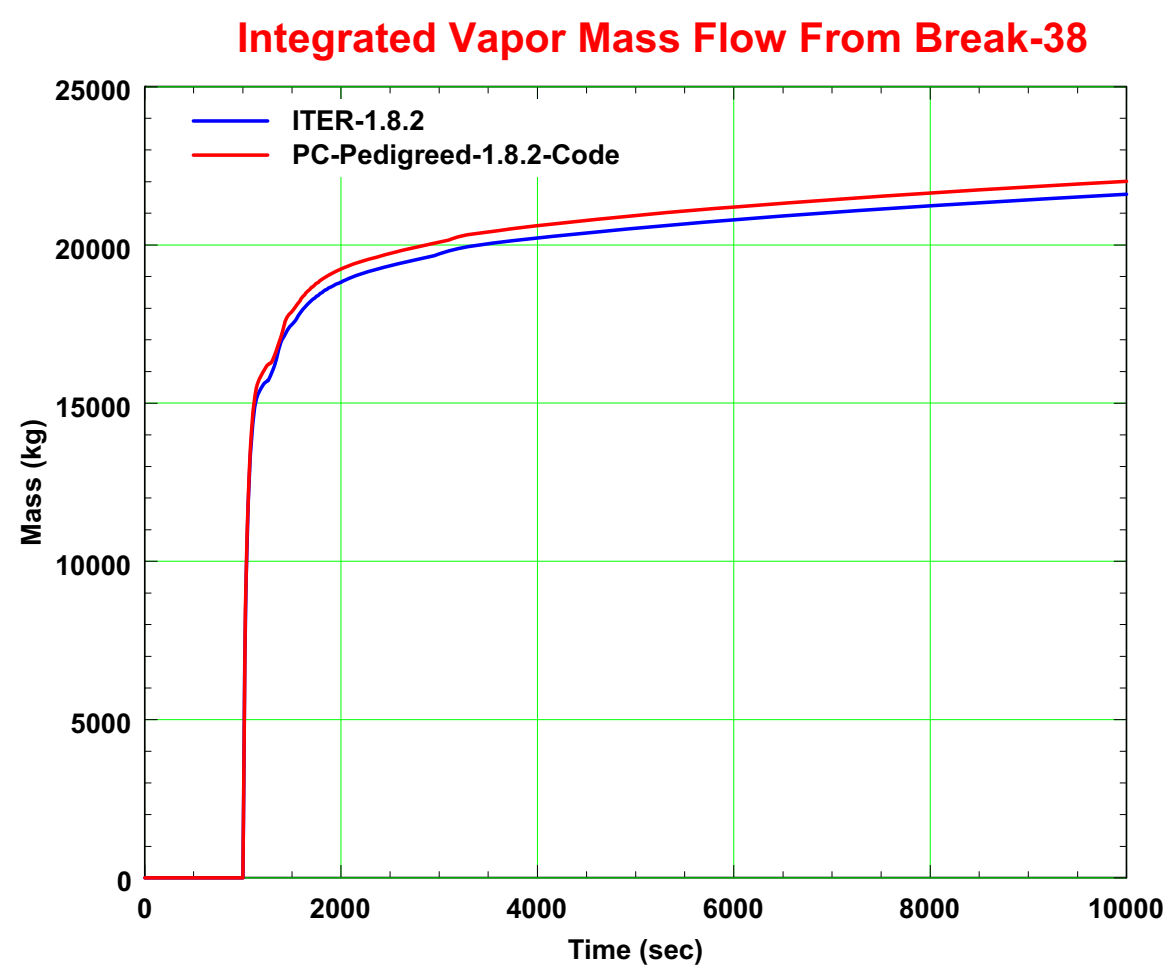

Figure 43. Integrated vapor mass flow from break-38.

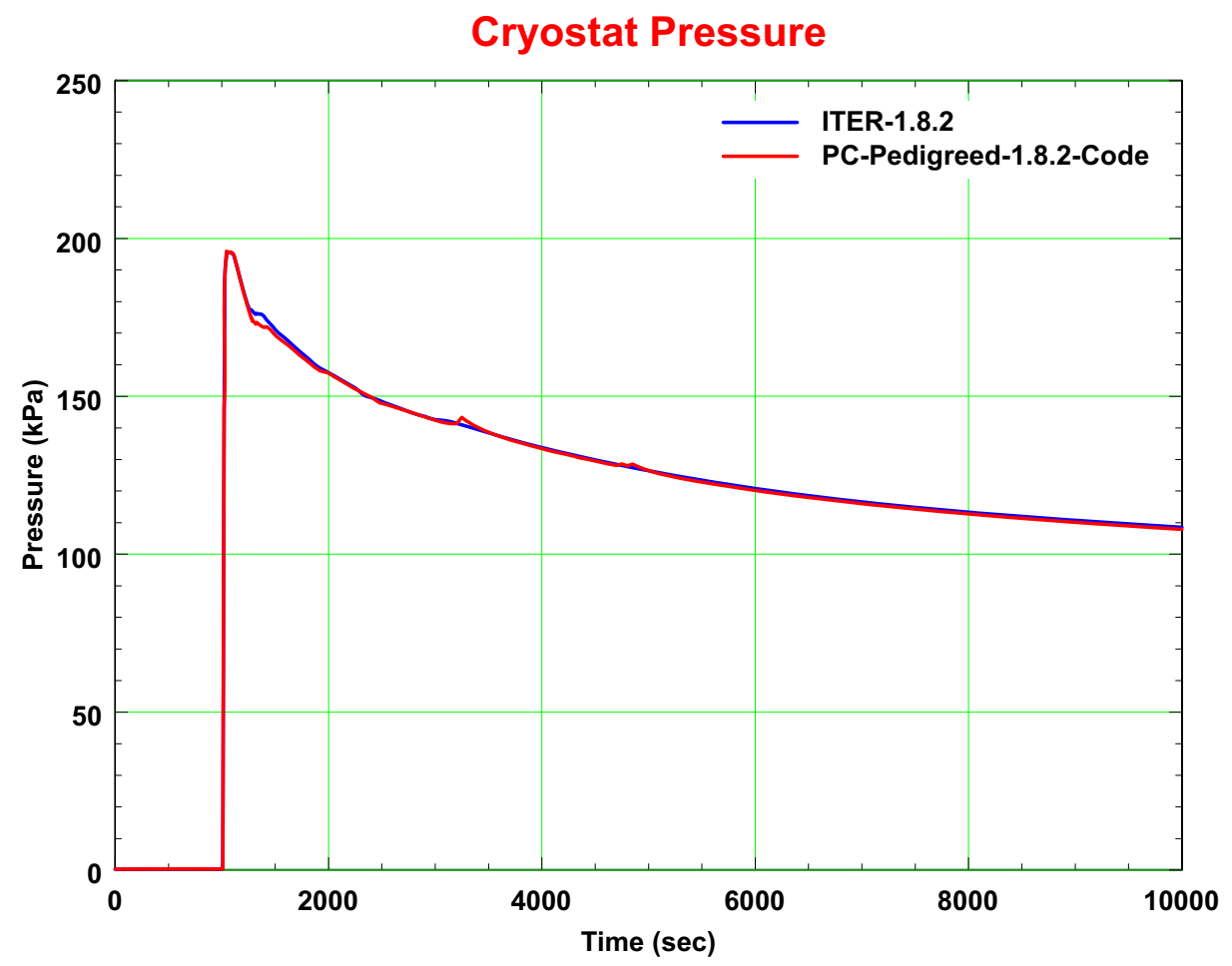

Figure 44. Cryostat pressure. 
TWCS Vault Pressure

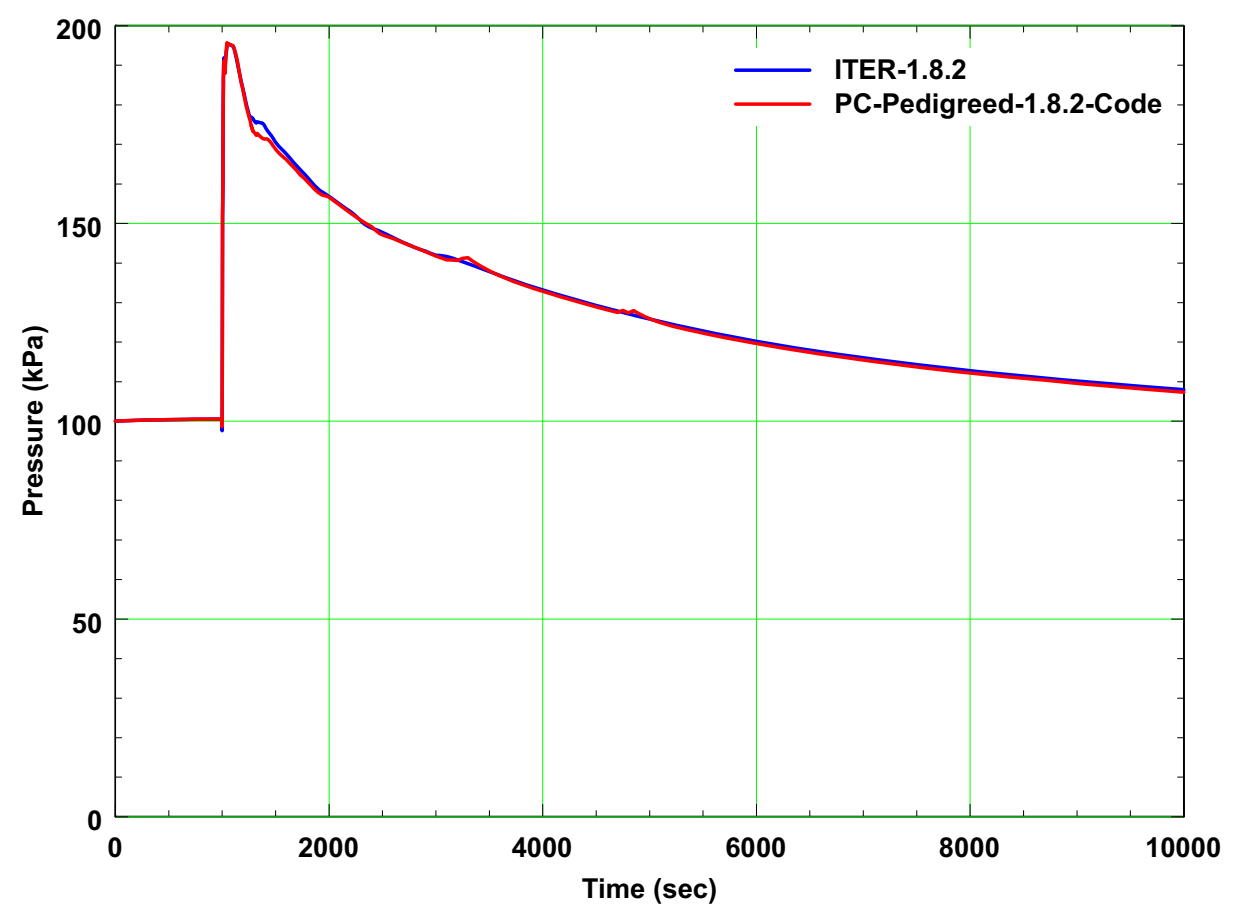

Figure 45. TWCS vault pressure.

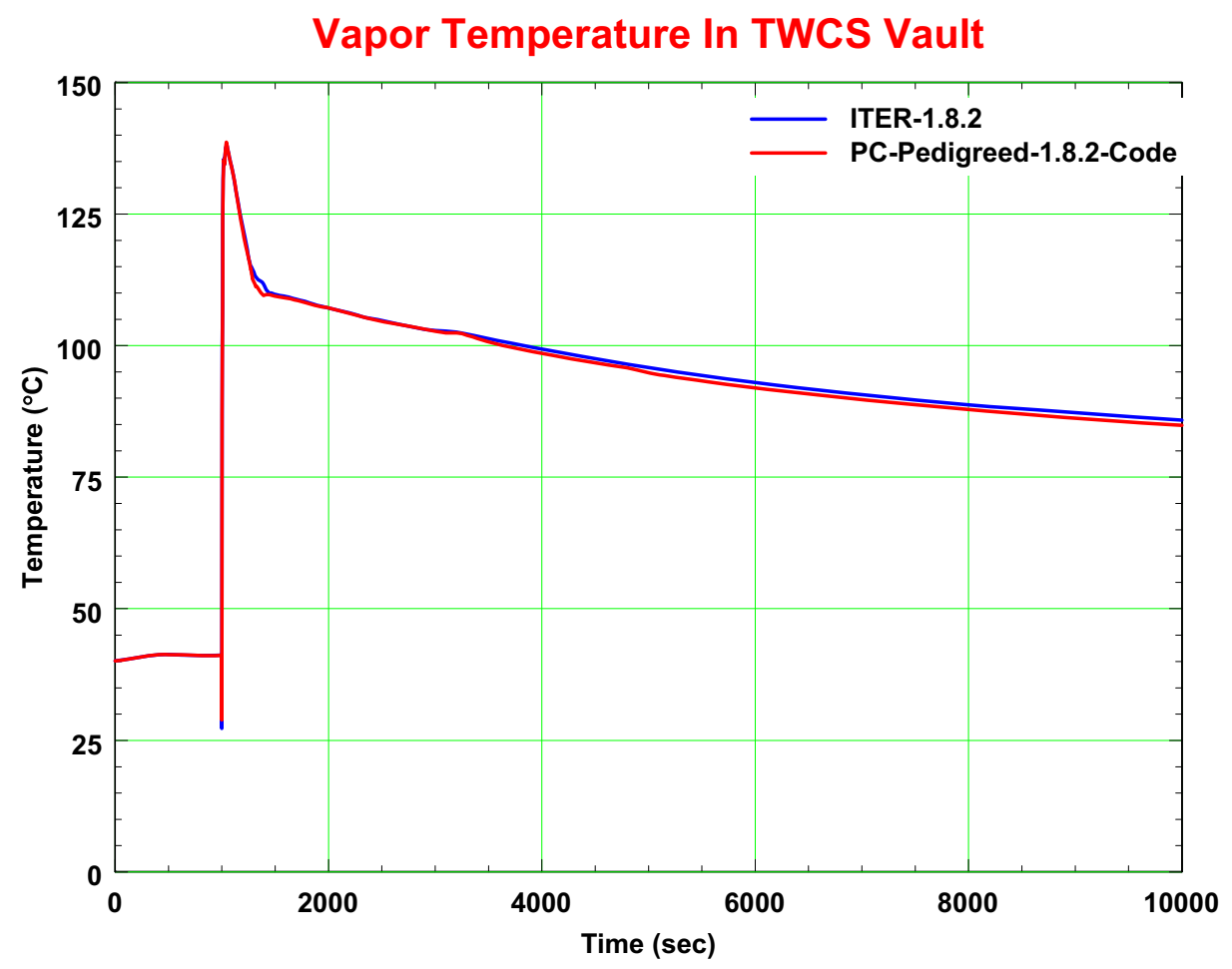

Figure 46. Vapor temperature in TWCS vault. 


\subsection{VV \& Cryostat Boundary Failure Accident}

For this accident it is assumed that energy from a magnet fault results in an intense electrical arc that is sufficient to melt the wall of the VV pumping duct and the cryostat boundary. This event impairs both the first barrier (VV) and the second barrier (cryostat) by producing two $1 \mathrm{~m}^{2}$ ruptures, resulting in a pathway that connects the interior of the $\mathrm{VV}$ to the cryostat air space room, thus allowing the tritium and activated dust in the VV to migrate into the cryostat, the cryostat air space room and the gallery.

The wall rupture of the VV pumping duct results in a double-ended break of the two VV cooling loops. $50 \%$ of the break flow area is assumed to create a flow path into the $\mathrm{VV}$, and the other $50 \%$ into the cryostat. The total break size is $0.1 \mathrm{~m}^{2}$. The pressure difference between the cryostat $(500 \mathrm{~Pa})$ and the VV primary heat transport system (PHTS) $(1.1 \mathrm{MPa})$ causes the VV coolant to blow down as a steam/water mixture into the VV and cryostat.

The magnet damage from the arc event includes a simultaneous break of a magnet cooling line, releasing $4.5 \mathrm{~K}$ helium from the TF magnet coils $\left(21 \mathrm{~m}^{3}\right)$ into the cryostat at a spill rate of $231 \mathrm{~kg} / \mathrm{s}$ during the first $2.5 \mathrm{~s}$ and $60 \mathrm{~kg} / \mathrm{s}$ thereafter. Atmospheric air from the cryostat space room will enter the cryostat when this barrier fails.

Figures 47 and 48 contain the helium mass flow rates from the cryostat space room to the cryostat corresponding to flow paths 001 and 021 . Viewing the figures we see that up until approximately 6 seconds the agreement between the ITER FEAT results and the pedigreed result are excellent. At 6 seconds the mass flow rates deviate and become more oscillatory in the pedigreed version's prediction. This is due in large part to a coding change that existed in the ITER FEAT version of MELCOR 1.8.2 that was not included in the pedigreed version of this code. The change dealt with the density being used by the code to calculate velocities in a given flow path. In the ITER FEAT version, the density was the average value of the two control volumes that are connected by this flow path. This change was made to allow the code to run more stably at high vacuum conditions. In the original version of the code, the density was donor celled, meaning the flow density equals that of a control volume from which the flow originates. During the non-regression analysis it was discovered that this change had a pronounced affect on the predicted results for the demonstration problem. As a consequence, this change was not included in the pedigreed version. This non-change results in a $\approx 12 \%$ difference in the net mass flow from the cryostat space room to the cryostat as seen in Figure 49. The mass flow rates and net mass flow for nitrogen through the same flow paths are shown in Figures 50, 51, and 52, respectively. The same trends as seen for the helium flow also exist for the nitrogen flow.

The vapor mass flow rates from the VV to the cryostat through flow paths 014 and 024 and are presented in Figures 53 and 54 respectively. The integrated mass flow from the two flow paths are presented in Figures 55 and 56, respectively. The results from both MELCOR versions of the code are approximately the same.

Figures 57 and 58 present the time history of the vapor and liquid temperature in the cryostat. There is excellent agreement between the temperature results produced by the two versions of the code.

The mass of airborne dust, the mass of dust in the pool, and dust deposited on the cryostat structure are presented in Figures 59, 60, and 61, respectively. As seen there is again very little difference in the result produced by the two code versions.

For this accident there is again good agreement between the predicted results from the two versions of the code, even given the change described above. 


\section{Helium Mass Flow Rate From Cryostat Space Room to Cryostat}

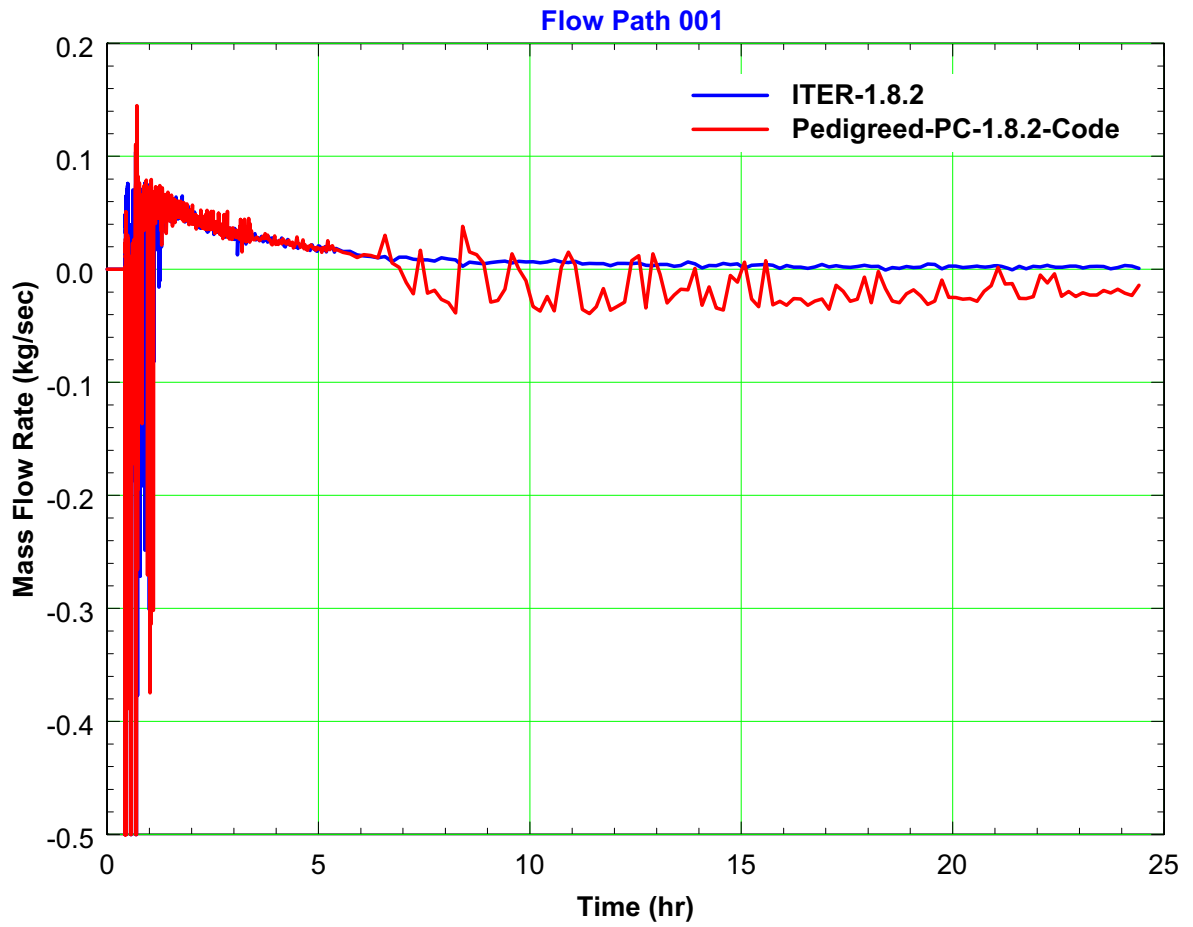

Figure 47. Helium mass flow rate from cryostat space room to cryostat (flow path 001).

\section{Helium Mass Flow Rate From Cryostat Space Room To Crystat}

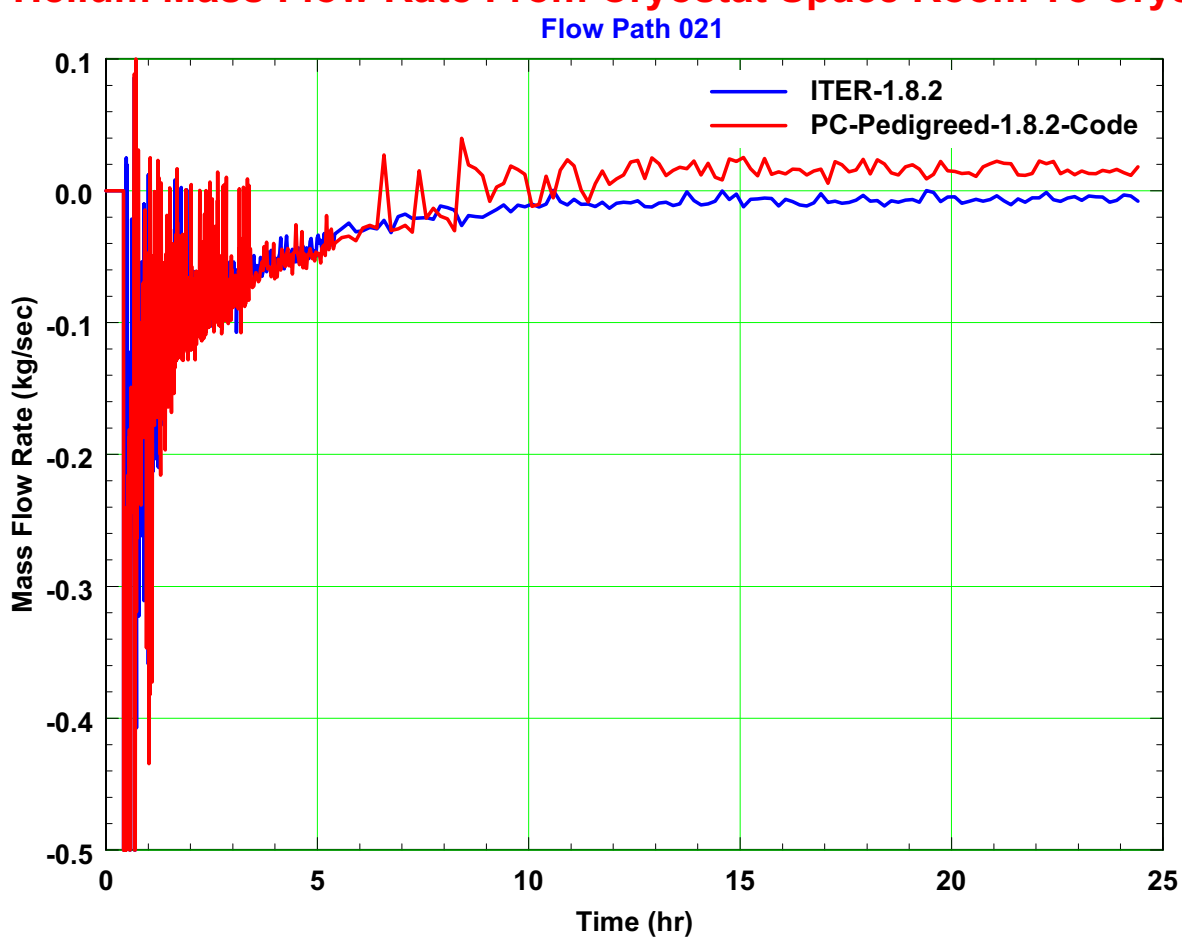

Figure 48. Helium mass flow rate from cryostat space room to cryostat (flow path 021). 
Integrated Net Helium Mass Flow From Cryostat Room to Cryostat

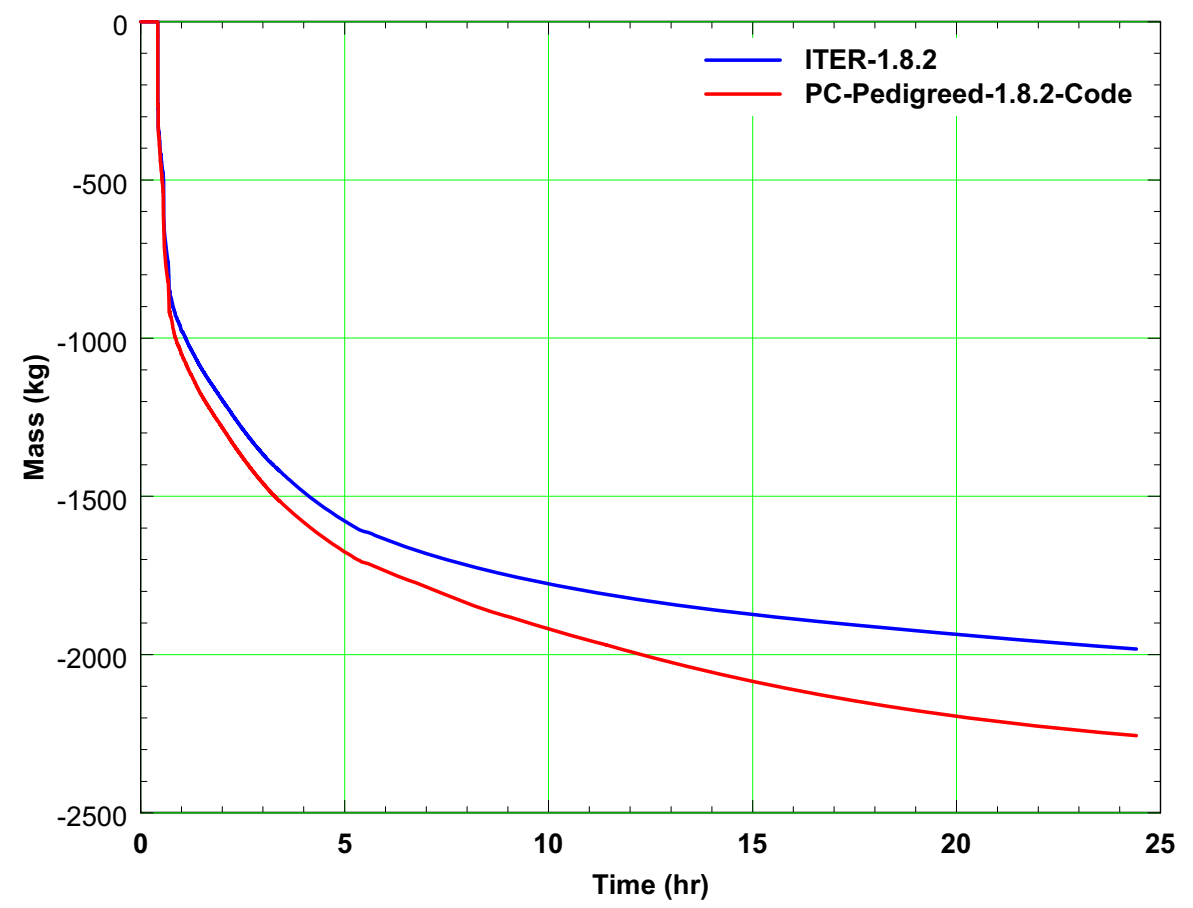

Figure 49. Integrated net helium mass flow from cryostat room to cryostat.

\section{Nitrogen Mass Flow Rate From Cryostat Space Room to Cryostat}

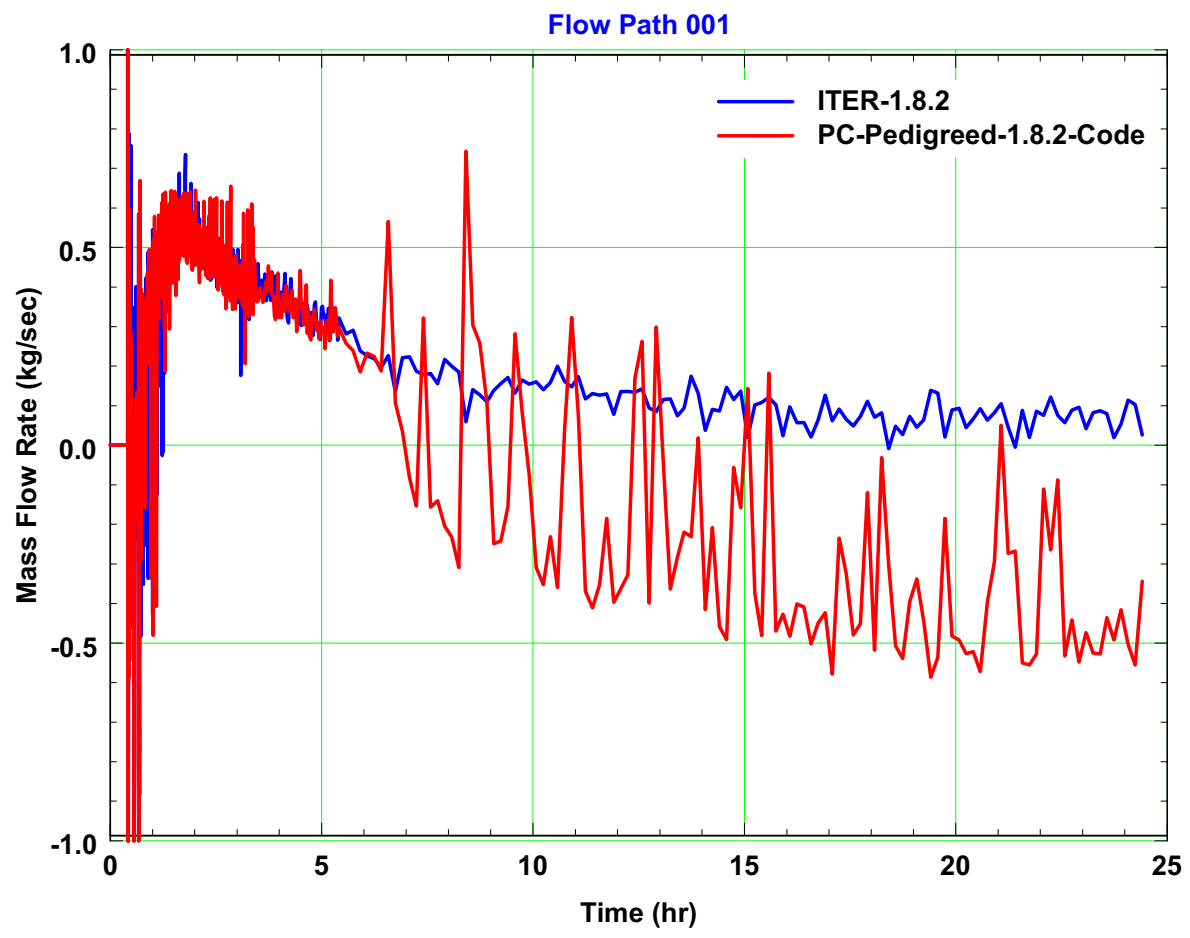

Figure 50. Nitrogen mass flow rate from cryostat space room to cryostat (flow path 001). 
Nitrogen Mass Flow Rate From Cryostat Space Room To Cryostat Flow Path 021

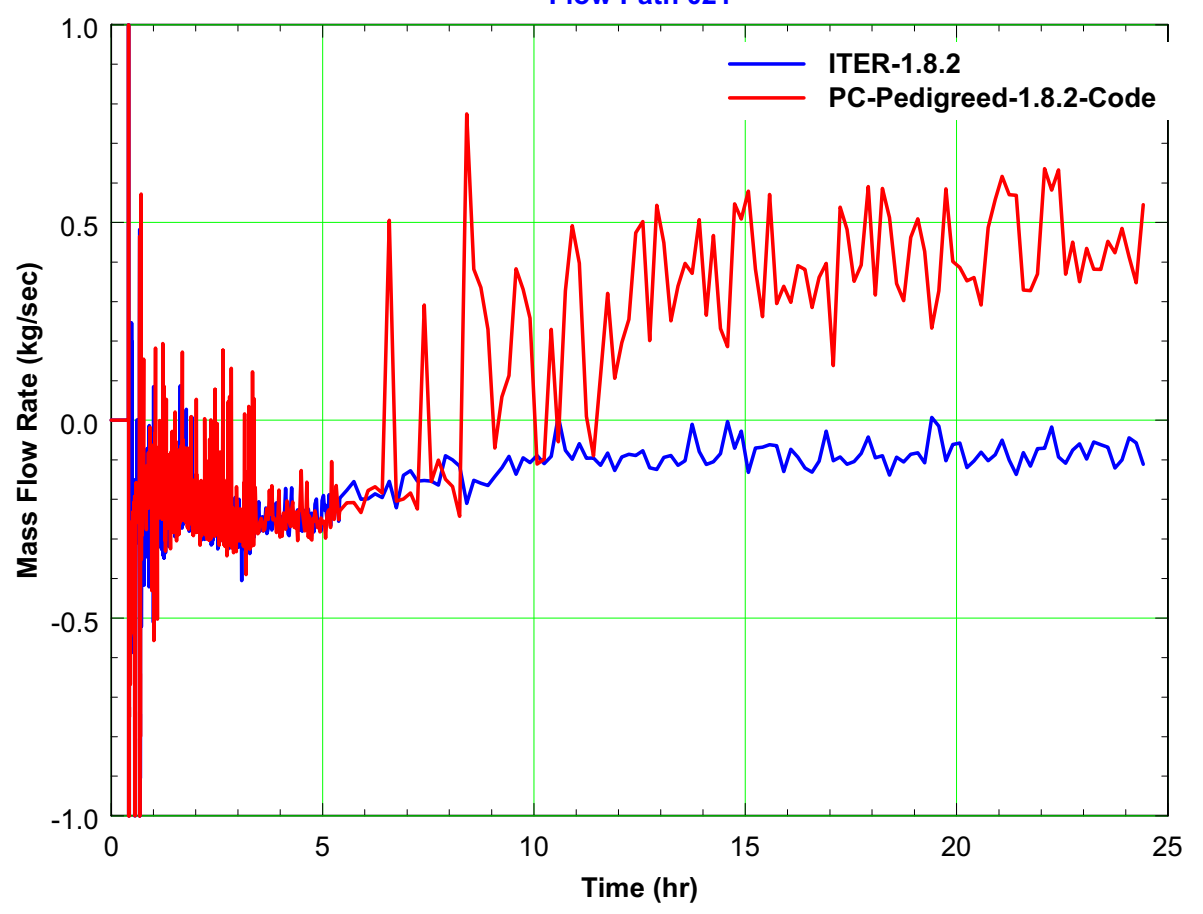

Figure 51. Nitrogen mass flow rate from cryostat space room to cryostat (flow path 021 ).

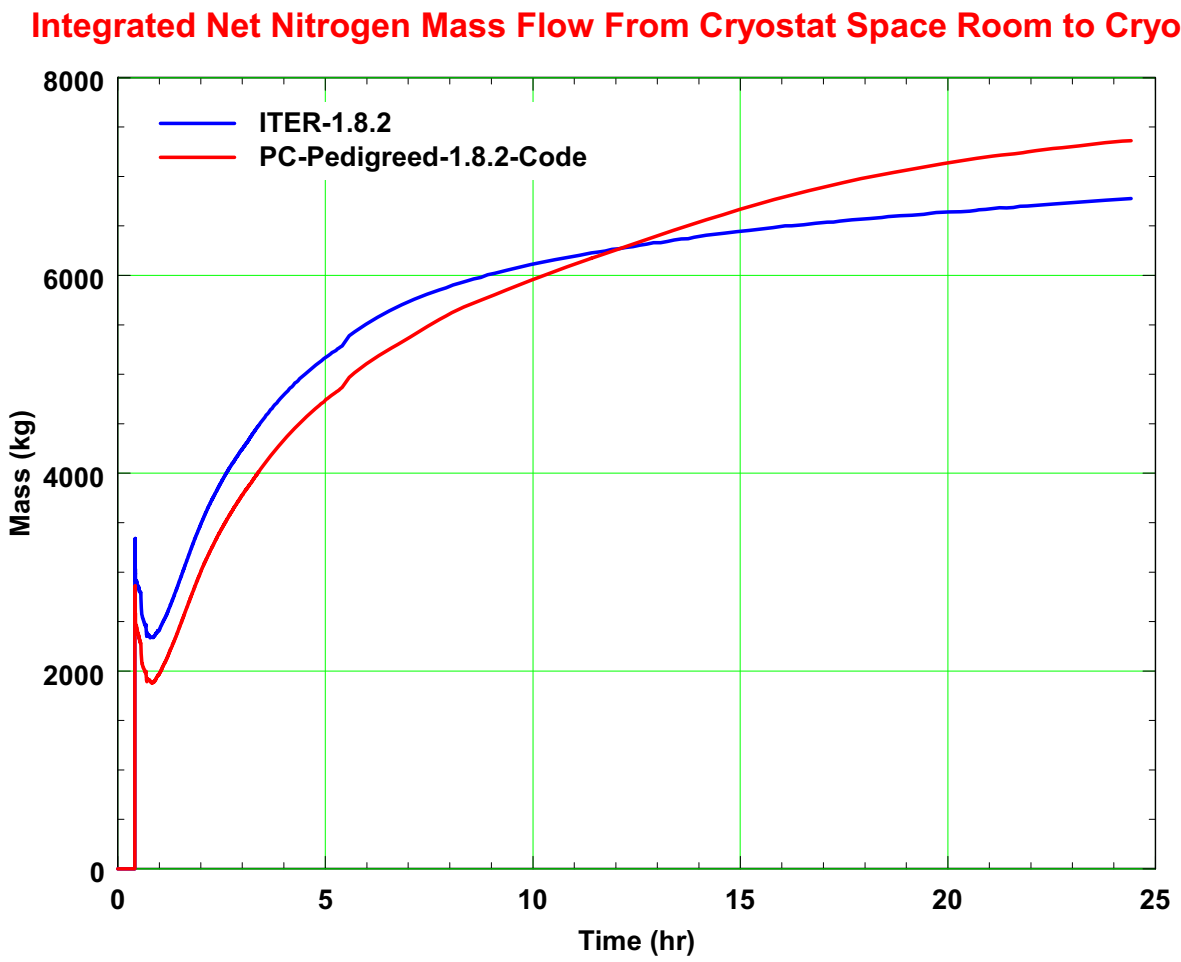

Figure 52. Integrated net nitrogen mass flow from cryostat space room to cryostat. 


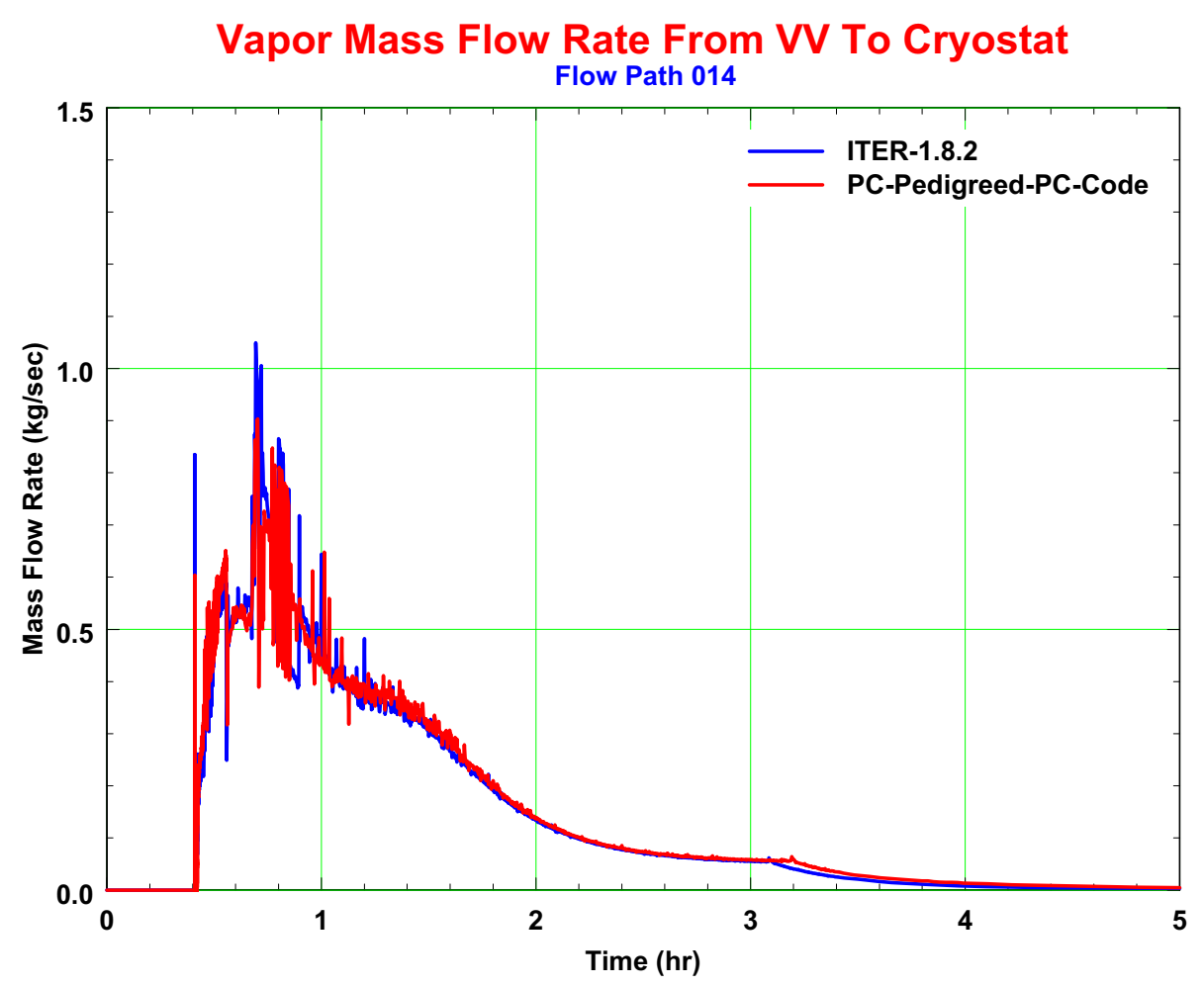

Figure 53. Vapor mass flow rate from VV to cryostat (flow path 014).

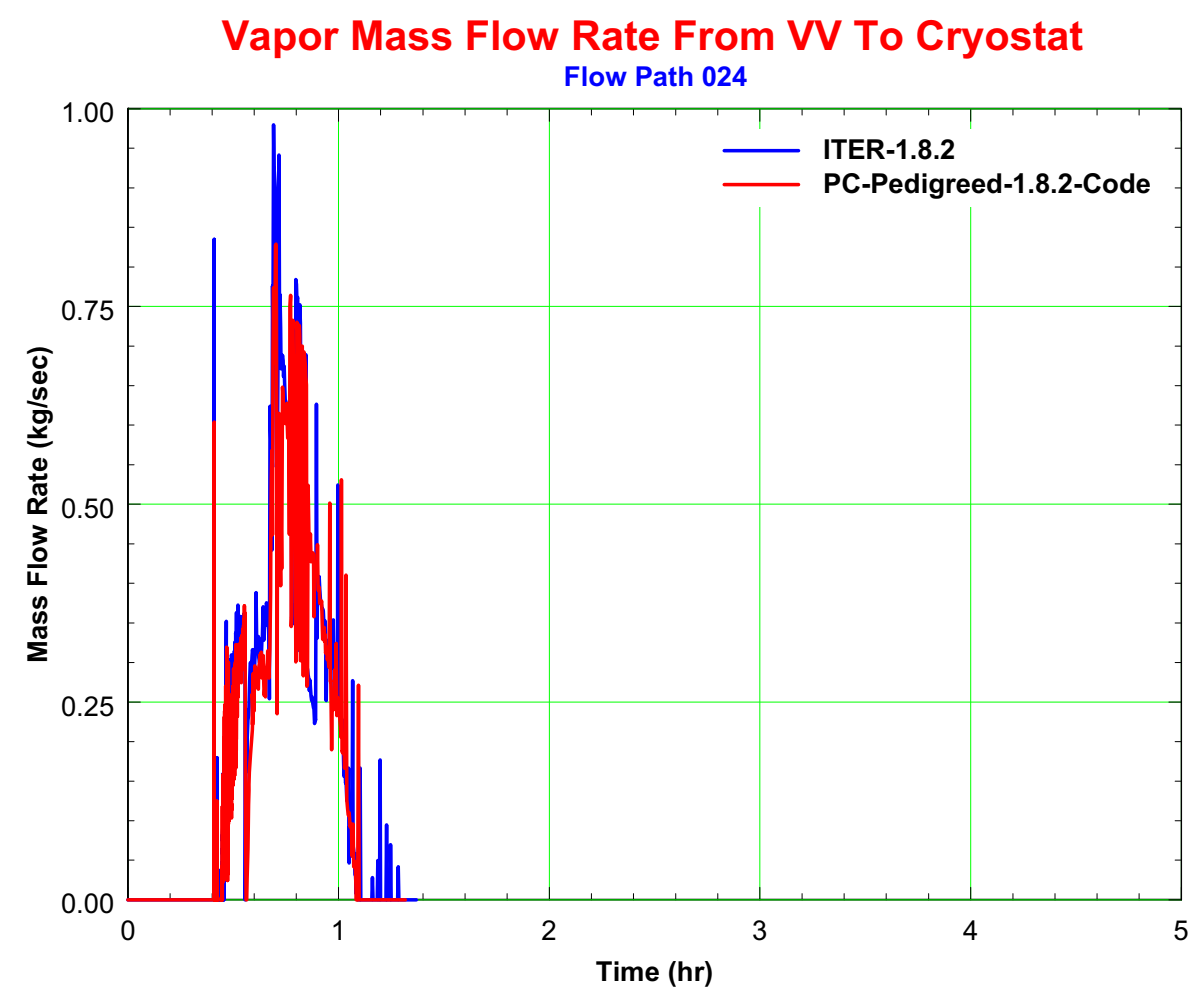

Figure 54. Vapor mass flow rate from VV to cryostat (flow path 024). 
Integrated Vapor Mass Flow From VV To Cryostat Flow Path 014

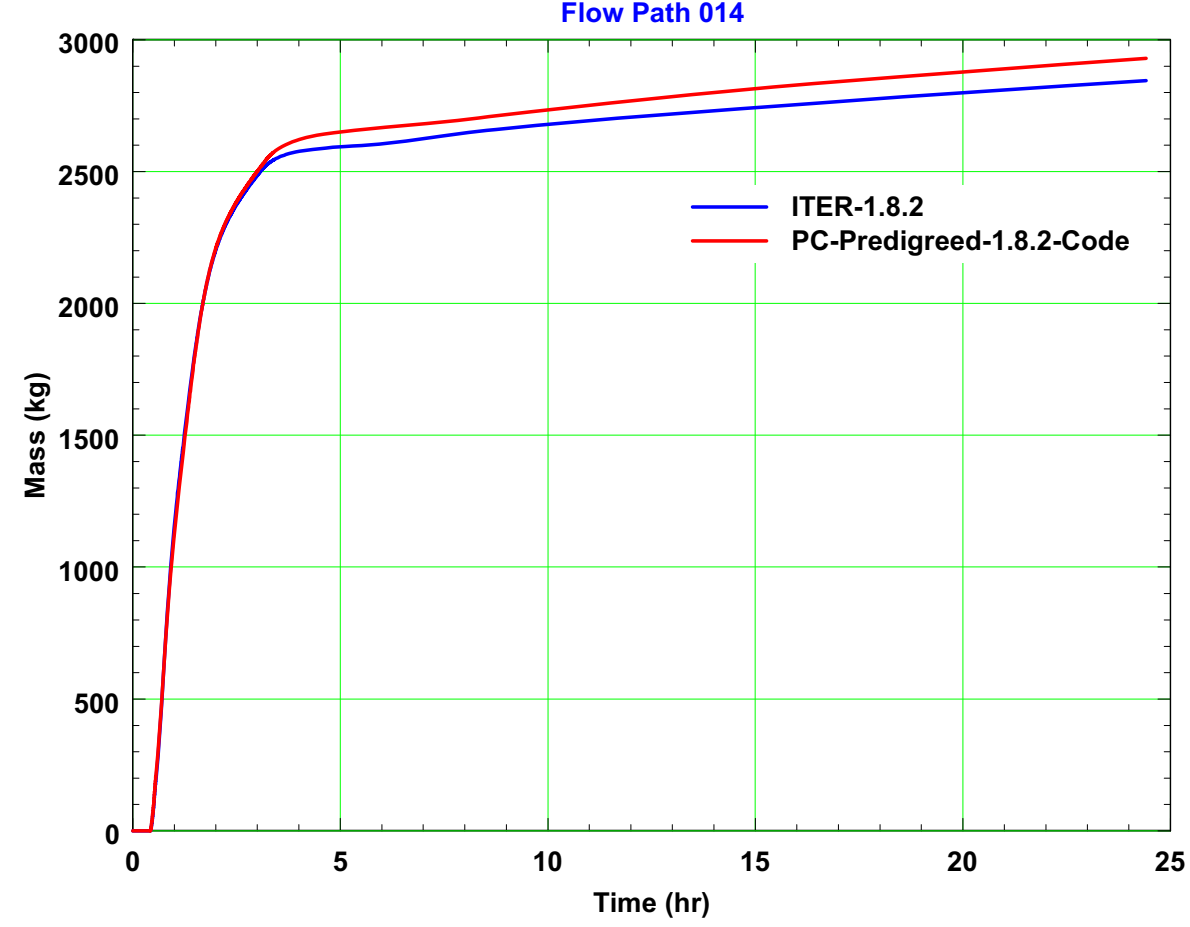

Figure 55. Integrated vapor mass flow from VV to cryostat (flow path 014).

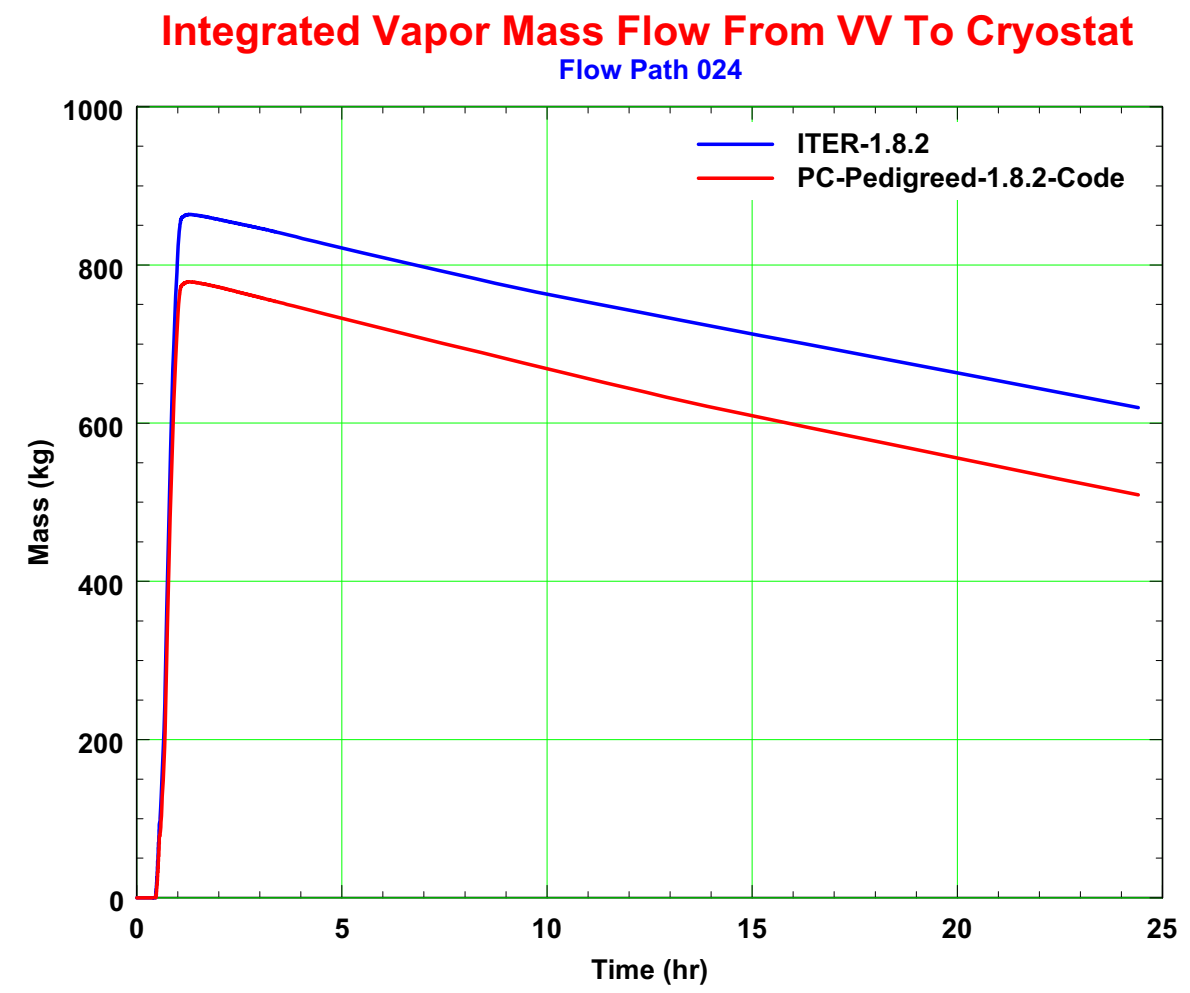

Figure 56. Integrated vapor mass flow from VV to cryostat (flow path 024). 


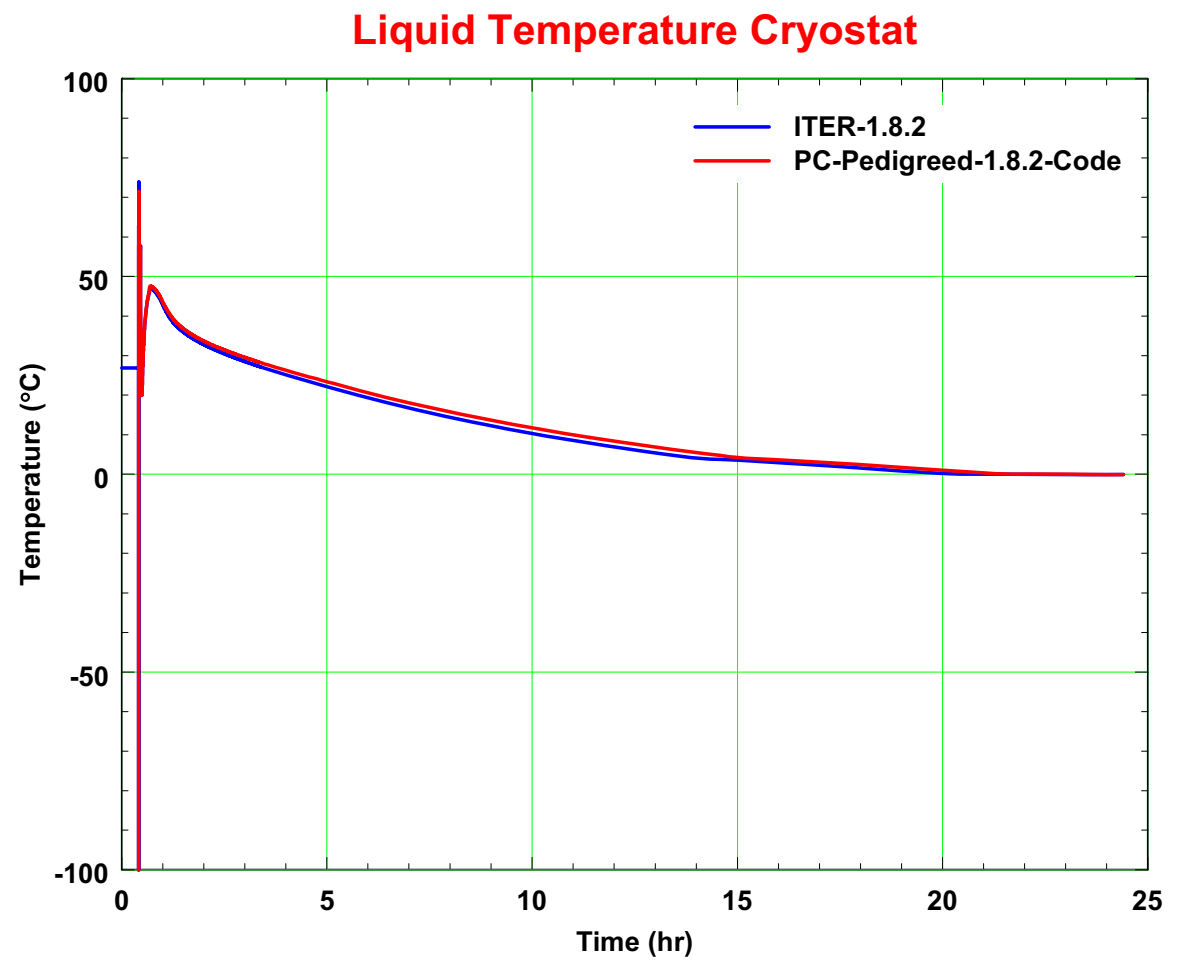

Figure 57. Liquid temperature in cryostat.

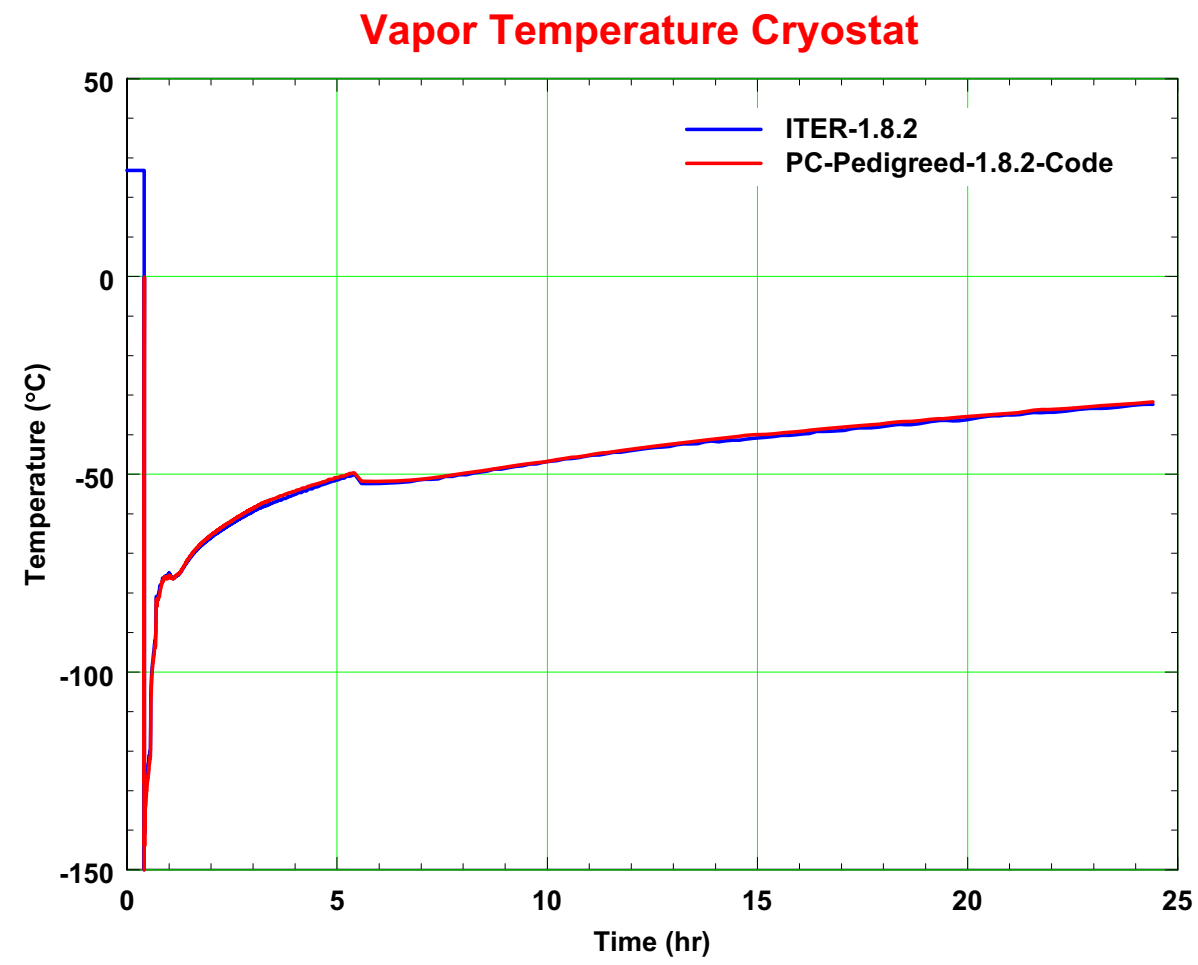

Figure 58. Vapor temperature in cryostat. 


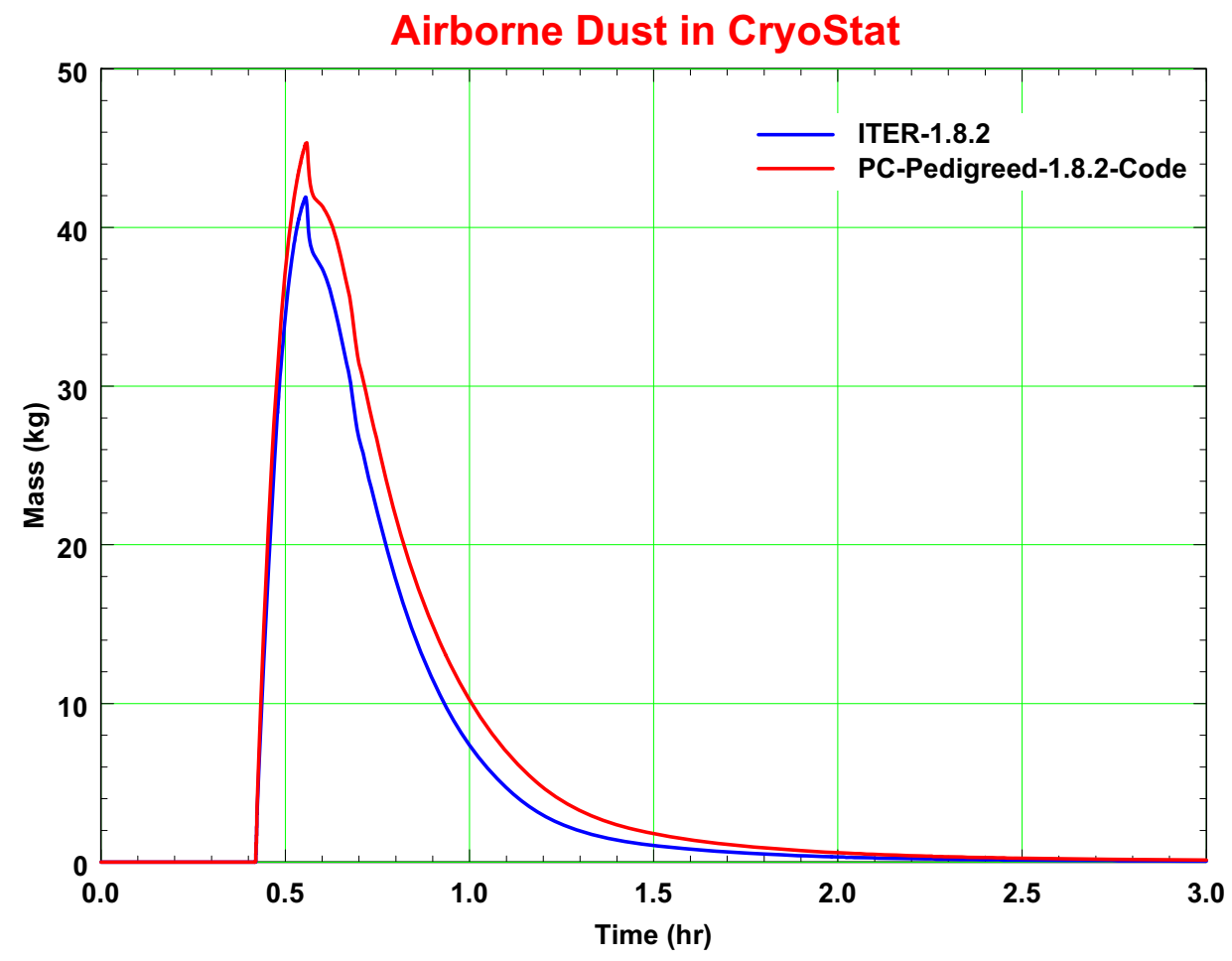

Figure 59. Airborne dust in cryostat.

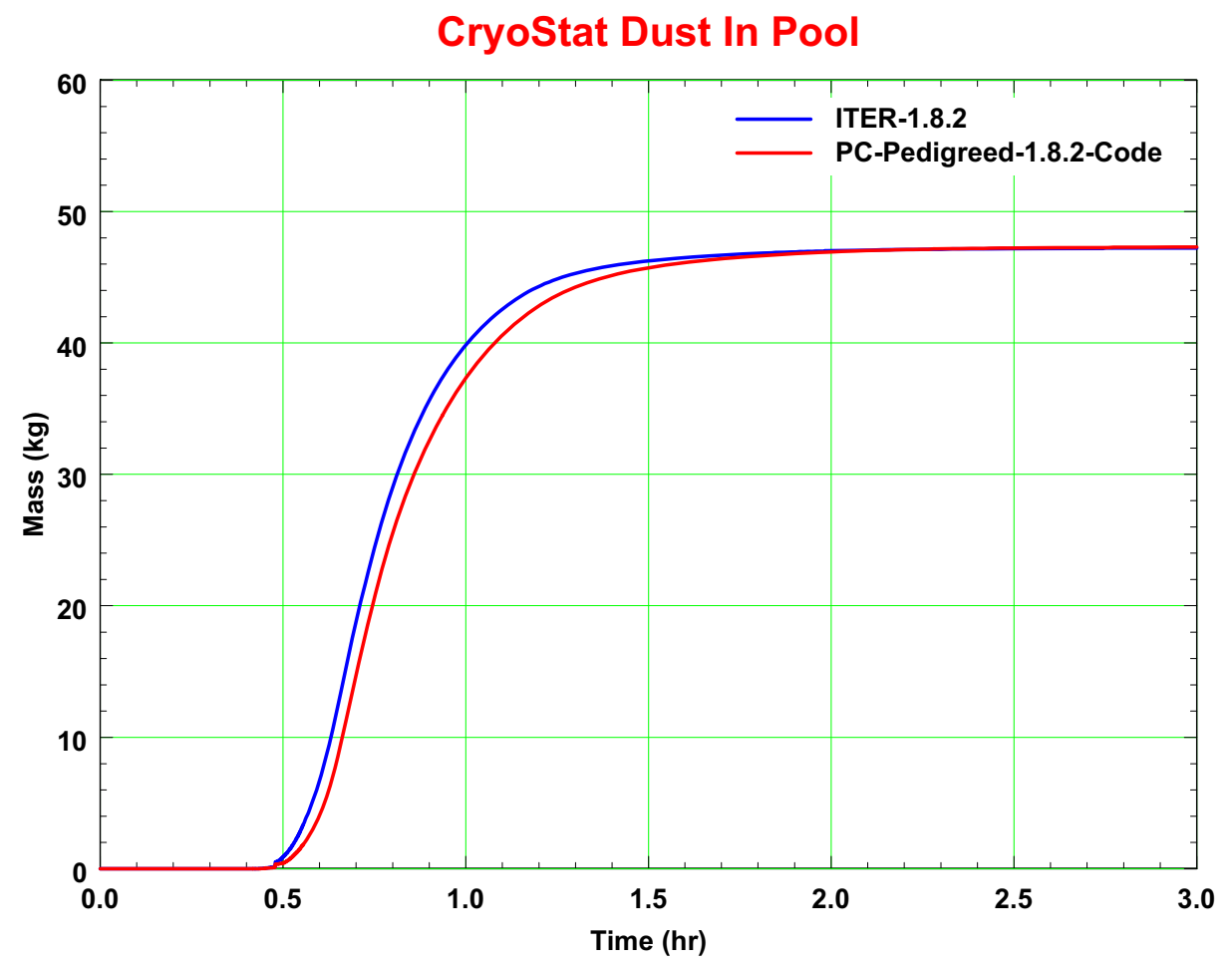

Figure 60. Cryostat dust in pool. 


\section{Cryostat Dust Deposited}

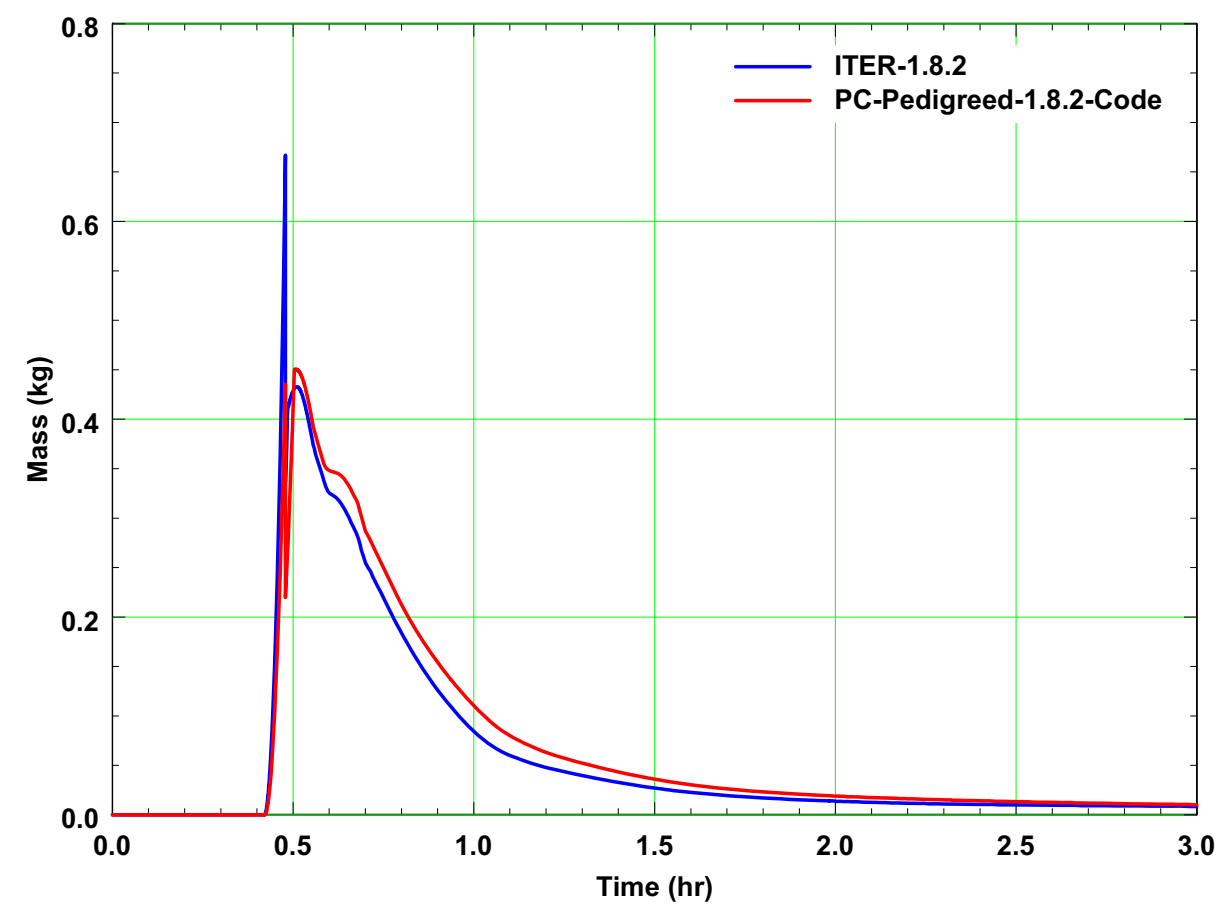

Figure 61. Cryostat dust deposited.

\section{DEVELOPMENTAL TEST PROBLEMS COMPARISON}

As stated in the introduction section, modifications were first made to MELCOR 1.8.2 between 1995 and 1997 by the INL and documented in References 4, 5, 6 and 7. These references describe developmental or test problems which were run in order to assess the execution of this modified version of the MELCOR 1.8.2 code. Several of these test problems were re-run with the pedigreed version of MELCOR 1.8.2 and compared to the results cited in References 4, 5,6 and 7. This comparison was performed to demonstrate that modifications made in the 1995-1997 time frame execute properly in the pedigreed version of the MELCOR 1.8.2 code, as well as showing the effects any additional modifications or corrections have on the predictions from the pedigreed version which were not part of the 1995-1997 modifications, for example the recent change to update the oxidation equations to match those the now appear in SADL2003. ${ }^{12}$ A consistent problem faced in this comparison was the developmental problem input decks were not preserved, so these input decks had to be re-developed based on the descriptions in the References 4 , 5, 6 and 7. However, this input deck re-development was not $100 \%$ successful.

\subsection{Water Freezing Test Problem}

\subsubsection{Water Freezing Test Problem Model Description}

The first test problem is one which demonstrates the capability of the fusion version of MELCOR to model the freezing of water in the event that a coolant pipe break in the cryostat were to occur. This test problem, as described in Reference 4 and repeated here for clarity, consists of one control volume and one 
heat structure. The volume and height of the control volume are $20300 \mathrm{~m}^{3}$ and $32 \mathrm{~m}$, respectively. The control volume is initially filled with steam and air. The mixture of steam and air is assumed to have a total pressure of $1.0 \mathrm{E}+05 \mathrm{~Pa}$ and a temperature of $373 \mathrm{~K}$. The partial pressure of the steam was assumed to be $0.9999 \mathrm{E}+05 \mathrm{~Pa}$. The heat structure within this control volume is stainless steel with a surface area of $6040 \mathrm{~m}^{2}$ and an initial temperature of $4.5 \mathrm{~K}$. The heat structure was placed six meters above the floor of the control volume, extends $20 \mathrm{~m}$ vertically and is $0.487 \mathrm{~m}$ thick. The dimensions of this problem are characteristic of those of the cryostat and magnet structures of 1995 version of the ITER design. Ten thermal nodes were placed in this structure, which vary in thickness from $0.005 \mathrm{~m}$ at the front surface (surface adjacent to the steam) and 0.1 at the back of the structure. The back surface is assumed to be adiabatic, while at the front surface the normal MELCOR heat transfer package was applied. This test problem is depicted schematically in Figure 62.

The input deck for this problem had to be reconstructed based on the description given above because the original deck was not archived. Considerable effort was given to re-creating the input deck; nonetheless the placement of the nodes in the structure may not be the same as in the original deck. The material properties (SS316 at cryogenic temperatures) used for the stainless steel heat structure (obtained from Reference 12) are probably different than used in the original input deck since SADL-2003 was not available at the time of the original development effort. Also the partial pressure of the air in the control volume may be slightly different from that used in the original analysis. These potential differences in the input deck may yield a significant different result; however, the basic phenomena occurring during the transient should be the same.

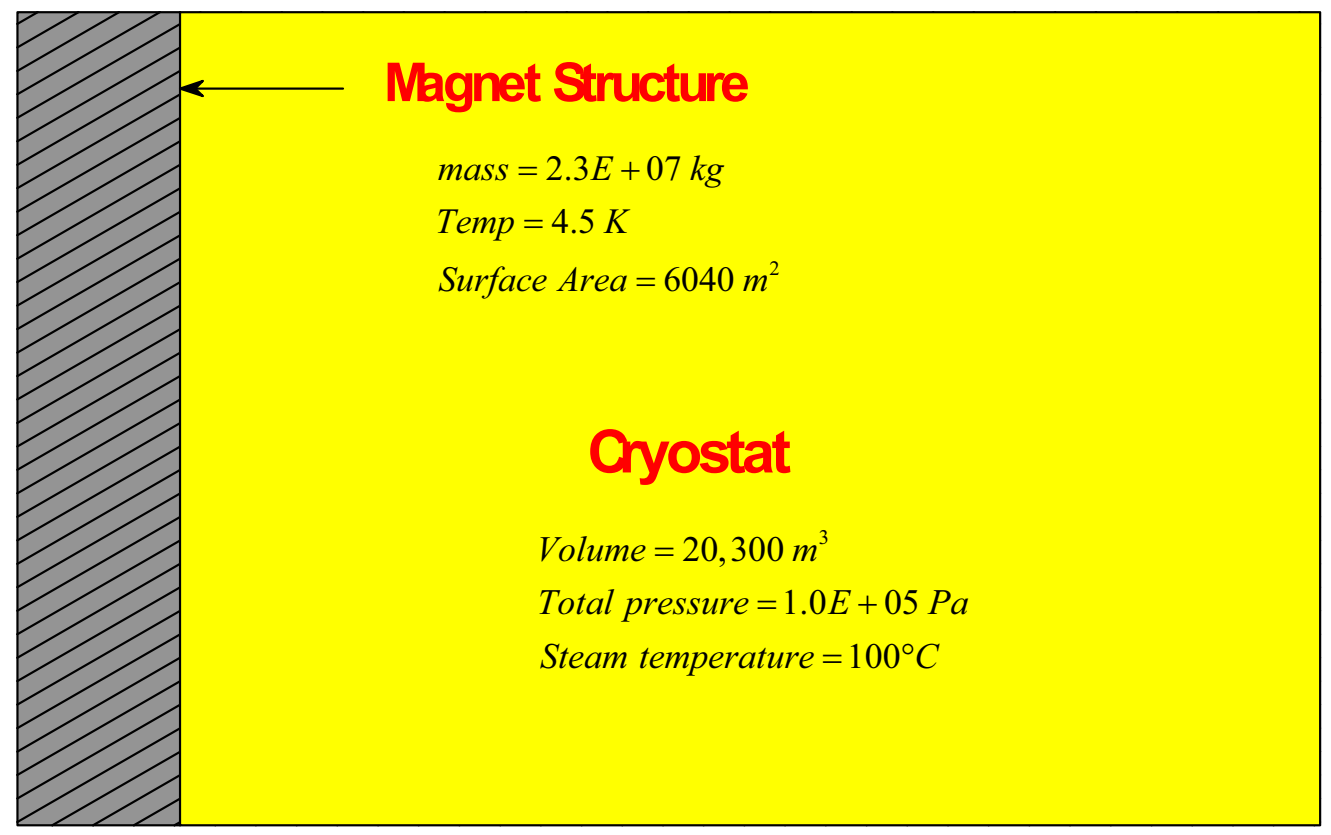

Figure 62. Single cell test problem for testing MELCOR ice freezing modifications.

\subsubsection{Water Freezing Test Problem Results}

The results of the comparison between the fusion pedigreed version and the fusion 1995 version of MELCOR 1.8.2 for this test problem are contained in Figures 63 through 66. Figure 63 contains the heat structure front and back surface temperatures. The peak temperature for the magnet heat structure corresponding to the 1995 version was approximately $175 \mathrm{~K}$ occurring at approximately 50 seconds into the transient. The peak heat structure temperature corresponding to the pedigreed version was $172 \mathrm{~K}$ and occurred at 60 seconds into the transient. The back surface temperature corresponding to the 1995 
version increased from $4.5 \mathrm{~K}$ to $18 \mathrm{~K}$ while the back surface temperature for the pedigreed version only increased from $4.5 \mathrm{~K}$ to $4.7 \mathrm{~K}$ during the 500 second transient. This difference in the back surface temperatures could be due to differences in the thermal properties used for the heat structure. Figure 64 shows the pressure variation in the control volume for the two cases. The pressure corresponding to the 1995 version decreases at a faster rate than the pedigreed version, however by 200 seconds the pressure in the control volume for both cases are approximately the same $(500 \mathrm{~Pa})$. Figure 65 contains the history of the vapor temperature in the control volume. The vapor temperature corresponding to the 1995 version drops linearly from $373 \mathrm{~K}$ down to $273 \mathrm{~K}$ by 160 seconds whereas the vapor temperature corresponding to the pedigreed version takes 215 seconds to drop linearly from $373 \mathrm{~K}$ down to $273 \mathrm{~K}$. In both cases the triple point temperature is maintained for approximately 100 seconds before solidification is complete, after which time the vapor temperature once again begins to drop. At approximately 450 seconds the slope of the vapor temperature history changes as the vapor temperature in the control volume comes into equilibrium with the SS heat structure. Figure 66 contains the ice layer thickness on the surface of the magnet heat structure for this test case. The ice layer corresponding to the 1995 version grew to $0.0023 \mathrm{~m}$ by 500 seconds whereas the ice layer corresponding to the pedigreed version grew to $0.0018 \mathrm{~m}$ by 200 seconds and remained constant for the remainder of the transient.

Most of these differences can be attributed to a slower rate of condensation for the pedigreed version of MELCOR 1.8.2. This condensation is determined by the rate at which water will diffuse through the noncondensable boundary layer of air or helium that develops near the surface of the heat structure. In the 1995 version of MELCOR 1.8.2, a subroutine, called DABMIX, was introduced into the code to calculate binary diffusion coefficients for steam through this boundary layer based on the gas mixture in the control volume. This subroutine contained its own diffusion coefficient correlations, but only addressed five gases: steam, hydrogen, nitrogen, oxygen, and helium. Subsequent to 1998, it was discovered that the original MELCOR 1.8.2 code already possessed a similar capability as the DABMIX subroutine, although the correlations for binary diffusion coefficients are slightly different. It was decided that the best approach for the pedigreed version would be to remove DABMIX and use the base MELCOR routines instead. While the resulting diffusion coefficients may be lower, the difference in predictions between the 1995 and pedigreed versions are not large, usually within a few percent of each other.

\section{Heat Structure Surface Temperatures}

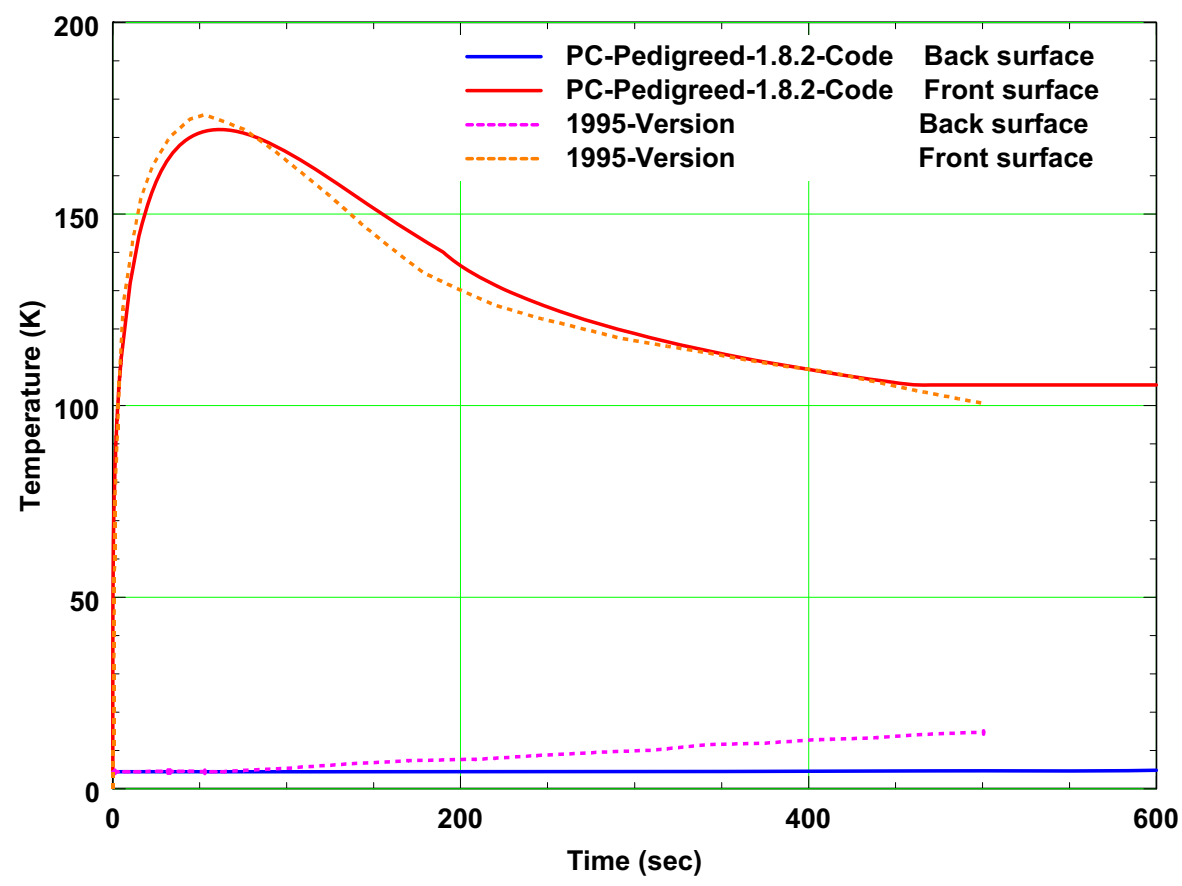

Figure 63. Magnet heat structure temperature single cell water freezing test problem. 


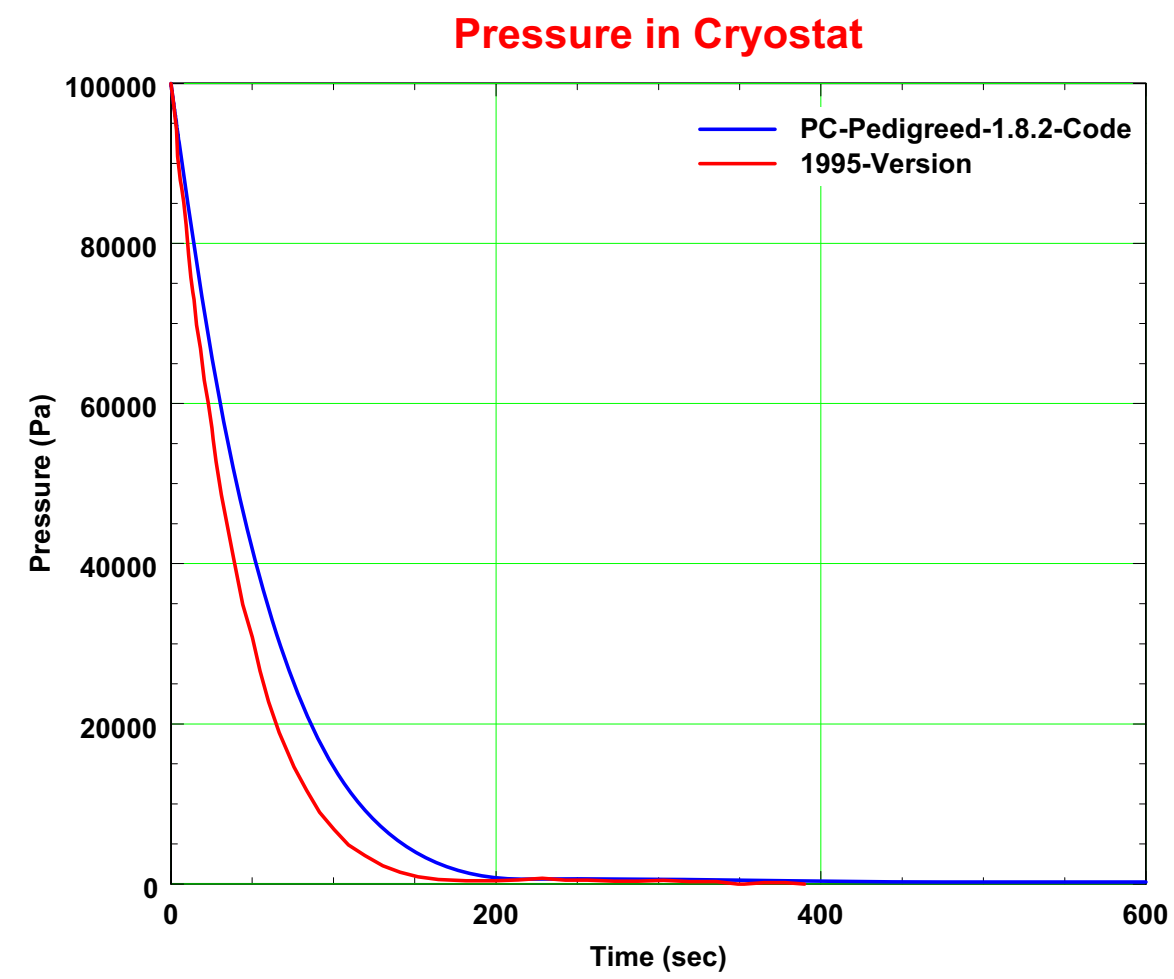

Figure 64. Pressure for the single cell water freezing test problem.

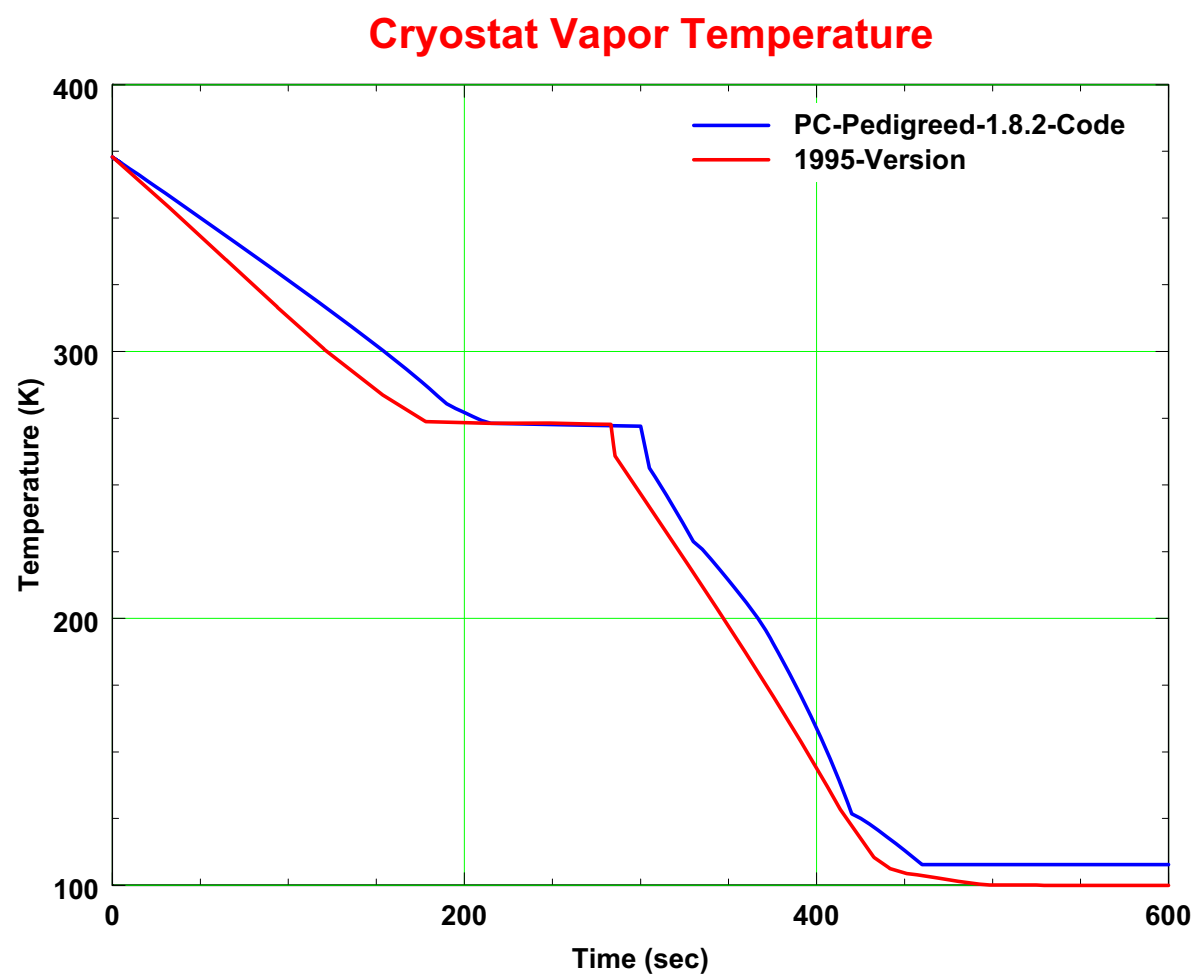

Figure 65. Vapor temperature for the single cell freezing test problem. 
Ice Thickness

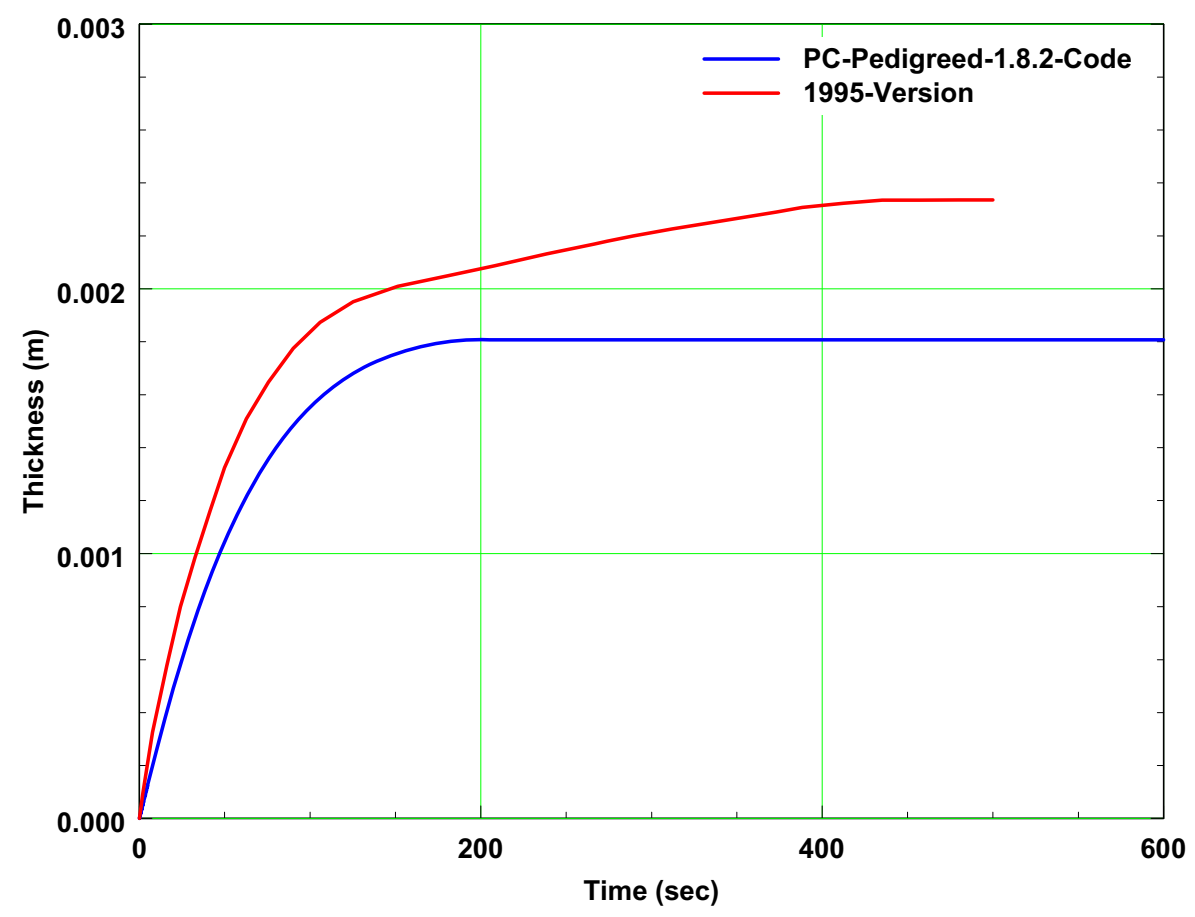

Figure 66. Ice thickness on magnet heat structure for the single cell water freezing test problem.

\subsection{Air Condensation Test Problem}

The air condensation model as described in reference 4 was reexamined during the process of pedigreeing the MELCOR 1.8.2 code to be used for ITER's RPrS. It was discovered that the polynomial equations used by this model to calculate the nitrogen and oxygen saturated liquid enthalpy had different reference energies than the non-condensable equations used by the original MELCOR code to calculate the nitrogen and oxygen vapor enthalpy. The result was an incorrect estimate of the energy change by this model during condensation of these two gases. This correction, along with some other minor changes to the air condensation model, is documented in Reference 13. The effects associated with these changes are discussed below.

\subsubsection{Air Condensation Test Problem Model Description}

The test problem for the air condensation model is the same as that for the single control volume water freezing test problem (see Figure 62), but air has replaced the steam in the control volume.

\subsubsection{Air Condensation Test Problem Results}

The results of the comparison between the fusion pedigreed version and the fusion 1995 version of MELCOR 1.8.2 for this test problem are contained in Figures 67 through 70 . Figure 67 contains pressures within the cryostat volume. As seen in Figure 67 the pressures corresponding to the pedigreed version decrease at a slower rate than those calculated using the 1995 version of the code. This is due to the slower condensation rate of both the nitrogen and oxygen as depicted in Figure 68, which in turn is related to the removal of subroutine DABMIX mentioned in Section 4.1 and the energy change problem 
that was reported and corrected in reference 13. As seen in the figure, the total mass of air that was condensed using the 1995 version of the code was $16500 \mathrm{~kg}$ compared to $7900 \mathrm{~kg}$ using the pedigreed version. Figure 69 depicts the air temperature in the cryostat. As seen in the figure the air temperature corresponding to the pedigreed version decreased at a slower rate than the air temperature calculated using the 1995 version of the code which is again indicative of the different condensation rates. Figure 70 gives temperatures for the front and back surface of the magnet heat structure. The front surface temperature, that is the surface on which the air condenses, peaks at 145 seconds with a temperature of 54 $\mathrm{K}$ using the pedigreed version of the code. The peak temperature corresponding to the 1995 version of the code was $65 \mathrm{~K}$ and occurred at approximately 30 seconds into the transient. These differences in the timing and temperatures are again related to the energy change problem discussed in Reference 13, plus the uncertainty associated with possible differences in steel material properties between the original problem input and the re-derived problem input.

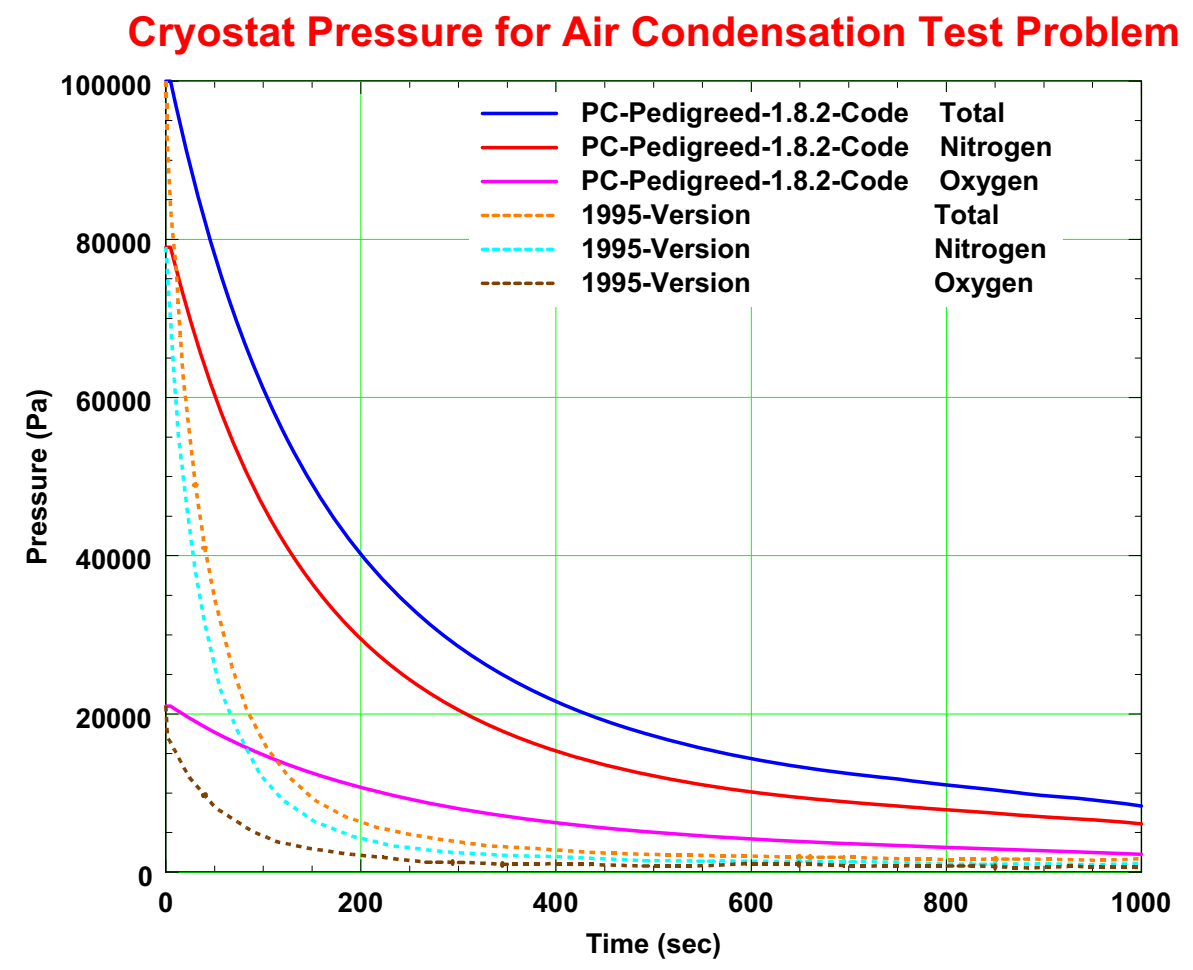

Figure 67. Cryostat volume pressure for the air condensation test problem. 


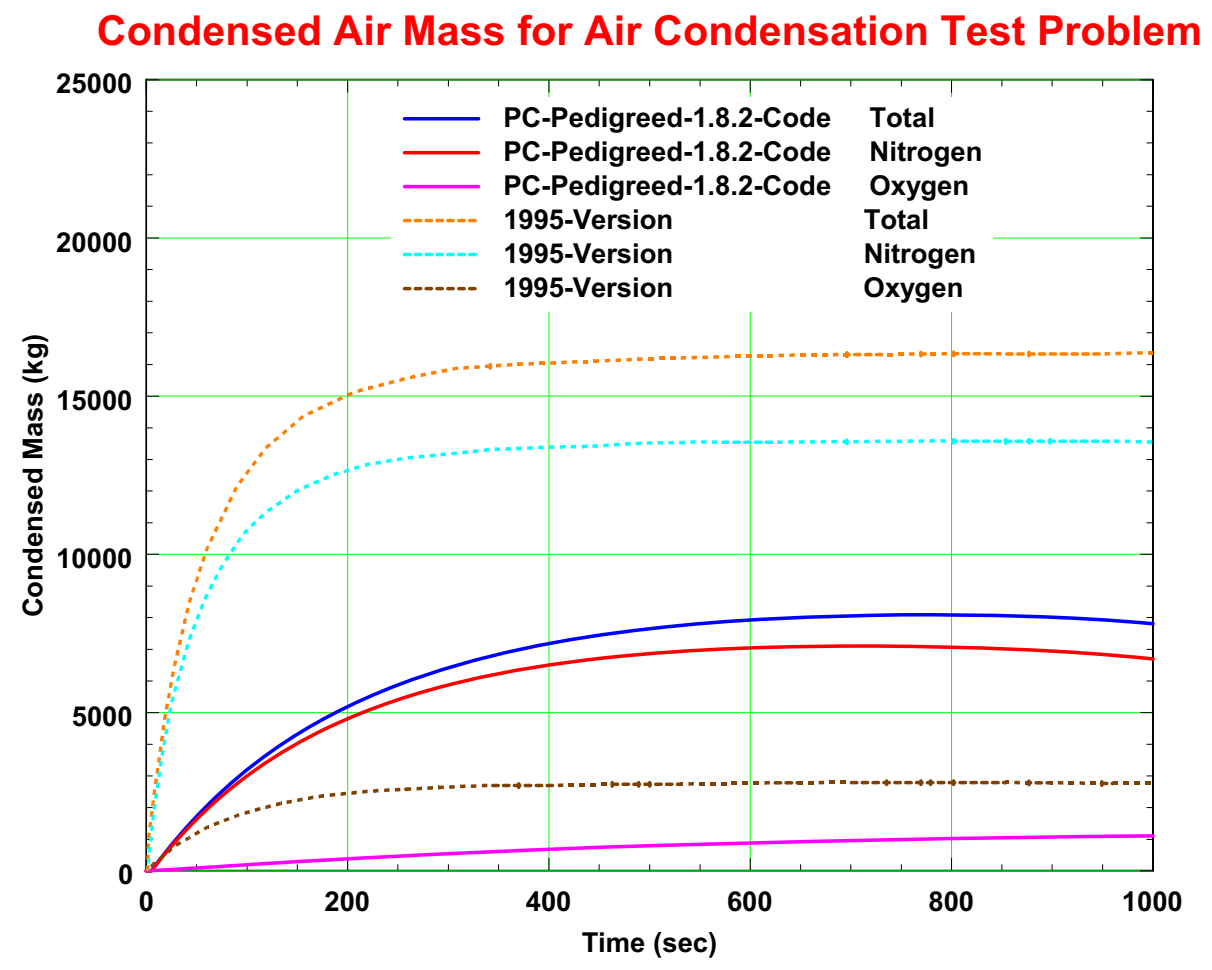

Figure 68. Condensed air mass for the air condensation test problem.

Cryostat Air Temperature for Air Condensation Test Problem

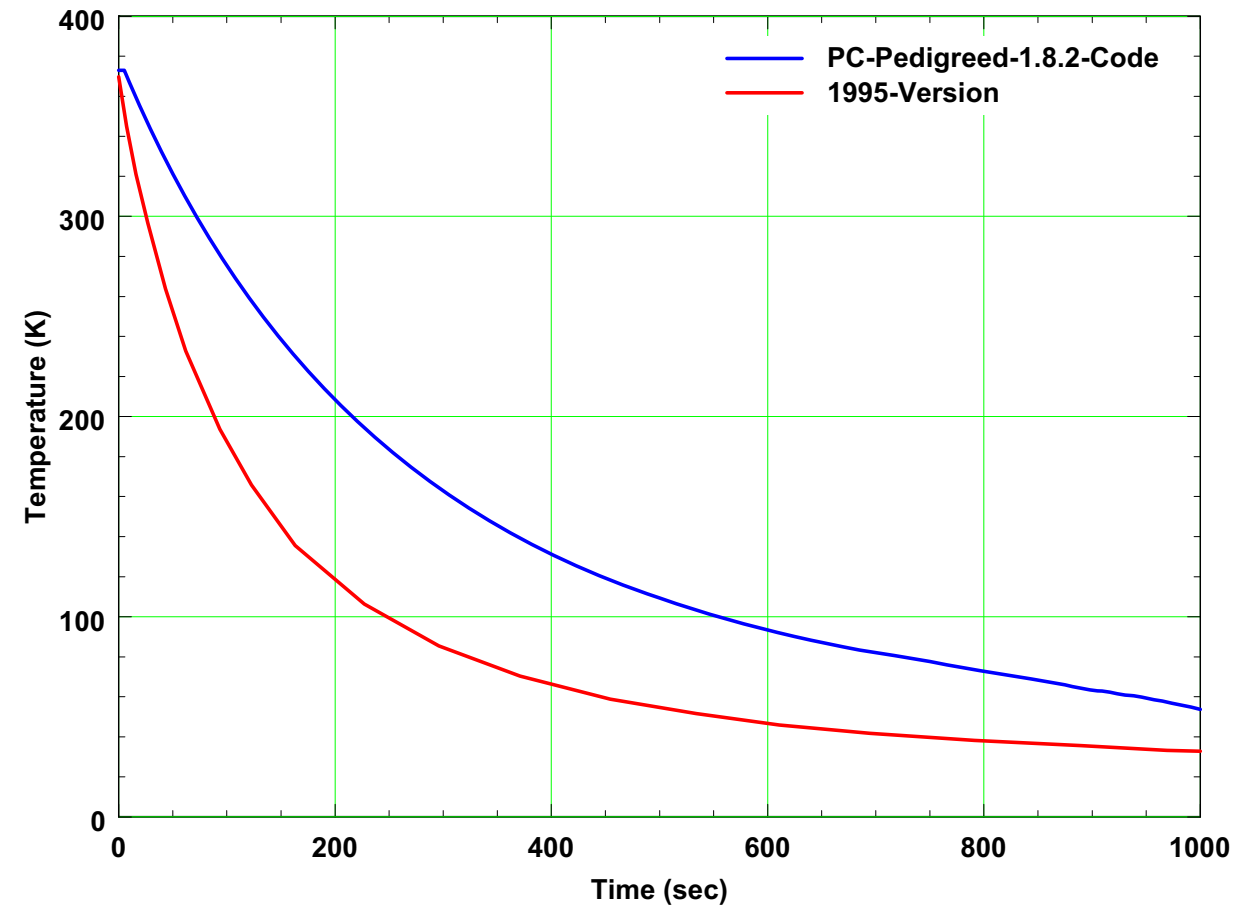

Figure 69. Cryostat volume air temperature for the air condensation test problem. 


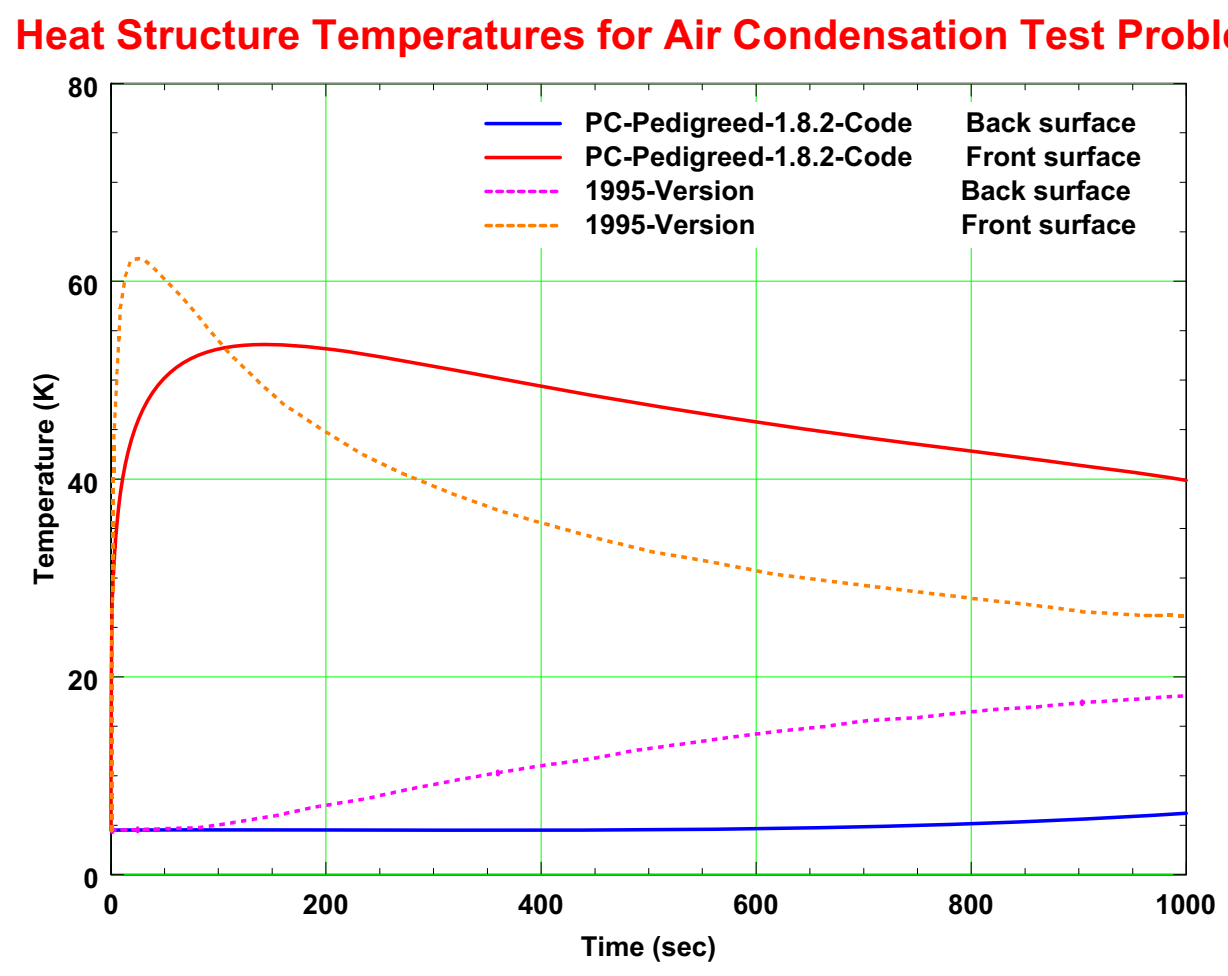

Figure 70. Magnet heat structure temperature for the air condensation test problem.

\subsection{Steam Oxidation Test Problem}

The input deck used in 1995 for this developmental problem has not been preserved, thus a new deck was constructed using the description of the test problem given below. However, neither the material properties, heat structure modeling assumptions or the heat structure initial temperature distribution appear to be different than those used in the original deck. Also as stated in Reference 13, new beryllium oxidation correlations have been added to the pedigreed version of the code.

\subsubsection{Steam Oxidation Test Problem Model Description}

This test problem, as described in Reference 4 and repeated here for clarity, consists of one control volume and two heat structures as depicted in Figure 71. A single control volume model was developed that has a volume of $3650 \mathrm{~m}^{3}$ and contains two heat structures clad either with $0.005 \mathrm{~m}$ of beryllium or carbon as the plasma facing component (PFC) material. These heat structures are stainless steel with a void fraction of $50 \%$, thickness of $0.5 \mathrm{~m}$, and surface areas of $400 \mathrm{~m}^{2}$ and $800 \mathrm{~m}^{2}$. These dimensions are similar to those of the inboard and outboard first wall (FW)/blanket structures, and vacuum vessel of the 1995 ITER design.

Three nodes were used to model the PFC material per heat structure, with an initial temperature of 1400 $\mathrm{K}$. Three nodes were also used to model the SS FW/Blanket structure, with initial temperatures of $500 \mathrm{~K}$, $750 \mathrm{~K}$, and $1200 \mathrm{~K}$ going from the back to the front of the heat structure, respectively. The vacuum vessel volume was initially filled with a saturated steam/water mixture at a pressure of $1.0 \mathrm{E}+05 \mathrm{~Pa}$ and a mass of $1.05 \mathrm{E}+05 \mathrm{~kg}$. 


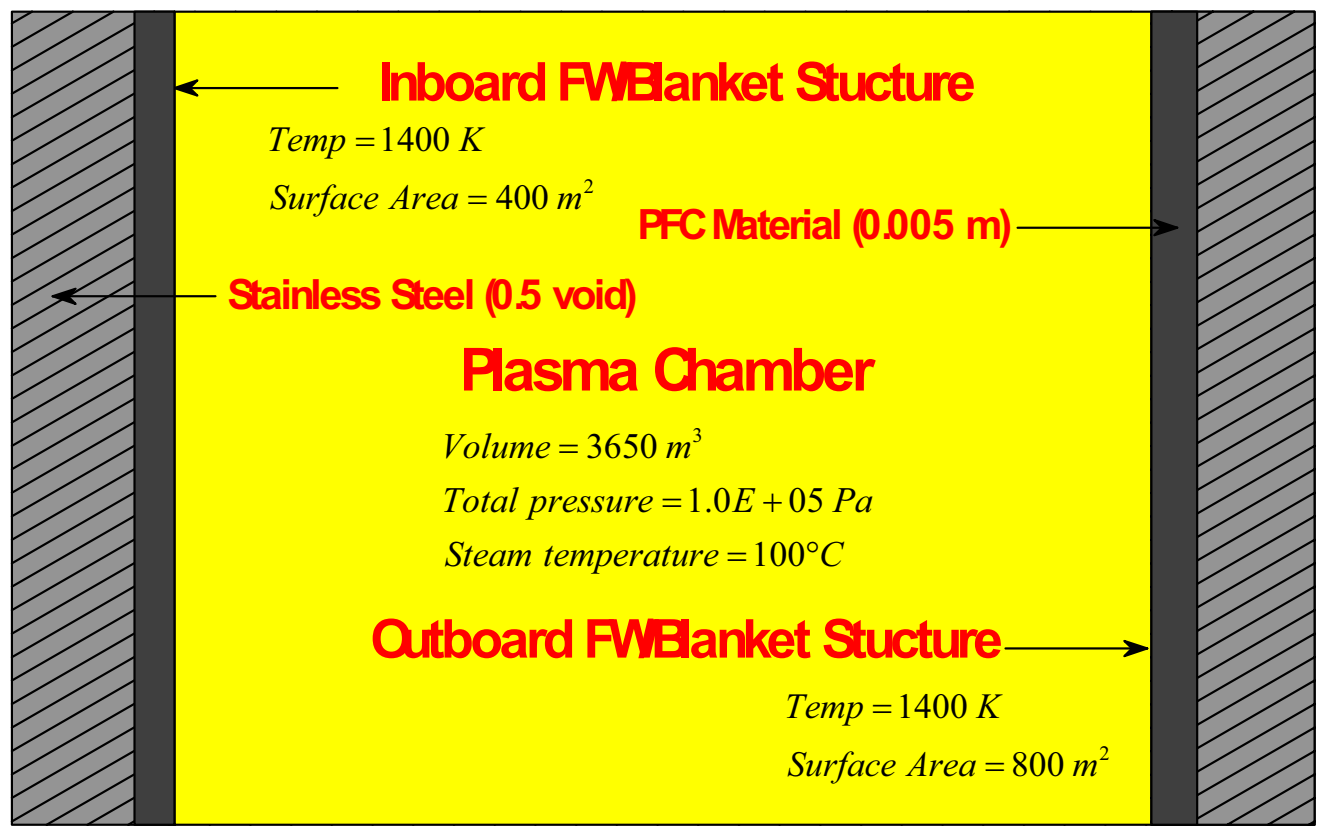

Figure 71. Schematic of MELCOR model developed for the oxidation model test problem.

\subsubsection{Steam Oxidation Test Problem Results for Beryllium}

Figure 72 contains the FW surface temperature for the 1995 version of the code, which was the version under development in 1995, the ITER FEAT version of the code, which was the version used by the JCT for the Reference GSSR, and the pedigreed version of the code using new beryllium oxidation correlations for the PFC material. Viewing Figure 72 we see large differences in the temperature response of the outboard surface between the original 1995 results and the pedigreed code results. Therefore since the original 1995 version of the code no longer exists we decided to run the new input deck with the ITER FEAT version of the code. The results from that run are in closer agreement with the results produced by the pedigreed code; with any difference being due to the new beryllium oxidation rates in the pedigreed code.

Figure 73 contains the hydrogen generation history due to the interaction of the hot beryllium surface with the steam. At approximately 500 seconds, the PFC beryllium is completely consumed for both the pedigreed and the ITER FEAT versions of the code. The 1995 version shows that the beryllium is completely consumed by 715 seconds. The differences in the results are likely due to the difference in the wall thermal properties; however, this can not be substantiated due to the missing original input deck. 
FW Temperature Beryllium Oxidation Test Problem

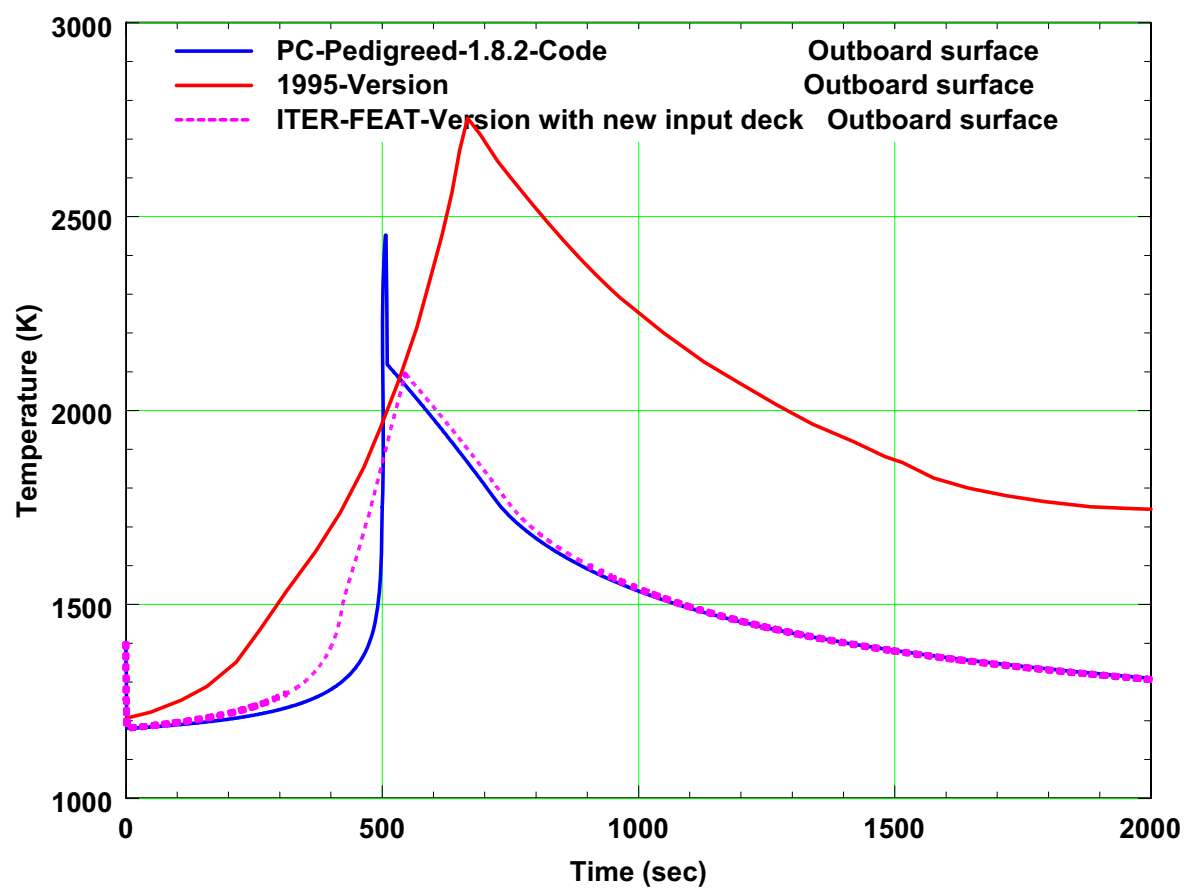

Figure 72. FW temperature for the oxidation model test problem with beryllium as a PFC material.

\section{Hydrogen Generation Beryllium Oxidation Test Problem}

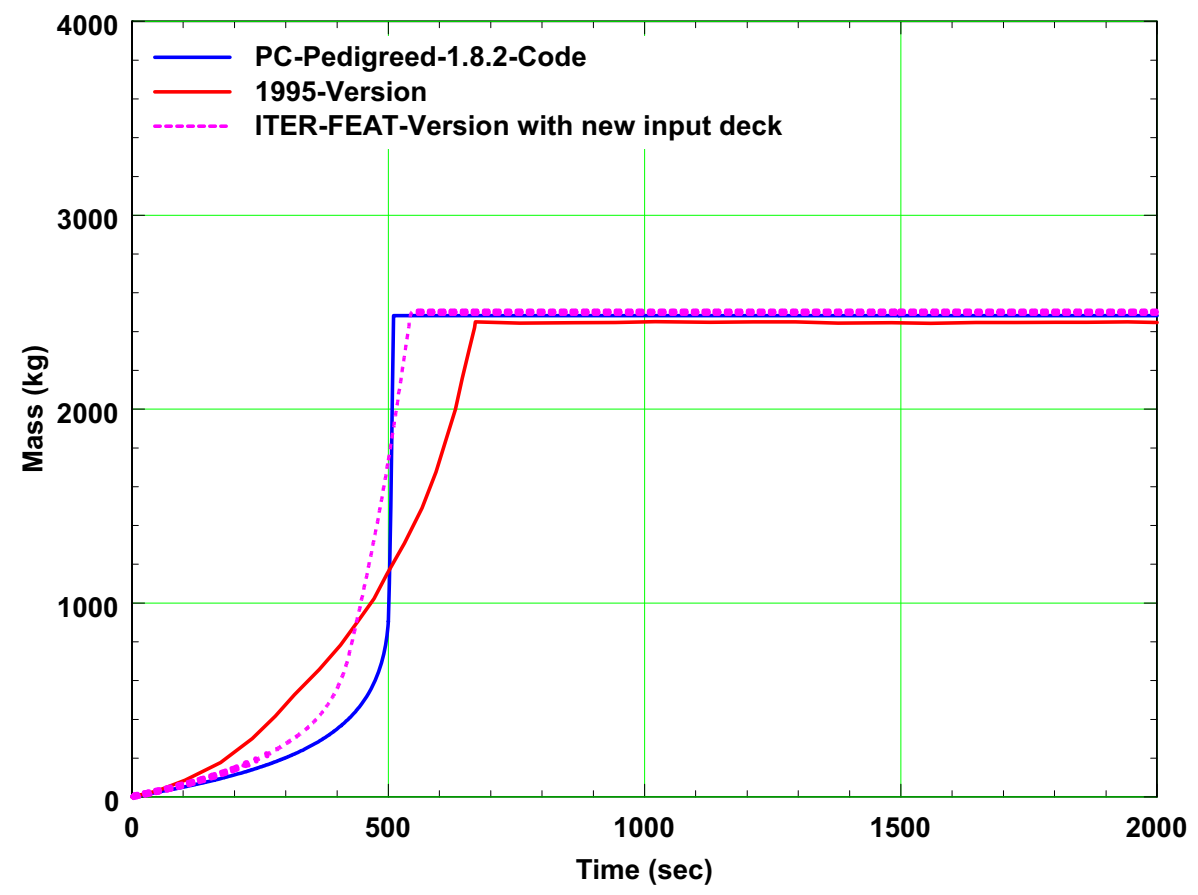

Figure 73. Hydrogen generation for the oxidation model test problem with beryllium as a PFC material. 


\subsubsection{Steam Oxidation Test Problem Results for Carbon}

The results for the case of steam oxidation of carbon are presented in Figures 74 and 75 . Figure 74 contains the surface temperature history of the FW using carbon as the PFC. As seen in Figure 74 the FW temperature history corresponding to the pedigreed code is 40 to $50 \mathrm{~K}$ higher than the temperature history from the 1995 version of the code. As with the beryllium results this is probably due to either a difference in the material properties or modeling assumptions used for the first wall in the lost input file. We ran a second case with the pedigreed code where we prescribed the temperature history of the back surface of the 1995 results onto the back surface of the new model as a boundary condition. The results from this run are nearly the same as the 1995 results lending support to the conclusion that different material properties or modeling assumptions were probably used in the original input deck.

The histories of the hydrogen generation for the three cases described above are presented in Figure 75. The hydrogen generation corresponding to the pedigreed code is higher by a factor of $3.4(0.51 \mathrm{~kg}$ vs. $0.15 \mathrm{~kg}$ ) than for the 1995 version of the code due to the strong coupling of the reaction rate to temperature. The case where we prescribed the carbon clad back surface temperature as a boundary condition and ran the pedigreed code, we get closer agreement in the amount of hydrogen produced $(0.202 \mathrm{~kg}$ vs. $0.15 \mathrm{~kg})$, with the difference still due to our inability to reproduce the lower PFC surface temperatures of the 1995 result.

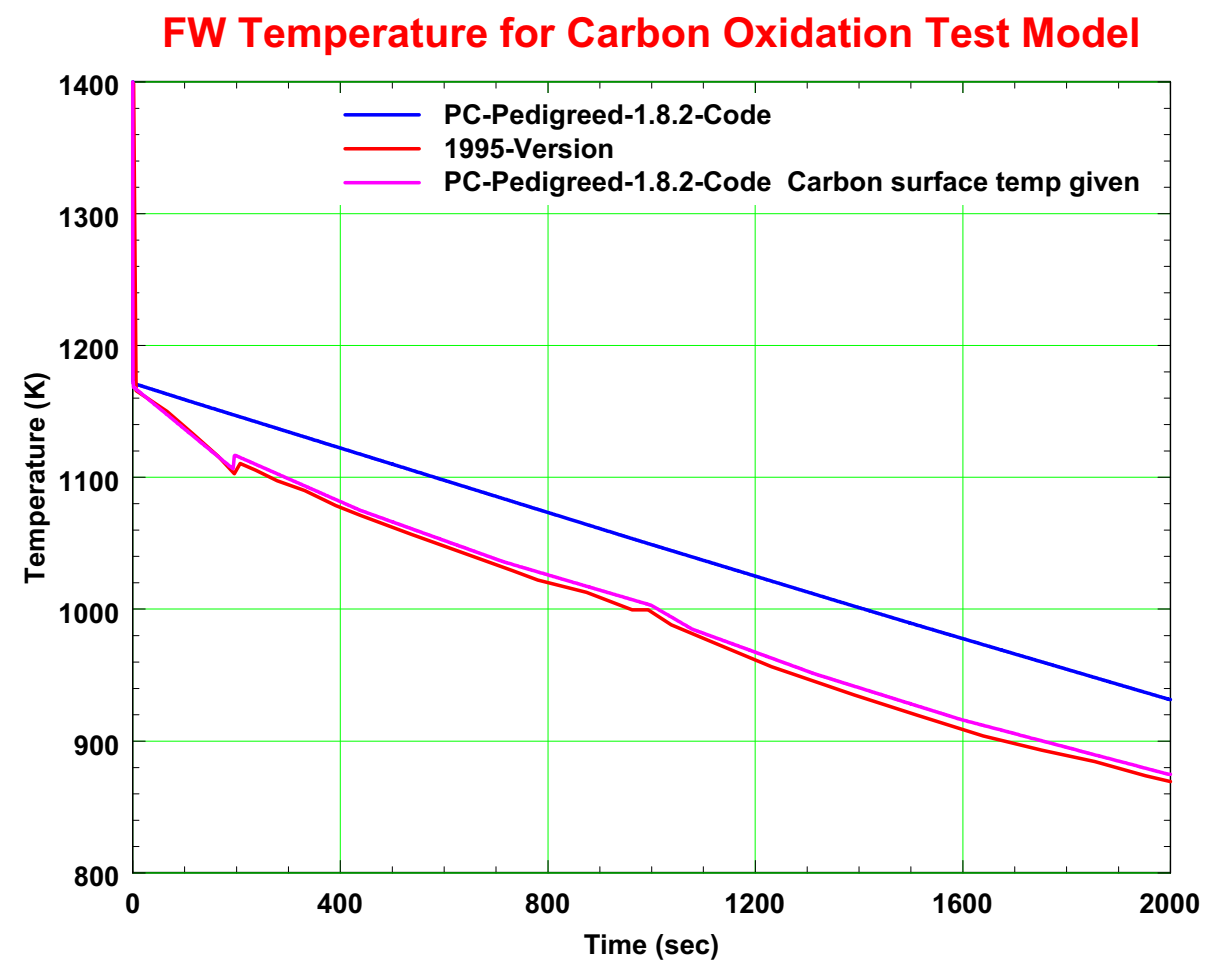

Figure 74. FW temperature for the oxidation model test problem with carbon as a PFC material. 
Hydrogen Generation for Carbon Oxidation Test Problem

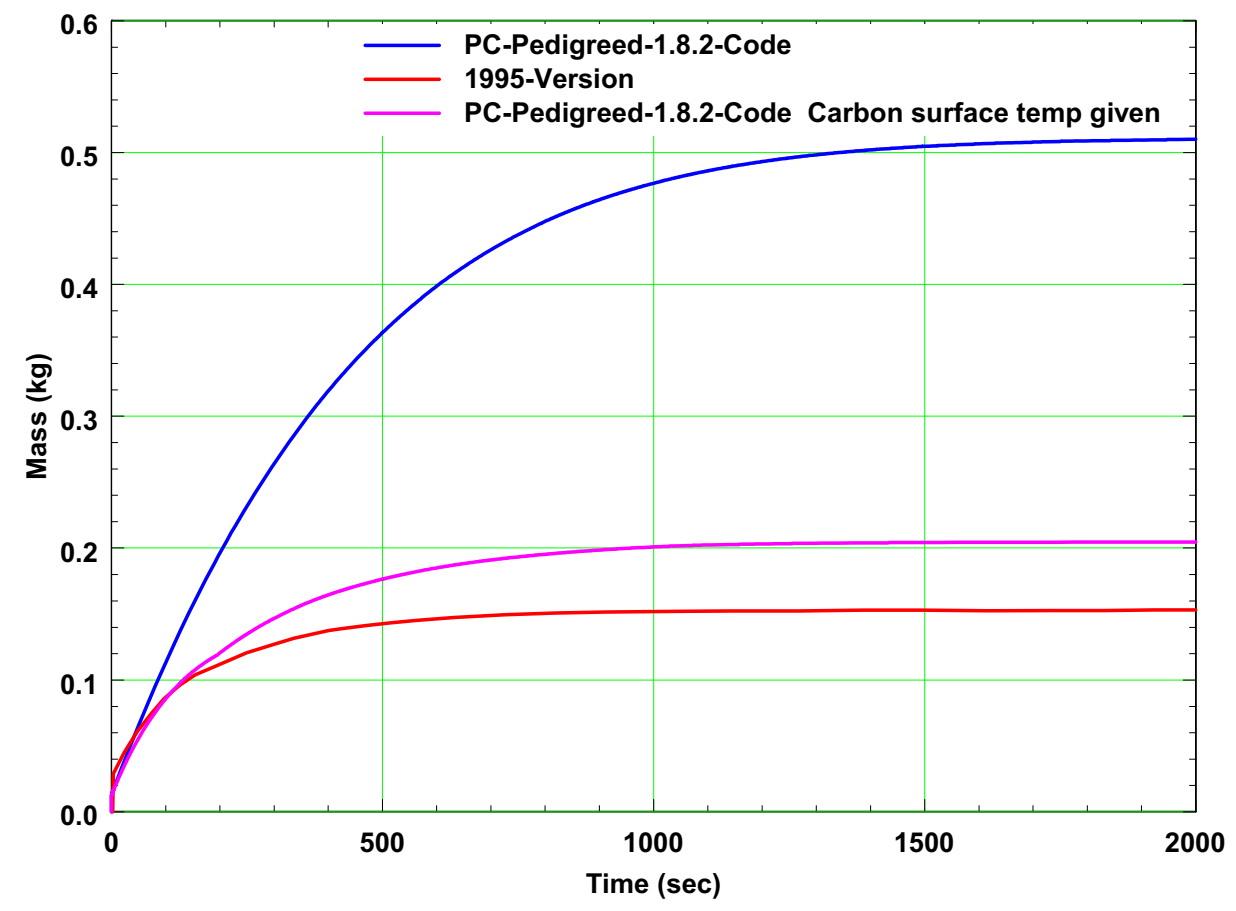

Figure 75. Hydrogen generation for the oxidation model test problem with carbon as a PFC material.

\subsection{Enclosure Thermal Radiation Heat Transport Model}

A thermal radiation heat transport capability was added to the fusion version of MELCOR 1.8.2 in 1997. This model was added because the existing MELCOR radiation model did not allow for the direct exchange of radiant power between walls of an enclosed structure, or account for the presence of an atmosphere between these components that absorbs and re-radiates this power. The model, model equations and a test problem to verify that the model was implemented correctly into the MELCOR 1.8.2 code are described in Reference 7. A listing of the test problem input deck used to verify the model was also included in Reference 7.

\subsubsection{Radiation Test Problem Model Description}

Figure 76 contains a schematic of the radiation test problem, which is an enclosure composed of four walls of different initial temperatures, emissivities, and an absorbing gaseous atmosphere. The enclosure walls are assumed to be $5 \mathrm{~mm}$ thick stainless steel heat structures with a depth of $1 \mathrm{~m}$. The boundary conditions for the back surface of the walls are adiabatic. Heat transfer from the front surface of these walls was only through the net enclosure radiation model. 


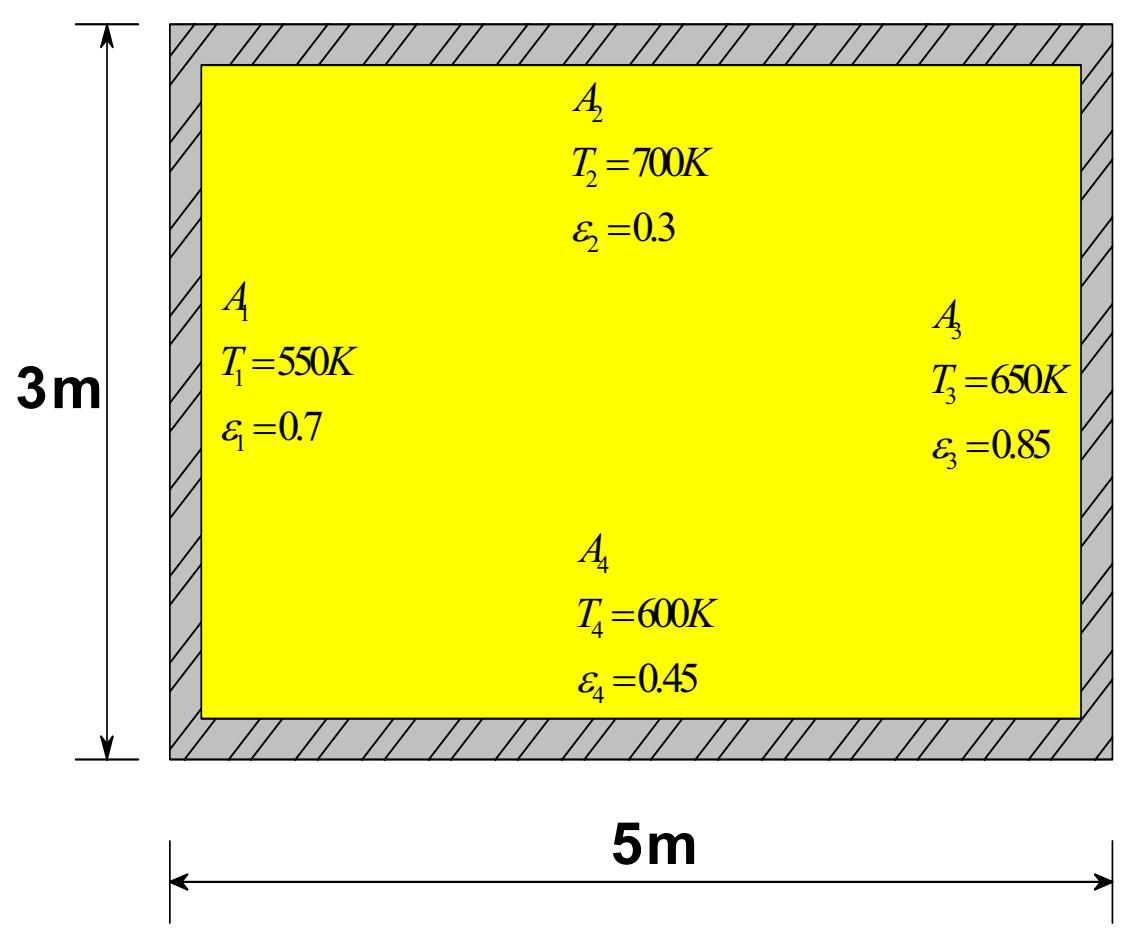

Figure 76. Schematic of test problem for enclosure net radiation model.

\subsubsection{Radiation Test Problem Results}

Figure 77 contains wall surface and gas temperatures for an absorbing atmosphere enclosure out to a time of 3000 seconds. For the conditions of this enclosure the gas emissivity ranges from 0.18 to 0.22 . The enclosure temperatures show the gas heats up and the wall temperatures converge to about $620 \mathrm{~K}$ by 3000 seconds. This demonstrates that the enclosure net radiation heat transfer model is transferring energy both between the walls and the walls and gas. The temperatures corresponding to the pedigreed code are exactly the same as generated for the case that was run in 1997 and presented in Reference 7 . This is what one would expect since the enclosure radiation model and coding have not changed since it was initially put into the fusion version of MELCOR 1.8.2. 


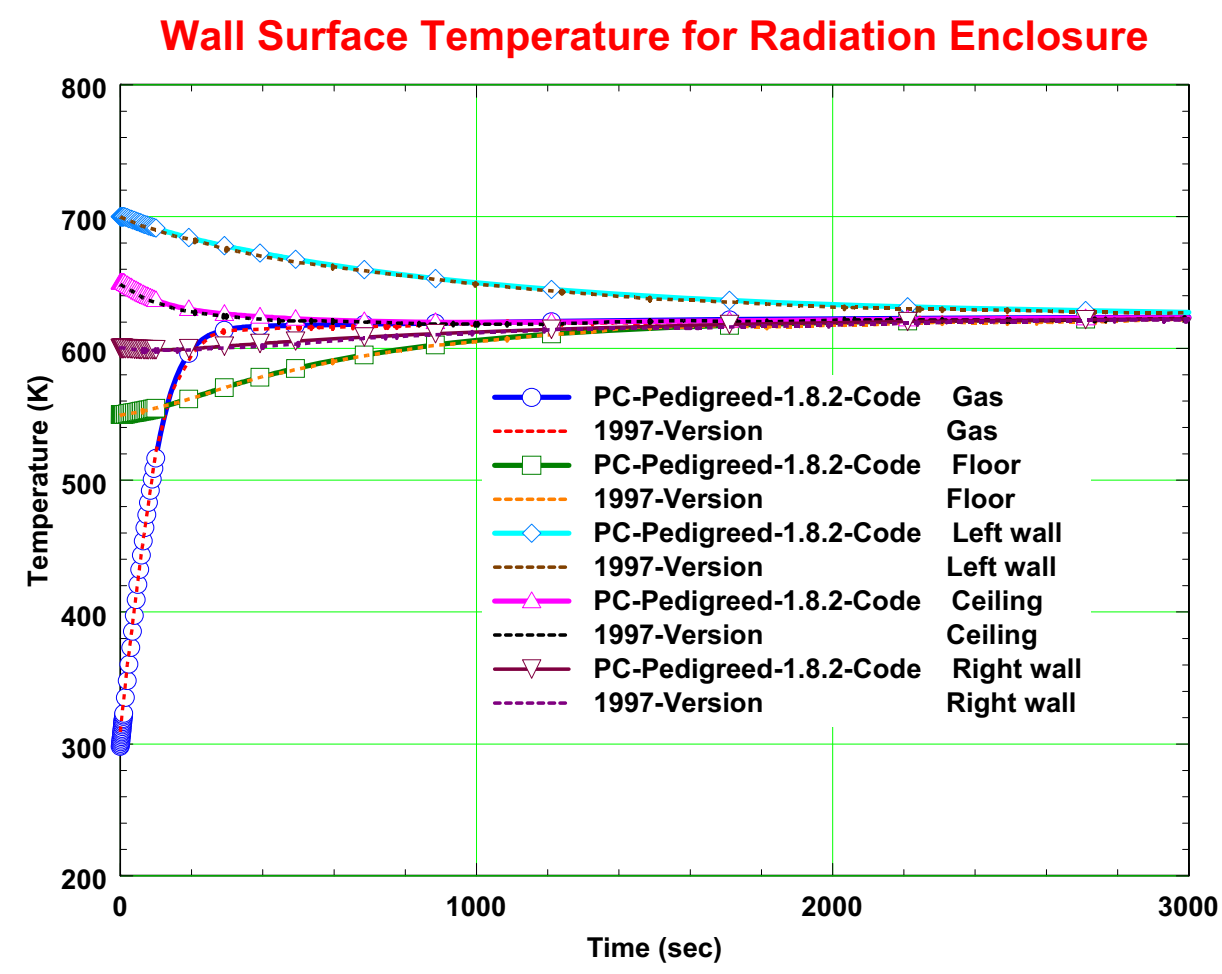

Figure 77. Wall surface and atmosphere temperature for an enclosure that contains an atmosphere that absorbs thermal radiation.

\section{CONCLUSIONS}

The version of MELCOR 1.8.2 that is to be used to analyze the accidents for the RPrS has been pedigreed as reported in this document. It was determined that all modifications and corrections to the original MELCOR 1.8.2 code for fusion use have been implemented into the pedigreed version of the code properly and documented in the references provided in the reference section of this document. 


\section{References}

1. R.M. Summers, et al., MELCOR 1.8.0: A Computer Code for Nuclear Reactor Severe Accident Source Term and Risk Assessment Analyses, NUREG:CR-5531 and SAND90-0364, USNRC report, Sandia National Laboratory, January 1991.

2. R.O. Gauntt, et al., MELCOR Computer Code Manuals Vol. 1: Primer and Users' Guide Version 1.8.6, NUREG/CR-6119, Vol. 1, Rev.3, Sandia National Laboratory, September 2005.

3. Merrill, B. J., et al., "Assessment of CONTAIN and MELCOR for Performing LOCA and LOVA Analyses in ITER," EGG-FSP-11386, Idaho National Engineering Laboratory Report, September 1994.

4. B.J. Merrill, Initial Modifications to the MELCOR Code, ITER/US/95/TE/SA-18, Idaho National Engineering Laboratory, June 30, 1995.

5. R.L. Moore and R.C Martineau, Documentation of New MELCOR Flow Boiling, and Diffusion Coefficient Subroutines, ITER/US/97/TE/SA-6, Idaho National Engineering Laboratory, May 12, 1997.

6. B.J. Merrill and D.L. Hagrman, MELCOR aerosol transport module modifications for NSSR-1, ITER/US/96/TE/SA-03 (INEL-96/0081), Idaho National Engineering Laboratory, March 1996.

7. B.J. Merrill, An Enclosure Thermal Radiation Heat Transport Model for the MELCOR code, ITER/US/97/TE/SA-04, Idaho National Engineering Laboratory, January 31, 1997.

8. RELAP-3D Code Manual Volume 1: Code Structures, System Models, and Solution Methods, INEEL-EXT-98-00834, Revision 2.4, Idaho National Laboratory, June 2005.

9. ITER Non-Site Specific Safety Report (NSSR-1), ITER JCT, Volume 7, January 1997

10. ITER Non-Site Specific Safety Report (NSSR-2), ITER JCT, Volume 7, December 1997

11. Generic Site Safety Report (GSSR) Volume VII, Analysis of Reference Events, G 84 RI 6 01-07-10 R 1.0 ITER report, 2001.

12. Safety Analysis Data List (SADL), Version 4.0.3, September 26, 2003.

13. B.J. Merrill, Recent Updates to the MELCOR 1.8.2 Code for ITER Applications, INL/EXT-0712493, Idaho National Laboratory, April 2007.

14. R.L. Moore, Status Report on an ITER ITA on Comparison of MELCOR 1.8.5 Results to MELCOR 1.8.2 Results for a Select Set of Accident Analysis Cases Relevant to ITER FEAT, EDF-5470, Idaho National Laboratory, January 14, 2005. 